Supporting Information for:

\title{
Synthesis of Bifunctional Potassium Acyltrifluoroborates
}

Sizhou M. Liu, Dmitry Mazunin, Vijaya R. Pattabiraman and Jeffrey W. Bode*

Laboratorium für Organische Chemie

Department of Chemistry and Applied Biosciences ETH Zürich

Vladimir-Prelog Weg 3, 8093 Zürich, Switzerland

Email: bode@org.chem.ethz.ch

Homepage: http://www.bode.ethz.ch/ 


\section{Table of Contents}

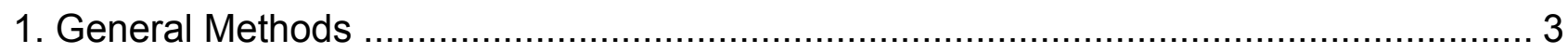

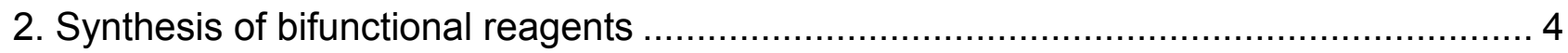

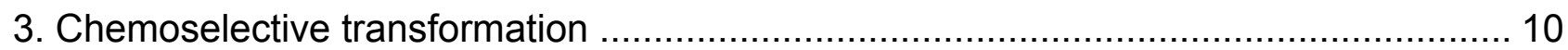

4. Preparation and KAT ligation of potassium acyltrifluoroborate containing SUMO2 Cterminal peptide sequence ................................................................................... 15

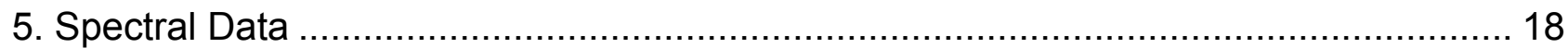

5.1. Potassium 4-(carboxy)benzoyltrifluoroborate ........................................... 18

5.2. Potassium 4-(perfluorophenylcarboxy)benzoyltrifluoroborate.......................... 20

5.3. Potassium 4-(formyl)benzoyltrifluoroborate ............................................... 22

5.4. Potassium 6-chlorohexanoyltrifluoroborate .......................................... 24

5.5. 1-(Methoxy(3-((tert-butyldimethylsilyl)oxy)phenyl)methyl)-1H-benzotriazole ......... 26

5.6. Potassium 3-(hydroxy)benzoyltrifluoroborate............................................ 27

5.7. 1-(1-Phenoxy-6-(trimethylsilyl)hex-5-yn-1-yl)-1H-benzotriazole ......................... 28

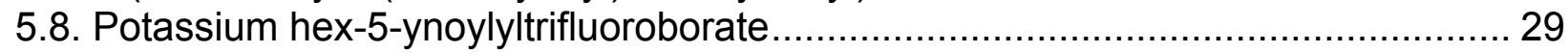

5.9. Potassium 6-azidohexanoyltrifluoroborate ................................................. 31

5.10. Potassium 4-(3-(ethoxy)-3-oxoprop-1-en-1-yl)benzoyltrifluoroborate ................... 33

5.11. Potassium 3-((7-(diethylamino)-2H-chromen-2one)methoxy)benzoyltrifluoroborate.

5.12. tert-Butyl ((diethylcarbamoyl)oxy)(2-(2-(2-hydroxyethoxy)ethoxy)ethyl)carbamate

5.13. 6-(tert-Butoxycarbonyl)-3-ethyl-4-oxo-5,9,12-trioxa-3,6-diazatetradecan-14-yl methanesulfonate 38

5.14. Potassium 3-((6-(tert-butoxycarbonyl)-3-ethyl-4-oxo-5,9,12-trioxa-3,6diazatetradecan-14-yl)oxy)benzoyltrifluoroborate

5.15. 2-(6-Hydroxy-3-oxo-3H-xanthen-9-yl)-4(5)-((2-(2-(2-(2-(4-(4-oxo-4(phenethylamino)butyl)-1H-1,2,3-triazol-1yl)ethoxy)ethoxy)ethoxy)ethyl)carbamoyl)benzoic acid.

5.16. 2-(6-(Diethylamino)-3-(diethyliminio)-3H-xanthen-9-yl)-5-( N-(2-(2-(2-((1-(6-oxo-6(phenethylamino)hexyl)-1H-1,2,3-triazol-4yl)methoxy)ethoxy)ethoxy)ethyl)sulfamoyl) benzenesulfonate 42

6. References 44 


\section{General methods:}

Reactions involving air- and/or moisture-sensitive reagents were conducted in dry glassware sealed with a rubber septum under an atmosphere of dry $\mathrm{N}_{2}$. Tetrahydrofuran (THF) was distilled from Na/benzophenone ketyl; all other solvents (acetone, MeCN, DMF, $\mathrm{CH}_{2} \mathrm{Cl}_{2}$ ) were used as supplied (ACS or HPLC grade). Starting materials were used as supplied by commercial vendors or prepared by methods described in literature. Thin layer chromatography (TLC) was performed on Merck TLC plates $(0.245 \mathrm{~mm})$ pre-coated with silica gel 60 F254 and visualized by UV quenching and/or staining with $\mathrm{KMnO}_{4}$ solution and warming with a heat gun. Flash column chromatography was performed under a forced-flow of air using Silicycle SiliFlash F60 (40-63 $\mu \mathrm{m}$ particle size). ${ }^{1} \mathrm{H}$ NMR was performed on a Varian AV400 (400 MHz) or Bruker Avance III 600 (600 MHz) and spectra are referenced to residual protonated solvent $\left(\mathrm{CDCl}_{3}: 7.26 \mathrm{ppm}\right.$; aceton- $d_{6}$ : $2.05 \mathrm{ppm}$; DMSO- $d_{6}: 2.50$ ppm, CD $\left.{ }_{3} \mathrm{OD}: 3.31 \mathrm{ppm}\right) .{ }^{13} \mathrm{C}$ NMR was performed on a Varian AV 400 $(100 \mathrm{MHz})$ or Bruker Avance III $600(150 \mathrm{MHz})$ and spectra are referenced to residual protonated solvent $\left(\mathrm{CDCl}_{3}\right.$ : $77.16 \mathrm{ppm}$; acetone- $d_{6}$ : $29.84 \mathrm{ppm}$; DMSO-d $: 39.52 \mathrm{ppm}$, $\left.\mathrm{CD}_{3} \mathrm{OD}: 49.00 \mathrm{ppm}\right) .{ }^{19} \mathrm{~F}$ NMR was performed on a Bruker Avance III (282 $\mathrm{MHz}$ ) and Bruker DRX500 (470 MHz) and referenced to an external standard of trifluoroacetic acid (-76.53 ppm); trifluoroborate multiplets are reported as the average of the observed signals. ${ }^{11} \mathrm{~B}$ NMR was acquired on a Bruker DRX500 (160 MHz) and referenced to an external sample of $\mathrm{BF}_{3} \cdot \mathrm{OEt}_{2}(0 \mathrm{ppm})$; trifluoroborate multiplets are reported as an average of the observed signals. All chemical shifts are reported in ppm ( $\delta)$. Splitting patterns are indicated as follows: br, broad; s, singlet; d, doublet; t, triplet; q, quartet; m, multiplet. Melting points are uncorrected; as the acyltrifluoroborates precipitate as amorphous powders melting points were not acquired. IR spectra were obtained on a Varian $800 \mathrm{FT}$ IR (ATR) spectrometer; the wavenumbers of the bands are reported in $\mathrm{cm}^{-1}$. High-resolution mass spectra were obtained by the mass spectrometry service of the ETH Zürich Laboratorium für Organische Chemie on a Bruker Daltonics maXis ESI-QTOF. 


\section{Synthesis of bifunctional reagents}

\section{Synthesis of potassium 4-(ethyl carboxylate)benzoyltrifluoroborate (3)}<smiles>CCOC(=O)c1ccc(C(=O)Br)cc1</smiles>

In a flame-dried round-bottom flask under an atmosphere of dry $\mathrm{N}_{2}$, (ethylthiotrifluoroborate)-methane dimethyliminium $\quad(1.25 \mathrm{~g}$, $6.74 \mathrm{mmol}, 1.0$ equiv) and ethyl 4-iodobenzoate (1.86 g, $6.74 \mathrm{mmol}, 1.0$ equiv) were dissolved in dry THF (25 mL) and cooled to $-78^{\circ} \mathrm{C}$. $n$-Butyllithium (1.6 M in hexane, $4.6 \mathrm{~mL}, 7.42 \mathrm{mmol}, 1.1$ equiv) was added dropwise over 30 min by syringe pump. After addition of $n$-butyllithium, the reaction was stirred for an additional hour at $-78^{\circ} \mathrm{C}$ before quenching with acetone $(0.5 \mathrm{~mL})$ and a sat. aq KF solution $(3 \mathrm{~mL})$. The flask was removed from the cooling bath and stirred for $1 \mathrm{~h}$. $\mathrm{CH}_{2} \mathrm{Cl}_{2}(25 \mathrm{~mL})$ was added to the reaction mixture and filtered. The filter cake was washed with $\mathrm{CH}_{2} \mathrm{Cl}_{2}(25 \mathrm{~mL})$ before the product was extracted from the filter cake with acetone. The filtrate was concentrated in vacuo and the product 3 was obtained as a white solid (1.63 g, $5.73 \mathrm{mmol}, 85 \%$ ). Full characterization is reported and not duplicated here. ${ }^{1}$

\section{Synthesis of potassium 4-(carboxy)benzoyltrifluoroborate (4)}<smiles>O=C(O)c1ccc(C(=O)Br)cc1</smiles>

In a flame-dried round-bottom flask under an atmosphere of dry $\mathrm{N}_{2}$, KAT $3(1.63 \mathrm{~g}, \quad 5.75 \mathrm{mmol}, 1.0$ equiv) and potassium trimethylsiloxide $(0.88 \mathrm{~g}, 6.90 \mathrm{mmol}, 1.2$ equiv) were suspended in MeCN (20 mL) and stirred at rt overnight. The solvent was removed in vacuo and the resulting solid was suspended in $\mathrm{CH}_{2} \mathrm{Cl}_{2}(30 \mathrm{~mL})$. The suspension was filtered and washed with $\mathrm{CH}_{2} \mathrm{Cl}_{2}(100 \mathrm{~mL})$ before the product was extracted from the filter cake with DMF. The solvent was removed in vacuo to give product 4 as a white solid (1.42 g, $4.83 \mathrm{mmol}, 84 \%)$ m.p. $>250{ }^{\circ} \mathrm{C}$ (decomp); ${ }^{1} \mathrm{H}$ NMR $\left(600 \mathrm{MHz}, \mathrm{DMSO}-d_{6}\right): \delta 7.83$ $(\mathrm{d}, J=8.3 \mathrm{~Hz}, 2 \mathrm{H}), 7.79(\mathrm{~d}, J=8.3 \mathrm{~Hz}, 2 \mathrm{H}) ;{ }^{13} \mathrm{C}$ NMR (151 MHz, DMSO-d $)$ : $\delta 233.1$ (br), 169.2, 143.0, 141.1, 128.2, 126.6; ${ }^{19} \mathrm{~F}$ NMR (470 MHz, DMSO-d 6 ): $\delta-141.4 ;{ }^{11} \mathrm{~B}$ NMR (160 MHz, DMSO- $d_{6}$ ): $\delta-0.94$; IR (thin film): v 1585, 1545, 1387, $1078 \mathrm{~cm}^{-1}$; ESI-HRMS calcd for $\mathrm{C}_{8} \mathrm{H}_{5} \mathrm{BF}_{3} \mathrm{O}_{3}\left[\mathrm{M}-\mathrm{K}_{2}+\mathrm{H}\right]^{-}$217.0291, found 217.0286. 


\section{Synthesis of potassium 4-(perfluorophenylcarboxy)benzoyltrifluoroborate (5)}<smiles>O=C(Br)c1ccc(C(=O)Oc2c(F)c(F)c(F)c(F)c2F)cc1</smiles>

In a flame-dried round-bottom flask under an atmosphere of dry $\quad \mathrm{N}_{2}, \quad \mathrm{KAT} \quad 4 \quad(1.42 \mathrm{~g}, \quad 4.82 \mathrm{mmol}, 1.0$ equiv), perfluorophenyl trifluoroacetate $(0.88 \mathrm{~g}, 5.78 \mathrm{mmol}$, 1.2 equiv) and $\mathrm{N}^{i} \mathrm{Pr}_{2} \mathrm{Et}(0.84 \mathrm{~mL}, 4.82 \mathrm{mmol}, 1.0$ equiv) were dissolved in dry DMF $(25 \mathrm{~mL})$ and stirred at rt overnight. $\mathrm{CH}_{2} \mathrm{Cl}_{2}(150 \mathrm{~mL})$ was added and the resulting suspension filtered, washed with $\mathrm{CH}_{2} \mathrm{Cl}_{2}$ $(3 \times 50 \mathrm{~mL})$ and dried in vacuo to afford product 5 as an off-white solid $(2.03 \mathrm{~g}, 4.77 \mathrm{mmol}$, quant). m.p. $210^{\circ} \mathrm{C}$ (decomp); ${ }^{1} \mathrm{H}$ NMR (600 MHz, acetone-d $): \delta 8.25$ (d, J = $2.3 \mathrm{~Hz}, 4 \mathrm{H}$ ) ${ }^{13} \mathrm{C}$ NMR (151 MHz, acetone- $\left.d_{6}\right): \delta 235.0(\mathrm{br}), 163.2,146.6,143.1\left(\left\{{ }^{19} \mathrm{~F}\right\}\right), 141.4\left(\left\{{ }^{19} \mathrm{~F}\right\}\right)$, $139.7\left(\left\{{ }^{19} \mathrm{~F}\right\}\right), 138.1\left(\left\{{ }^{19} \mathrm{~F}\right\}\right), 131.2,129.5,129.1 ;{ }^{19} \mathrm{~F}$ NMR (470 MHz, acetone- $\left.d_{6}\right)$ : $\delta-145.3,-155.0,-160.3,-164.8 ;{ }^{11}$ B NMR (160 MHz, acetone- $\left.d_{6}\right)$ : $\delta-0.90$; IR (thin film): v 1757, 1683, 1519, $1207 \mathrm{~cm}^{-1}$; ESI-HRMS calcd for $\mathrm{C}_{14} \mathrm{H}_{4} \mathrm{BF}_{8} \mathrm{O}_{3}[\mathrm{M}-\mathrm{K}]^{-} 383.0134$, found 383.0126 .

\section{Synthesis of potassium 4-(formyl)benzoyltrifluoroborate (8)}<smiles>O=Cc1ccc(C(=O)Br)cc1</smiles>

In a flame-dried round-bottom flask under an atmosphere of dry $\mathrm{N}_{2}$, 4-(diethoxymethyl)benzaldehyde $(8.6 \mathrm{~mL}, 43.2 \mathrm{mmol}, 1.0$ equiv), benzotriazole $(5.15 \mathrm{~g}, 43.2 \mathrm{mmol}, 1.0$ equiv), $\mathrm{MeOH} \quad(3.5 \mathrm{~mL}$, $86.4 \mathrm{mmol}, \quad 2.0$ equiv) and trimethylorthoformate $\quad(14.2 \mathrm{~mL}$, $129.7 \mathrm{mmol}, 3.0$ equiv) were dissolved in dry THF (200 mL). To this solution was added conc. $\mathrm{H}_{2} \mathrm{SO}_{4}$ (13 drops). The reaction was stirred for $30 \mathrm{~min}$ and subsequently quenched with solid $\mathrm{NaHCO}_{3}(12 \mathrm{~g})$ and the reaction mixture was filtered. The filter cake was washed with $\mathrm{CH}_{2} \mathrm{Cl}_{2}(50 \mathrm{~mL})$ and the resulting filtrate was concentrated in vacuo to afford crude 1(methoxy(4-(diethoxymethyl)phenyl)methyl)-1H-benzotriazole 7. Compound 7 was dissolved in dry THF $(100 \mathrm{~mL})$ without further purification and cooled to $-90{ }^{\circ} \mathrm{C}$ using an acetone $/ \mathrm{N}_{2}$ ice bath. $n$-Butyllithium (1.6 M in hexane, $24.4 \mathrm{~mL}, 39.0 \mathrm{mmol}, 1.0$ equiv) was added slowly and the reaction mixture was stirred for $5 \mathrm{~min}$. $\mathrm{B}(\mathrm{OMe})_{3}(8.7 \mathrm{~mL}, 77.9 \mathrm{mmol}$, 2.0 equiv) was added and the reaction was allowed to stir for $2 \mathrm{~h}$ before it was quenched with a sat. aq $\mathrm{KHF}_{2}$ solution. The reaction flask was removed from the cooling bath and allowed to stir at $\mathrm{rt}$ overnight. The solvent was removed in vacuo and the residue suspended in $\mathrm{CH}_{2} \mathrm{Cl}_{2}(100 \mathrm{~mL})$, filtered and washed with $\mathrm{CH}_{2} \mathrm{Cl}_{2}(50 \mathrm{~mL})$. The product was 
extracted from the filter cake with acetone and dried in vacuo to afford KAT 8 as a light yellow solid (1.60 g, $8.0 \mathrm{mmol}, 17 \%)$. m.p. >250 ${ }^{\circ} \mathrm{C}$ (decomp); ${ }^{1} \mathrm{H}$ NMR $(600 \mathrm{MHz}$, DMSO$\left.d_{6}\right): \delta 10.06(\mathrm{~s}, 1 \mathrm{H}), 8.06(\mathrm{~d}, J=8.1 \mathrm{~Hz}, 2 \mathrm{H}), 7.94(\mathrm{~m}, 2 \mathrm{H}) ;{ }^{13} \mathrm{C}$ NMR $(151 \mathrm{MHz}$, DMSO$\left.d_{6}\right): \delta 233.2(\mathrm{br}), 193.3,137.3,129.3,128.1,128.1 ;{ }^{19} \mathrm{~F}$ NMR (470 MHz, DMSO-d $): \delta$ -142.1; ${ }^{11} \mathbf{B}$ NMR (160 MHz, DMSO-d $)$ : $\delta-1.13$; IR (thin film): v 2915, 1692, 1634, 1299 $\mathrm{cm}^{-1}$; ESI-HRMS calcd for $\mathrm{C}_{8} \mathrm{H}_{5} \mathrm{BF}_{3} \mathrm{O}_{2}[\mathrm{M}-\mathrm{K}]^{-}$201.0340, found 201.0345.

\section{Synthesis of potassium 6-chlorohexanoyltrifluoroborate (11)}

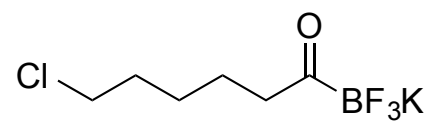

In a flame-dried, $100 \mathrm{~mL}$ two-neck flask equipped with a low temperature thermometer under an atmosphere of dry $\mathrm{N}_{2}$, 1-(6chloro-1-phenoxyhexyl)-1H-benzotriazole 10 (1.09 g, $3.32 \mathrm{mmol}$, 1.0 equiv) was dissolved in dry THF $(50 \mathrm{~mL})$ at $\mathrm{rt}$, and then cooled to $-110{ }^{\circ} \mathrm{C}$ (reaction mixture measured by internal thermometer) in an $\mathrm{EtOH} / \mathrm{N}_{2}$ ice bath. $n$-Butyllithium (1.54 M in hexane, titrated, $2.2 \mathrm{~mL}, 3.32 \mathrm{mmol}, 1.0$ equiv) was added dropwise over $2 \mathrm{~min}$, resulting in a red-brown solution. The reaction was stirred for $25 \mathrm{~min}$, followed by dropwise addition of $\mathrm{B}(\mathrm{OMe})_{3}(0.74 \mathrm{~mL}, 6.64 \mathrm{mmol}, 2.0$ equiv) resulting in a brownish mixture. If solidification of the reaction mixture was observed, the reaction was warmed to $-90{ }^{\circ} \mathrm{C}$ for $30 \mathrm{~min}$, resulting in a clear yellow solution, before cooling to $-110^{\circ} \mathrm{C}$ and stirring for an additional $1 \mathrm{~h}$. The reaction was quenched with a sat. aq $\mathrm{KHF}_{2}$ solution $(15 \mathrm{~mL})$ and allowed to warm to rt overnight. The solvent was removed in vacuo to give an off-white solid, which was washed with $\mathrm{Et}_{2} \mathrm{O}(50 \mathrm{~mL})$ and $\mathrm{CH}_{2} \mathrm{Cl}_{2}(50 \mathrm{~mL})$. The product was extracted with acetone to afford the crude product as a white solid. The crude was dissolved in $2 \mathrm{~mL}$ acetone and precipitated slowly with $\mathrm{Et}_{2} \mathrm{O}(20 \mathrm{~mL})$. After filtration, the filter cake was washed with $\mathrm{CH}_{2} \mathrm{Cl}_{2}(20 \mathrm{~mL})$. Potassium 6-chlorohexanoyltrifluoroborate was dried in vacuo and obtained as a white solid $(0.49 \mathrm{~g}, 2.07 \mathrm{mmol}, 62 \%)$. Full characterization is reported and not duplicated here. ${ }^{2}$ 
Synthesis of 1-(methoxy(3-((tert-butyldimethylsilyl)oxy)phenyl)methyl))-1H-benzo triazole (12a)<smiles>COC(Br)c1cccc(OCCS)c1</smiles>

solution was added conc. $\mathrm{H}_{2} \mathrm{SO}_{4}$ (4 drops). The reaction was stirred overnight and subsequently concentrated in vacuo. Purification by flash column chromatography eluting with 9:1 hexane/EtOAc yielded product $12 \mathrm{a}$ as a colorless oil $(4.80 \mathrm{~g}, 13.0 \mathrm{mmol}, 79 \%) .{ }^{1} \mathrm{H}$ NMR $\left.(600 \mathrm{MHz} \text {, acetone-d })_{6}\right) \delta 8.05(\mathrm{dt}, J=7.9 \mathrm{~Hz}, 1.2 \mathrm{~Hz}, 1 \mathrm{H}), 7.46-7.36(\mathrm{~m}, 3 \mathrm{H}), 7.29$ (dt, $J=7.7 \mathrm{~Hz}, 0.9 \mathrm{~Hz}, 1 \mathrm{H}), 7.16(\mathrm{~s}, 1 \mathrm{H}), 7.08-7.01(\mathrm{~m}, 1 \mathrm{H}), 6.91-6.85(\mathrm{~m}, 2 \mathrm{H}), 3.46(\mathrm{~s}$, $3 \mathrm{H}), 0.92(\mathrm{~s}, 9 \mathrm{H}), 0.11(\mathrm{~s}, 3 \mathrm{H}), 0.10(\mathrm{~s}, 3 \mathrm{H}) ;{ }^{13} \mathrm{C}$ NMR (151 MHz, acetone- $\left.d_{6}\right): \delta 156.7$, $147.8,139.3$, 132.1, 130.6, 128.3, 125.0, 121.5, 120.6, 119.9, 118.4, 112.4, 91.4, 57.1, 26.0, 18.7, -4.4; IR (thin film): v 3003, 2953, 2858, 1738, 1448, 1364, $1217 \mathrm{~cm}^{-1}$; ESIHRMS calcd for $\mathrm{C}_{20} \mathrm{H}_{27} \mathrm{~N}_{3} \mathrm{NaO}_{2} \mathrm{Si}[\mathrm{M}+\mathrm{Na}]^{+} 392.1765$, found 392.1767.

\section{Synthesis of potassium 3-(hydroxy)benzoyltrifluoroborate (12)}<smiles>O=C(Br)c1cccc(O)c1</smiles>

In a flame-dried, $100 \mathrm{~mL}$ two-neck flask equipped with a low temperature thermometer under an atmosphere of dry $\mathrm{N}_{2}$, precursor $12 \mathrm{a}(4.50 \mathrm{~g}$, $12.1 \mathrm{mmol}, 1.0$ equiv) was dissolved in dry THF $(30 \mathrm{~mL})$ and cooled to $-110^{\circ} \mathrm{C}$ (reaction mixture measured by internal thermometer) using an $\mathrm{EtOH} / \mathrm{N}_{2}$ ice bath. $n$-Butyllithium (1.54 M in hexane, titrated, $7.9 \mathrm{~mL}, 12.1 \mathrm{mmol}, 1.0$ equiv) was added dropwise over $2 \mathrm{~min}$ and the reaction mixture was stirred for $30 \mathrm{~min}$. $\mathrm{B}(\mathrm{OMe})_{3}$ (2.7 $\mathrm{mL}, 24.2 \mathrm{mmol}, 2.0$ equiv) was added and the reaction was allowed to stir for $2 \mathrm{~h}$ before it was quenched with a sat. aq $\mathrm{KHF}_{2}$ solution. The reaction flask was removed from the cooling bath and allowed to stir at rt overnight. The solvent was removed in vacuo and the residue suspended in $\mathrm{CH}_{2} \mathrm{Cl}_{2}$, filtered and washed with $\mathrm{CH}_{2} \mathrm{Cl}_{2}$. The product was extracted from the filter cake with acetone and dried in vacuo to afford KAT 12 as a white solid (1.11 g, $4.9 \mathrm{mmol}, 40 \%)$ m.p. $>195{ }^{\circ} \mathrm{C}$ (decomp); ${ }^{1} \mathrm{H}$ NMR $\left(600 \mathrm{MHz}\right.$, acetone- $\left.d_{6}\right)$ : $\delta$ 8.43 (s, 1H), 7.69 (d, J = 7.6 Hz, 1H), 7.58 (ddd, J = $2.6 \mathrm{~Hz}, 0.9 \mathrm{~Hz}, 0.4 \mathrm{~Hz}, 1 \mathrm{H}$ ), 7.21 (ddd, $J=8.0,7.6,0.4 \mathrm{~Hz}, 1 \mathrm{H}), 6.93(\mathrm{ddd}, J=8.0 \mathrm{~Hz}, 2.6 \mathrm{~Hz}, 1.1 \mathrm{~Hz}, 1 \mathrm{H}) ;{ }^{13} \mathrm{C}$ NMR $(151 \mathrm{MHz}$, acetone- $\left.d_{6}\right): \delta 235.5(\mathrm{br}), 158.0,143.6,129.5,120.8,119.1,115,8 ;{ }^{19} \mathrm{~F}$ NMR (470 MHz, 
acetone- $d_{6}$ ): $\delta-144.4 ;{ }^{11}$ B NMR (160 MHz, acetone- $d_{6}$ ): $\delta-0.82 ;$ IR (thin film): v 3382, 1637, 1589, 1453, $1283 \mathrm{~cm}^{-1}$; ESI-HRMS calcd for $\mathrm{C}_{7} \mathrm{H}_{5} \mathrm{BF}_{3} \mathrm{O}_{2}[\mathrm{M}-\mathrm{K}]^{-}$189.0341, found 189.03439.

\section{Synthesis of 1-1(-phenoxy-6-(trimethylsilyl)hex-5-yn-1-yl (13a)}

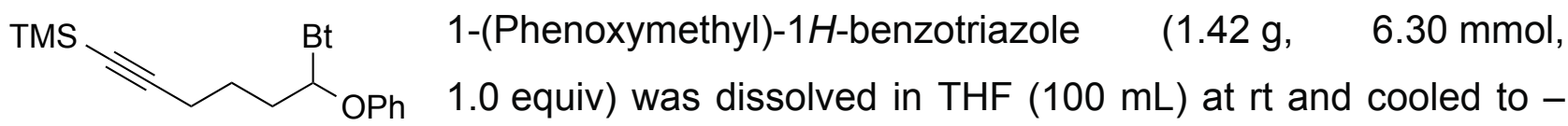
$78^{\circ} \mathrm{C}$. $n$-Butyllithium (1.54 $\mathrm{M}$ in hexane, titrated, $4.5 \mathrm{~mL}, 6.93 \mathrm{mmol}, 1.1$ equiv) was added down the side of the flask over 2 min, resulting in a brownish yellow solution. This was stirred at $-78{ }^{\circ} \mathrm{C}$ for $1 \mathrm{~h}$ before (5-iodopent-1-yn-1-yl)trimethylsilane $(1.68 \mathrm{~g}, 6.30 \mathrm{mmol}$, 1.0 equiv) was added directly into the reaction. The reaction was stirred overnight as the bath gradually warmed to $\mathrm{rt}$, and then quenched with $\mathrm{H}_{2} \mathrm{O}(60 \mathrm{~mL})$. The layers were separated, the aqueous phase extracted with EtOAc $(2 \times 50 \mathrm{~mL})$, and the combined organic layers washed with brine $(25 \mathrm{~mL})$, dried over $\mathrm{Na}_{2} \mathrm{SO}_{4}$, filtered, and concentrated in vacuo. Purification by flash column chromatography eluting with 9:1 hexane/EtOAc gave precursor $13 \mathrm{a}(1.80 \mathrm{~g}, 4.95 \mathrm{mmol}, 79 \%)$ as a yellow oil. ${ }^{1} \mathrm{H}$ NMR (600 MHz, $\left.\mathrm{CDCl}_{3}\right): \delta 8.04$ $(\mathrm{dt}, J=8.4 \mathrm{~Hz}, 1.0 \mathrm{~Hz}, 1 \mathrm{H}), 7.81(\mathrm{dt}, J=8.4 \mathrm{~Hz}, 1.0 \mathrm{~Hz}, 1 \mathrm{H}), 7.46$ (ddd, J = 8.4 Hz, 7.0 Hz, $1.0 \mathrm{~Hz}, 1 \mathrm{H}), 7.35$ (ddd, J = 8.4 Hz, 7.0 Hz, 1.0 Hz, 1H), 7.20-7.16 (m, 2H), 6.98-6.92 (m, $3 \mathrm{H}), 6.88(\mathrm{t}, J=6.9 \mathrm{~Hz}, 1 \mathrm{H}), 2.69-2.59(\mathrm{~m}, 1 \mathrm{H}), 2.47-2.40(\mathrm{~m}, 1 \mathrm{H}), 2.36-2.29(\mathrm{~m}, 2 \mathrm{H})$, 1.82-1.72 (m, 1H), 1.54-1.45 (m, 1H), $\left.0.13(\mathrm{~s}, 9 \mathrm{H}) ;{ }^{13} \mathrm{C} \mathrm{NMR} \mathrm{(151} \mathrm{MHz,} \mathrm{CDCl}\right): \delta 156.2$, $146.9,131.3,129.9,127.9,124.5,123.1,120.4,116.3,111.3,105.8,88.0,86.0,33.9$, 23.8, 19.4, 0.2; IR (thin film): v 3063, 3043, 2959, 2899, 2173, 1590, 1494, 1451, $1341 \mathrm{~cm}^{-}$

1; ESI-HRMS calcd for $\mathrm{C}_{21} \mathrm{H}_{26} \mathrm{~N}_{3} \mathrm{OSi}[\mathrm{M}+\mathrm{H}]^{+} 364.1840$, found 364.1842.

\section{Synthesis of potassium hex-5-ynoyltrifluoroborate (13)}

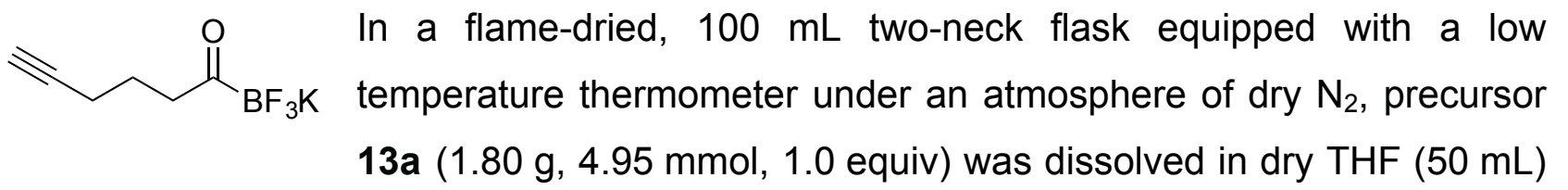
at $\mathrm{rt}$, and then cooled to $-110{ }^{\circ} \mathrm{C}$ (reaction mixture measured by internal thermometer) in an $\mathrm{EtOH} / \mathrm{N}_{2}$ ice bath. $n$-Butyllithium $(1.35 \mathrm{M}$ in hexane, titrated, $3.7 \mathrm{~mL}, 4.95 \mathrm{mmol}$, 1.0 equiv) was added dropwise over $2 \mathrm{~min}$, resulting in a red-brown solution. The mixture 
was stirred for $25 \mathrm{~min}$ followed by drop-wise addition of $\mathrm{B}(\mathrm{OMe})_{3}(1.1 \mathrm{~mL}, 9.90 \mathrm{mmol}$, 2.0 equiv), resulting in a brownish mixture. If solidification of the reaction mixture was observed, the reaction was warmed to $-90^{\circ} \mathrm{C}$ for $30 \mathrm{~min}$, resulting in a clear yellow solution, before cooling to $-110^{\circ} \mathrm{C}$ and stirring for an additional $1 \mathrm{~h}$. The reaction was quenched with a sat. aq $\mathrm{KHF}_{2}$ solution $(15 \mathrm{~mL})$ and allowed to warm to rt overnight. The solvent was removed in vacuo to give an off-white solid. The solid was extracted with acetone, the extract concentrated in vacuo, suspended in $3 \mathrm{~mL}$ sat. aq $\mathrm{KHF}_{2}$ solution and stirred at $65^{\circ} \mathrm{C}$ overnight. The solvent was removed in vacuo and the resulting solid suspended in $\mathrm{Et}_{2} \mathrm{O}(30 \mathrm{~mL})$. After filtration, the filter cake was washed with $\mathrm{CH}_{2} \mathrm{Cl}_{2}$ $(50 \mathrm{~mL})$. The product was extracted from the filter cake with acetone to yield product 13 as a white solid (0.55 g, $2.72 \mathrm{mmol}, 55 \%)$ m.p. $121{ }^{\circ} \mathrm{C}$ (decomp); ${ }^{1} \mathrm{H}$ NMR (600 MHz, acetone- $\left.d_{6}\right)$ : $\delta 2.50(\mathrm{t}, J=7.2 \mathrm{~Hz}, 2 \mathrm{H}), 2.25(\mathrm{t}, J=2.7 \mathrm{~Hz}, 1 \mathrm{H}), 2.13-2.07(\mathrm{~m}, 2 \mathrm{H}), 1.63(\mathrm{p}$, $J=7.3 \mathrm{~Hz}, 2 \mathrm{H}) ;{ }^{13} \mathrm{C}$ NMR (151 MHz, acetone- $\left.d_{6}\right): \delta 248.5(\mathrm{br}), 85.3,69.5,43.9,22.6$, 18.7; ${ }^{19}$ F NMR (470 MHz, acetone- $\left.d_{6}\right): \delta-151.0 ;{ }^{11}$ B NMR (160 MHz, acetone- $\left.d_{6}\right): \delta$ -1.70; IR (thin film): v 3295, 2951, 2874, $1657 \mathrm{~cm}^{-1}$; ESI-HRMS calcd for $\mathrm{C}_{6} \mathrm{H}_{7} \mathrm{BF}_{3} \mathrm{O}$ [M $\mathrm{K}]^{-}$163.0549, found 163.0544 .

\section{Synthesis of potassium 6-azidohexanoyltrifluoroborate (14)}<smiles>NCCCCCC(=O)Br</smiles>

In a flame-dried round-bottom flask under an atmosphere of dry $\mathrm{N}_{2}, 11$ ( $0.44 \mathrm{~g}, 1.82 \mathrm{mmol}, 1.0$ equiv), potassium iodide $(0.30 \mathrm{~g}$, $1.82 \mathrm{mmol}, 1.0$ equiv) and sodium azide $(0.35 \mathrm{~g}, 5.46 \mathrm{mmol}$, 3.0 equiv) were suspended in DMF $(10 \mathrm{~mL})$ and stirred at $80^{\circ} \mathrm{C}$ for $6 \mathrm{~h}$. The reaction mixture was filtered and the solvent was concentrate in vacuo. The resulting solid was dissolved in acetone and precipitated with $\mathrm{Et}_{2} \mathrm{O}$. After filtration the filter cake was washed with $\mathrm{Et}_{2} \mathrm{O}(50 \mathrm{~mL})$. The product was extracted from the filter cake with acetone to afford product 14 as a white solid $(0.29 \mathrm{~g}, 1.82 \mathrm{mmol}, 64 \%)$. m.p. $>125{ }^{\circ} \mathrm{C}$ (decomp); ${ }^{1} \mathbf{H}$ NMR $\left(600 \mathrm{MHz}\right.$, acetone- $\left.d_{6}\right): \delta 3.30(\mathrm{t}, J=6.9 \mathrm{~Hz}, 2 \mathrm{H}), 2.42(\mathrm{t}, J=7.3 \mathrm{~Hz}, 2 \mathrm{H}), 1.59-1.52(\mathrm{~m}$, $2 \mathrm{H}), 1.48$ (p, J = 7.4 Hz, 2H) 1.35-1.27 (m, 2H); ${ }^{13} \mathrm{C}$ NMR (151 MHz, acetone-d $): \delta 250.9$ (br), 51.9, 44.5 (br), 30.3, 27.4, 22.6; ${ }^{19}$ F NMR (470 MHz, acetone- $\left.d_{6}\right): \delta-153.5 ;{ }^{11}$ B NMR (160 MHz, acetone- $d_{6}$ ): $\delta-1.7$; IR (thin film): v 2934, 2862, 2095, $1660 \mathrm{~cm}^{-1}$; ESI-HRMS calcd for $\mathrm{C}_{6} \mathrm{H}_{10} \mathrm{BF}_{3} \mathrm{~N}_{3} \mathrm{O}[\mathrm{M}-\mathrm{K}]^{-}$208.0876, found 208.0876 . 


\section{Chemoselective transformation}

\section{Synthesis of potassium 4-(3-(ethoxy)-3-oxoprop-1-en-1-yl)benzoyltrifluoroborate}<smiles>CCOC(=O)/C=C/c1ccc(C(=O)Br)cc1</smiles>

In a flame-dried round-bottom flask under an atmosphere of dry $\mathrm{N}_{2}$, compound 8 (50 $\mathrm{mg}, 0.21 \mathrm{mmol}, 1.0$ equiv) and (carbethoxymethylene)triphenylphosphorane $15 \quad(109 \mathrm{mg}$, $0.31 \mathrm{mmol}, 1.5$ equiv) were suspended in dry THF $(5 \mathrm{~mL})$ and heated to reflux for $16 \mathrm{~h}$. The reaction mixture was allowed to cool to $\mathrm{rt}$, the solvent was removed in vacuo and the resulting solid suspended in $\mathrm{Et}_{2} \mathrm{O}(10 \mathrm{~mL})$. The suspension was filtered and washed with $\mathrm{Et}_{2} \mathrm{O}(3 \times 50 \mathrm{~mL})$. The product was extracted from the filter cake with acetone and dried in vacuo to give the product 16 as a white solid (50 $\mathrm{mg}, 0.16 \mathrm{mmol}$, $77 \%$ ). m.p. $200{ }^{\circ} \mathrm{C}$ (decomp); ${ }^{1} \mathrm{H}$ NMR (600 MHz, acetone- $\left.d_{6}\right): \delta 8.11$ (d, $\left.J=8.5 \mathrm{~Hz}, 2 \mathrm{H}\right)$, 7.72-7.66 (m, 3H), 6.59 (d, J = 16.1 Hz, 1H), 4.22 (q, J = 7.1 Hz, 2H), 1.29 (t, J = 7.1 Hz, $3 \mathrm{H}) ;{ }^{13} \mathrm{C}$ NMR (151 MHz, acetone- $\left.d_{6}\right): \delta 235.1$ (br), 166.9, 144.8, 137.5, 129.7, 129.6, 128.6, 120.0, 60.8, 14.6; ${ }^{19} \mathrm{~F}$ NMR (470 MHz, acetone- $\left.d_{6}\right): \delta-145.0 ;{ }^{11} \mathrm{~B}$ NMR (160 MHz, acetone- $d_{6}$ ): $\delta-0.86$; IR (thin film): $v 2984,1704,1636,1599 \mathrm{~cm}^{-1}$; ESI-HRMS calcd for $\mathrm{C}_{12} \mathrm{H}_{11} \mathrm{BF}_{3} \mathrm{O}_{3}[\mathrm{M}-\mathrm{K}]^{-} 271.0761$, found 271.0757 .

\section{Synthesis of potassium 3-((7-(diethylamino)-2H-chromen-2-one)methoxy)benzoyltri fluoroborate (18)}

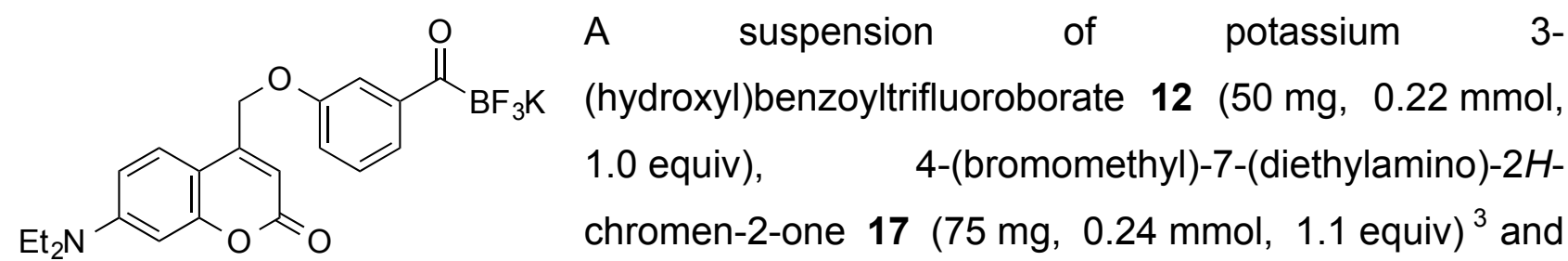
$\mathrm{K}_{2} \mathrm{CO}_{3}$ (36 mg, $0.26 \mathrm{mmol}, 1.2$ equiv) in acetone $(5 \mathrm{~mL})$ was stirred at $50{ }^{\circ} \mathrm{C}$ for $24 \mathrm{~h}$. The solvent was removed in vacuo and the resulting solid suspended in $\mathrm{CH}_{2} \mathrm{Cl}_{2}(20 \mathrm{~mL})$. The suspension was filtered and the filter cake was washed with $\mathrm{CH}_{2} \mathrm{Cl}_{2}(3 \times 20 \mathrm{~mL})$ before the product was extracted from the filter cake with DMF to afford product 18 as a yellow solid (77 mg, $0.13 \mathrm{mmol}, 77 \%)$ m.p. $>210{ }^{\circ} \mathrm{C}$ (decomp); ${ }^{1} \mathbf{H}$ NMR (600 MHz, acetone- $\left.d_{6}\right): \delta$ $7.83(\mathrm{~d}, J=7.6 \mathrm{~Hz}, 1 \mathrm{H}), 7.70(\mathrm{dd}, J=2.7 \mathrm{~Hz}, 1.2 \mathrm{~Hz}, 1 \mathrm{H}), 7.61(\mathrm{~d}, J=9.0 \mathrm{~Hz}, 1 \mathrm{H}), 7.35$ (ddd, J = 8.1 Hz, 7.6 Hz, 0.4 Hz, 1H), 7.18 (ddd, $J=8.1 \mathrm{~Hz}, 2.7 \mathrm{~Hz}, 1.0 \mathrm{~Hz}, 1 \mathrm{H}), 6.75$ (dd, $J=9.0 \mathrm{~Hz}, 2.6 \mathrm{~Hz}, 1 \mathrm{H}), 6.53(\mathrm{~d}, J=2.6 \mathrm{~Hz}, 1 \mathrm{H}), 6.21(\mathrm{t}, J=1.3 \mathrm{~Hz}, 1 \mathrm{H}), 5.33(\mathrm{~d}, J=$ 
$1.3 \mathrm{~Hz}, 2 \mathrm{H}$ ), $3.52(\mathrm{q}, J=7.1 \mathrm{~Hz}, 4 \mathrm{H}), 1.22(\mathrm{t}, J=7.1 \mathrm{~Hz}, 6 \mathrm{H}) ;{ }^{13} \mathrm{C}$ NMR $(151 \mathrm{MHz}$, acetone $\left.-d_{6}\right): \delta 235.0(\mathrm{br}), 161.6,158.9,157.4,152.0,151.7,144.1,129.8,126.3,123.5$, $118.4,114.1,109.5,107.1,106.9,98.1,66.5,45.2,12.8 ;{ }^{19} \mathrm{~F}$ NMR $\left(470 \mathrm{MHz}\right.$, acetone- $\left.d_{6}\right)$ : $\delta-144.6 ;{ }^{11} \mathbf{B}$ NMR $\left(160 \mathrm{MHz}\right.$, acetone- $d_{6}$ ): $\delta-0.88$; IR (thin film): $v 2970,2360,1737$, $1725,1602,1354,1230 \mathrm{~cm}^{-1}$; ESI-HRMS calcd for $\mathrm{C}_{21} \mathrm{H}_{20} \mathrm{BF}_{3} \mathrm{NO}_{4}[\mathrm{M}-\mathrm{K}]^{-} 418.1447$, found 418.1441 .

\section{Synthesis of tert-butyl ((diethylcarbamoyl)oxy)(2-(2-(2-hydroxyethoxy)ethoxy)ethyl) carbamate (19a)}<smiles>CCCCOC(=O)N(CCO)OC(=O)NCC</smiles>

To a solution of 2-(2-(2-chloroethoxy)ethoxy)ethanol (500 mg, $2.98 \mathrm{mmol}, \quad 0.43 \mathrm{~mL}, \quad 1.0$ equiv) and tert-butyl ((diethylcarbamoyl)oxy)carbamate $\quad(825 \mathrm{mg}, \quad 3.55 \mathrm{mmol}$, 1.3 equiv) in DMF $(10 \mathrm{~mL})$ were added $\mathrm{K}_{2} \mathrm{CO}_{3}(822 \mathrm{mg}, 5.96 \mathrm{mmol}, 2.0$ equiv) and potassium iodide $(495 \mathrm{mg}, 2.98 \mathrm{mmol}, 1.0$ equiv). The reaction mixture was heated to $70{ }^{\circ} \mathrm{C}$ and stirred for $16 \mathrm{~h}$, cooled to rt and quenched with $\mathrm{H}_{2} \mathrm{O}(50 \mathrm{~mL})$. The aqueous phase was extracted with $\mathrm{CH}_{2} \mathrm{Cl}_{2}(4 \times 50 \mathrm{~mL})$ and the combined organic layers were dried over $\mathrm{Na}_{2} \mathrm{SO}_{4}$. Removal of the solvent in vacuo gave hydroxylamine alcohol $19 \mathrm{a}$ as a pale yellow oil, which was used in the next step without further purification. ${ }^{1} \mathbf{H}$ NMR $(400 \mathrm{MHz}$, $\left.\mathrm{CDCl}_{3}\right)$ : d $3.81(\mathrm{br} \mathrm{s}, 1 \mathrm{H}), 3.77-3.57(\mathrm{~m}, 12 \mathrm{H}), 3.31(\mathrm{~m}, 4 \mathrm{H}), 1.45(\mathrm{~s}, 9 \mathrm{H}), 1.17(\mathrm{~m}, 6 \mathrm{H})$; ${ }^{13} \mathrm{C}$ NMR $\left(101 \mathrm{MHz}, \mathrm{CDCl}_{3}\right): \mathrm{d} 154.99,154.16,81.87,72.49,70.44,70.42,67.95,61.78$, 49.98, $42.97\left(-\mathrm{N}\left(\mathrm{CH}_{2} \mathrm{CH}_{3}\right)_{2}\right.$, rotomers $), 41.60\left(-\mathrm{N}\left(\mathrm{CH}_{2} \mathrm{CH}_{3}\right)_{2}\right.$, rotomers $), 28.18,14.14$ ($\mathrm{N}\left(\mathrm{CH}_{2} \mathrm{CH}_{3}\right)_{2}$, rotomers), $13.37\left(-\mathrm{N}\left(\mathrm{CH}_{2} \mathrm{CH}_{3}\right)_{2}\right.$, rotomers); IR (thin film): v 3479, 2976, 2935, 2875, 1742, 1423, 1367, 1269, 1132, 922, $746 \mathrm{~cm}^{-1}$; ESI-HRMS: calcd for $\mathrm{C}_{16} \mathrm{H}_{33} \mathrm{~N}_{2} \mathrm{O}_{7}{ }^{+}$ $[\mathrm{M}+\mathrm{H}]^{+}: 347.2282$, found 347.2283 .

\section{Synthesis of 6-(tert-butoxycarbonyl)-3-ethyl-4-oxo-5,9,12-trioxa-3,6-diazatetradecan- 14-yl methanesulfonate (19)}<smiles>CCCCCN(CCO[As])C(=O)OC(=O)NCC</smiles>

$0.66 \mathrm{mmol}, 1.2$ equiv). The reaction mixture was allowed to stir at $\mathrm{rt}$ for $2 \mathrm{~h}$ before removing the solvent in vacuo. The crude material was purified by flash column

To a solution of hydroxylamine $19 \mathrm{a}(200 \mathrm{mg}, 0.55 \mathrm{mmol}$, 1.0 equiv) and $\mathrm{NEt}_{3}\left(114 \mu \mathrm{L}, 0.82 \mathrm{mmol}, 1.5\right.$ equiv) in $\mathrm{CH}_{2} \mathrm{Cl}_{2}$ $(4 \mathrm{~mL})$ at $0{ }^{\circ} \mathrm{C}$ was added methanesulfonyl chloride $(51 \mu \mathrm{L}$, 
chromatography, eluting with cyclohexane/EtOAc (gradient 1:2 $\rightarrow 1: 3$ ) to give hydroxylamine 19 as a colorless oil $(205 \mathrm{mg}, 0.47 \mathrm{mmol}, 85 \%){ }^{1} \mathrm{H}$ NMR $\left(400 \mathrm{MHz}, \mathrm{CDCl}_{3}\right)$ : d 4.39-4.35 (m, 2H), 3.81 (br s, 2H), 3.78-3.74 (m, 2H), 3.69-3.62 (m, 6H), $3.32(\mathrm{q}, J=$ $6.7 \mathrm{~Hz}, 4 \mathrm{H}), 3.07(\mathrm{~s}, 3 \mathrm{H}), 1.46(\mathrm{~s}, 9 \mathrm{H}), 1.18(\mathrm{t}, J=7.1 \mathrm{~Hz}, 6 \mathrm{H}) ;{ }^{13} \mathrm{C} \mathrm{NMR}\left(101 \mathrm{MHz}, \mathrm{CDCl}_{3}\right)$ : d $154.98,154.16,81.88,70.65,70.32,69.25,69.07,67.95,49.99,43.00,41.63,37.72$, 28.19, 14.16, 13.40; IR (thin film): v 2976, 2936, 1741, 1475, 1423, 1352, 1269, 1175, 1132, 1018, 920, 799, $745 \mathrm{~cm}^{-1}$; ESI-HRMS: calcd for $\mathrm{C}_{17} \mathrm{H}_{38} \mathrm{~N}_{3} \mathrm{O}_{9} \mathrm{~S}^{+}\left[\mathrm{M}+\mathrm{NH}_{4}\right]^{+} 460.2323$, found 460.2321 .

\section{Synthesis of potassium 3-((6-(tert-butoxycarbonyl)-3-ethyl-4-oxo-5,9,12-trioxa-3,6-} diazatetradecan-14-yl)oxy)benzoyltrifluoroborate (20)

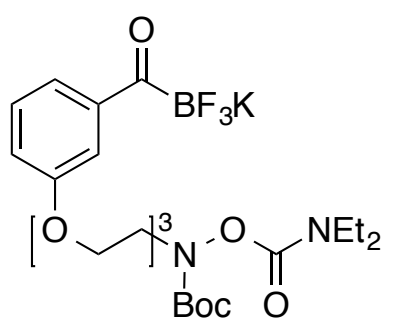

Potassium 3-(hydroxyl)benzoyltrifluoroborate $12 \quad$ (50 mg, $0.22 \mathrm{mmol}, 1.0$ equiv), $\mathrm{Cs}_{2} \mathrm{CO}_{3}$ (143 mg, $0.44 \mathrm{mmol}, 2.0$ equiv) and 6-(tert-butoxycarbonyl)-3-ethyl-4-oxo-5,9,12-trioxa-3,6-diazatetradecan-14-yl methanesulfonate 19 (146 mg, $0.33 \mathrm{mmol}, 1.5$ equiv) were suspended in acetone $(1 \mathrm{~mL})$ and stirred at $65^{\circ} \mathrm{C}$ for 2 days.

The mixture was filtered and washed with acetone $(2 \times 10 \mathrm{~mL})$. The filtrate was concentrated in vacuo and the resulting solid dissolved in 3 drops of acetone. $\mathrm{Et}_{2} \mathrm{O}$ was slowly added along the flask wall to precipitate the product as a white solid. The precipitate was filtered, washed with $\mathrm{Et}_{2} \mathrm{O}$ and dried to afford product 20 as a light yellow oil (95 $\mathrm{mg}$, $0.16 \mathrm{mmol}, 75 \%) .{ }^{1} \mathrm{H}$ NMR $\left(600 \mathrm{MHz}\right.$, acetone- $\left.d_{6}\right): \delta 7.71(\mathrm{~d}, J=7.4 \mathrm{~Hz}, 1 \mathrm{H}), 7.63(\mathrm{dd}, J$ $=2.6 \mathrm{~Hz}, 1.2 \mathrm{~Hz}, 1 \mathrm{H}$ ), $7.28(\mathrm{t}, J=8.0 \mathrm{~Hz}, 1 \mathrm{H}), 7.00$ (ddd, $J=8.1 \mathrm{~Hz}, 2.7 \mathrm{~Hz}, 1.0 \mathrm{~Hz}, 1 \mathrm{H}$ ), 4.16-4.13 (m, 2H), 3.83-3.82 (m, 2H), 3.77-3.72 (m, 1H), 3.71-3.61 (m, 7H), 3.32 (q, J = $7.0 \mathrm{~Hz}, 4 \mathrm{H}$ ), $1.44(\mathrm{~s}, 9 \mathrm{H}), 1.16$ (br.s, 6H); ${ }^{13} \mathrm{C}$ NMR (151 MHz, acetone- $\left.d_{6}\right): \delta 234.7$ (br), 159.6, 155.7, 154.7, 144.1, 129.5, 122.2, 118.1, 114.3, 81.7, 71.4, 71.1, 70.4, 68.5, 68.2, $50.7,43.6,42.3,28.4,14.5,13.7 ;{ }^{19} \mathrm{~F}$ NMR $\left(470 \mathrm{MHz}\right.$, acetone- $\left.d_{6}\right): \delta-141.6 ;{ }^{11} \mathrm{~B}$ NMR $\left(160 \mathrm{MHz}\right.$, acetone- $d_{6}$ ): $\delta-0.80$; IR (thin film): v 2978, 2935, 2877, 1737, 1633, 1577, 1479, 1428, $1368 \mathrm{~cm}^{-1}$; ESI-HRMS calcd for $\mathrm{C}_{23} \mathrm{H}_{35} \mathrm{BF}_{3} \mathrm{~N}_{2} \mathrm{O}_{8}[\mathrm{M}-\mathrm{K}]^{-} 535.2439$, found 535.2444 . 
Synthesis of 2-(6-Hydroxy-3-oxo-3H-xanthen-9-yl)-4(5)-((2-)-(2--(2-(4-(4-oxo-4(phenethylamino)butyl)-1H-1,2,3-triazol-1-yl)ethoxy)ethoxy)ethoxy)ethyl)carbamoyl) benzoic acid (23)

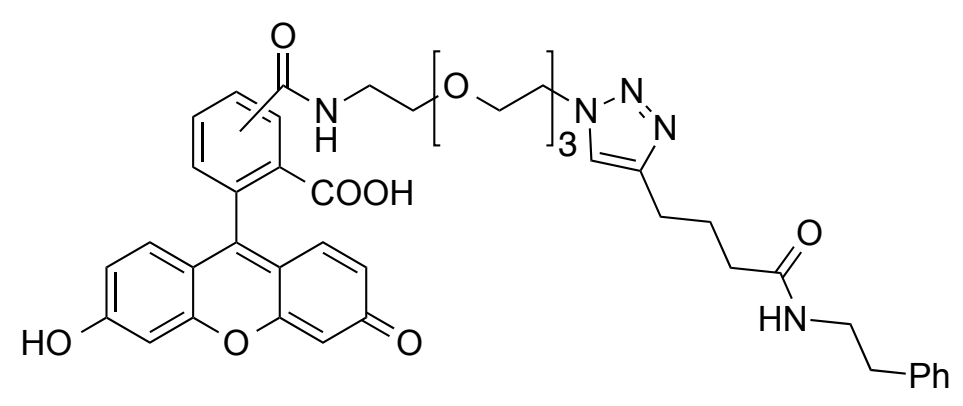

Potassium hex-5-ynoyltrifluoroborate 13 (21 mg, $104 \mu \mathrm{mol}, 2.0$ equiv), 4(5)-((2-(2-(2-(2-Azidoethoxy)ethoxy) etho-xy)ethyl)carbamoyl)-2-(6-hydroxy-oxo-3H-xanthen-9-yl)benzoic acid $21^{4}$ (30 mg, $52 \mu \mathrm{mol}, 1.0$ equiv), Cul (10 mg, $52 \mu \mathrm{mol}, 1.0$ equiv) and $\mathrm{NEt}_{3}\left(22 \mu \mathrm{L}, 156 \mu \mathrm{mol}, 3.0\right.$ equiv) in $1: 1 \mathrm{CH}_{3} \mathrm{CN} / \mathrm{H}_{2} \mathrm{O}$ $(1 \mathrm{~mL})$ was stirred for $12 \mathrm{~h}$ at rt. N,N-Diethyl-2-(phenethylamino)acetamide $22(31 \mathrm{mg}$, $130 \mu \mathrm{mol}, 2.5$ equiv) was added the mixture was allowed to stir for $12 \mathrm{~h}$. The reaction mixture was purified directly by preparative HPLC to afford product $\mathbf{2 3}$ as a yellow solid (24 mg, $31 \mu \mathrm{mol}, 59 \%$ ). m.p. $>90{ }^{\circ} \mathrm{C}$ (decomp); ${ }^{1} \mathrm{H}$ NMR (600 MHz, $\mathrm{CD}_{3} \mathrm{OD}$ ): $\delta 8.50$ (s, $0.5 \mathrm{H}$ ), 8.22 (dd, $J=8.0 \mathrm{~Hz}, 1.7 \mathrm{~Hz}, 0.5 \mathrm{H}), 8.17-8.12(\mathrm{~m}, 1 \mathrm{H}), 7.80(\mathrm{dd}, J=5.5 \mathrm{~Hz}, 2.9 \mathrm{~Hz}$, $0.5 \mathrm{H}), 7.75(\mathrm{~s}, 0.5 \mathrm{H}), 7.68(\mathrm{~s}, 0.5 \mathrm{H}), 7.33(\mathrm{~d}, J=8.0 \mathrm{~Hz}, 0.5 \mathrm{H}), 7.26-7.22(\mathrm{~m}, 2 \mathrm{H}), 7.18(\mathrm{~d}$, $J=7.9 \mathrm{~Hz}, 2 \mathrm{H}$ ), 7.15 (ddt, $J=8.7 \mathrm{~Hz}, 5.4 \mathrm{~Hz}, 1.3 \mathrm{~Hz}, 1 \mathrm{H}), 6.81(\mathrm{~d}, J=9.1 \mathrm{~Hz}, 2 \mathrm{H}), 6.75$ $(\mathrm{d}, J=8.3 \mathrm{~Hz}, 2 \mathrm{H}), 6.66(\mathrm{~d}, J=6.3 \mathrm{~Hz}, 2 \mathrm{H}), 4.51(\mathrm{t}, J=6.0 \mathrm{~Hz}, 1 \mathrm{H}), 4.46(\mathrm{t}, J=6.0 \mathrm{~Hz}$, $1 \mathrm{H}$ ), 3.86 (t, $J=6.0 \mathrm{~Hz}, 1 \mathrm{H}$ ), 3.79 (t, $J=6.0 \mathrm{~Hz}, 1 \mathrm{H}$ ), $3.70(\mathrm{t}, J=5.5 \mathrm{~Hz}, 1 \mathrm{H}$ ), 3.67-3.59 (m, 5H), $3.58(\mathrm{t}, J=5.5 \mathrm{~Hz}, 1 \mathrm{H}), 3.55-3.52(\mathrm{~m}, 1 \mathrm{H}), 3.52-3.49(\mathrm{~m}, 2 \mathrm{H}), 3.49(\mathrm{~s}, 2 \mathrm{H}), 3.38$ (q, J = 7.0 Hz, 2H), 2.76 (dt, $J=7.3 \mathrm{~Hz}, 3.0 \mathrm{~Hz}, 2 \mathrm{H}$ ), 2.63 (q, J = 8.2 Hz, 2H), 2.18 (dt, $J=9.6 \mathrm{~Hz}, 7.5 \mathrm{~Hz}, 2 \mathrm{H}), 1.93-1.84(\mathrm{~m}, 2 \mathrm{H}) ;{ }^{13} \mathrm{C}$ NMR (151 MHz, $\left.\mathrm{CD}_{3} \mathrm{OD}\right): \delta 175.4,169.9$, 168.3, 168.2, 163.4, 160.3, 160.0, 160.0, 159.8, 155.3, 155.1, 148.2, 141.9, 140.5, 137.9, $135.1,131.0,130.9,130.6,129.8,129.5,127.3,126.8,126.1,125.0,124.5,115.1,112.1$, 103.6, 71.6, 71.5, 71.5, 71.4, 71.4, 71.2, 70.5, 70.3, 70.3, 51.5, 51.4, 41.9, 41.2, 41.1, 36.5, 36.3, 26.7, 25.7; IR (thin film): v 3141, 3089, 2930, 2874, 1756, 1699, 1643, 1614, 1550, 1454, 1249, 1182, $1114 \mathrm{~cm}^{-1}$; ESI-HRMS calcd for $\mathrm{C}_{43} \mathrm{H}_{46} \mathrm{~N}_{5} \mathrm{O}_{10}[\mathrm{M}+\mathrm{H}]^{+} 792.3239$, found 792.3223 . 
Synthesis of 2-(6-(Diethylamino)-3-(diethyliminio)-3H-xanthen-9-yl)-5-(N-(2-(2-(2-)(1(6-oxo-6-(phenethylamino)hexyl)-1H-1,2,3-triazol-4-yl)methoxy)ethoxy)ethoxy)ethyl) sulfamoyl)benzenesulfonate (25)

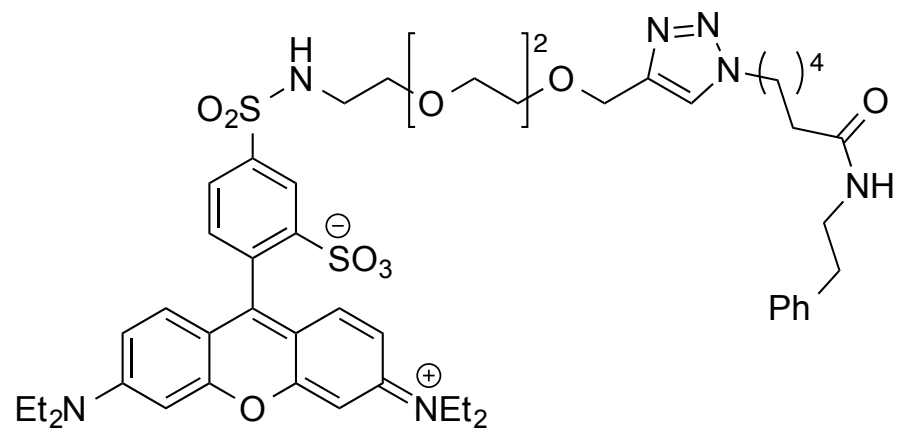

Potassium 6-azidohexanoyltrifluorobo rate 14 (20 mg, $41 \mu \mathrm{mol}, 2.0$ equiv), 2(6-(diethylamino)-3-(diethyliminio)-3Hxanthen-9-yl)-5-(N-(2-(2-(2-(prop-2-yn1 -yl oxy)ethoxy)ethoxy)ethyl)sulfamoyl) benzenesulfonate $24^{5}$ (30 mg, $82 \mu \mathrm{mol}$, 1.0 equiv), Cul ( $8 \mathrm{mg}, 41 \mu \mathrm{mol}, 1.0$ equiv) and $\mathrm{NEt}_{3}(5 \mu \mathrm{L}, 41 \mu \mathrm{mol}, 1.0$ equiv) in $1: 1$ $\mathrm{CH}_{3} \mathrm{CN} / \mathrm{H}_{2} \mathrm{O}(1 \mathrm{~mL})$ was stirred for $16 \mathrm{~h}$. N,N-diethyl-2-(phenethylamino)acetamide 22 (19 mg, $82 \mu \mathrm{mol}, 2.0$ equiv) was added and the reaction was allowed to stir for $12 \mathrm{~h}$ at $\mathrm{rt}$. Purification by HPLC gave the product as a purple solid (23 mg, $23 \mu \mathrm{mol}, 56 \%)$. m.p. $>210{ }^{\circ} \mathrm{C}$ (decomp); ${ }^{1} \mathrm{H}$ NMR (600 MHz, $\mathrm{CD}_{3} \mathrm{OD}$ ): $\delta 8.67$ (dd, $J=1.9 \mathrm{~Hz}, 0.4 \mathrm{~Hz}, 1 \mathrm{H}$ ), 8.11 (dd, $J=7.9 \mathrm{~Hz}, 1.9 \mathrm{~Hz}, 1 \mathrm{H}), 8.02(\mathrm{~s}, 1 \mathrm{H}), 7.49(\mathrm{~d}, J=8.3 \mathrm{~Hz}, 1 \mathrm{H}), 7.27-7.23(\mathrm{~m}, 2 \mathrm{H}), 7.19-$ $7.15(\mathrm{~m}, 3 \mathrm{H}), 7.11(\mathrm{~s}, 1 \mathrm{H}), 7.09(\mathrm{~s}, 1 \mathrm{H}), 6.98(\mathrm{dd}, J=9.5 \mathrm{~Hz}, 2.5 \mathrm{~Hz}, 2 \mathrm{H}), 6.92(\mathrm{~d}$, $J=2.5 \mathrm{~Hz}, 2 \mathrm{H}), 4.62(\mathrm{~s}, 2 \mathrm{H}), 4.36(\mathrm{t}, J=7.1 \mathrm{~Hz}, 2 \mathrm{H}), 3.69-3.63(\mathrm{~m}, 12 \mathrm{H}), 3.62-3.59(\mathrm{~m}$, $2 \mathrm{H}$ ), $3.57(\mathrm{dd}, J=4.2 \mathrm{~Hz}, 2.1 \mathrm{~Hz}, 1 \mathrm{H}), 3.56-3.53(\mathrm{~m}, 3 \mathrm{H}), 3.34(\mathrm{t}, J=7.3 \mathrm{~Hz}, 2 \mathrm{H}), 3.22(\mathrm{t}$, $J=5.3 \mathrm{~Hz}, 2 \mathrm{H}), 2.75-2.70(\mathrm{~m}, 2 \mathrm{H}), 2.10(\mathrm{t}, J=7.4 \mathrm{~Hz}, 2 \mathrm{H}), 1.86(\mathrm{p}, J=7.5 \mathrm{~Hz}, 2 \mathrm{H}), 1.57$ $(\mathrm{p}, J=7.5 \mathrm{~Hz}, 2 \mathrm{H}), 1.29(\mathrm{t}, J=7.1 \mathrm{~Hz}, 12 \mathrm{H}), 1.26-1.22(\mathrm{~m}, 2 \mathrm{H}) ;{ }^{13} \mathrm{C}$ NMR $(151 \mathrm{MHz}$, $\mathrm{CD}_{3} \mathrm{OD}$ ): $\delta 175.8,159.4,157.9,157.1,147.3,145.8,144.2,140.5,135.3,133.7,132.5$, 129.8, 129.5, 129.3, 127.7, 127.3, 125.4, 115.3, 115.1, 97.0, 71.6, 71.5, 71.3, 70.8, 70.7, $64.9,51.3,46.8,44.2,41.9,36.7,36.5,30.8,26.9,26.3,12.8$; IR (thin film): v 2978, 2932, 2871, 1591, 1416, 1338, $1180 \mathrm{~cm}^{-1}$; ESI-HRMS calcd for $\mathrm{C}_{50} \mathrm{H}_{65} \mathrm{~N}_{7} \mathrm{O}_{10} \mathrm{~S}_{2}[\mathrm{M}+\mathrm{H}]^{+}$ 988.4307, found 988.4295 . 


\section{Preparation and KAT ligation of potassium acyltrifluoroborate} containing SUMO2 C-terminal peptide sequence

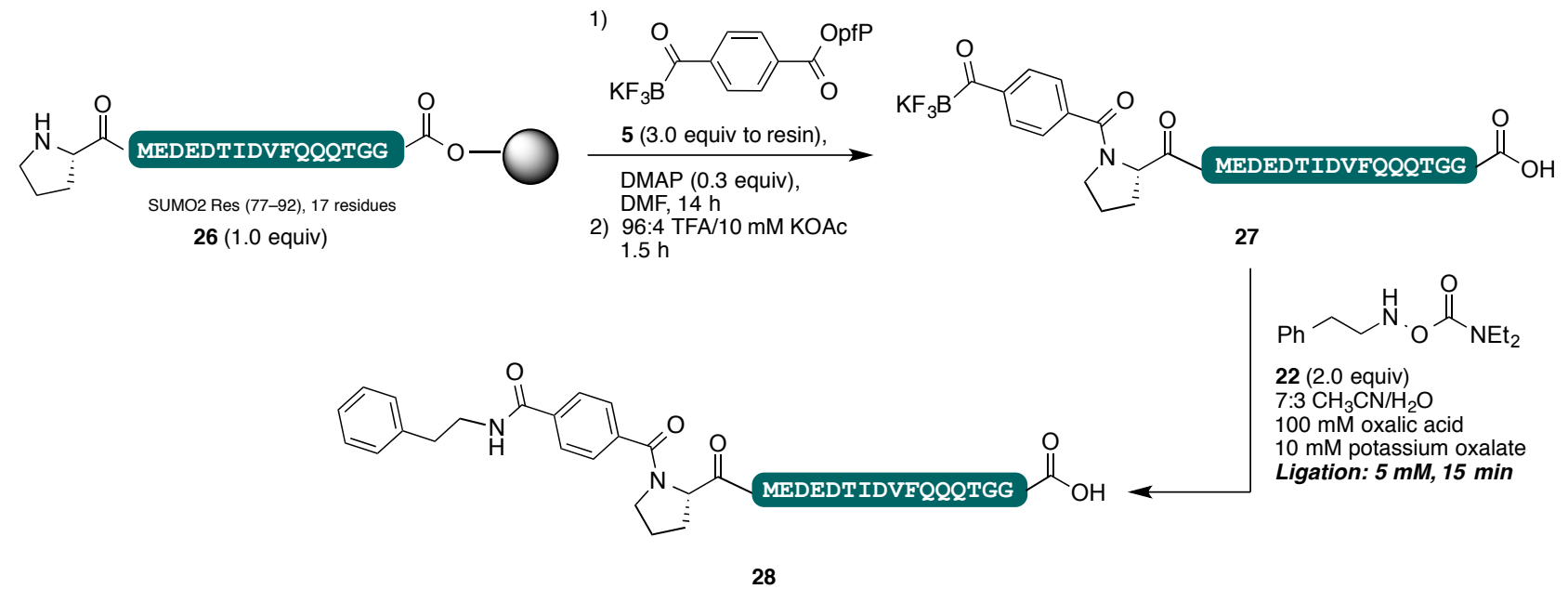

Peptide synthesis: The peptide was synthesized by standard automated Fmoc-SPPS using pre-loaded Fmoc-Gly-HMP-AM resin with a substitution capacity of $0.49 \mathrm{mmol} / \mathrm{g}$.

Coupling of KAT-pfP ester: The $N$-terminal proline containing peptide on-resin 26 (55.0 mg, $27.5 \mu \mathrm{mol}$ ) was treated with a solution of bifunctional KAT-pfP ester 5 (34.8 $\mathrm{mg}$, $82.5 \mu \mathrm{mol}, 3.0$ equiv to resin) and DMAP ( $1.0 \mathrm{mg}, 8.2 \mu \mathrm{mol}, 0.3$ equiv to resin) in DMF ( 1.5 $\mathrm{mL}$ ). The reaction was allowed to proceed for $14 \mathrm{~h}$. The resin was thoroughly washed with DMF $(3 \times 2 \mathrm{~mL})$ and $\mathrm{CH}_{2} \mathrm{Cl}_{2}(3 \times 2 \mathrm{~mL})$ and dried under a stream of nitrogen.

Cleavage of peptide from resin: The peptide containing the KAT group on-resin 27 $(55.0 \mathrm{mg}$ ) was treated with 96:4 TFA/10 mM KOAc, $\mathrm{pH}=4$ for $1.5 \mathrm{~h}$. The resin was filtered-off and the filtrate was concentrated in vacuo. The residue was triturated with $\mathrm{Et}_{2} \mathrm{O}$ ( $3 \times 5 \mathrm{~mL})$, centrifuged and dried to obtain an off-white solid $(22.8 \mathrm{mg}, 39 \%$ crude yield).

Purification of KAT-peptide: The crude peptide was purified by preparative HPLC using $\mathrm{pH} 4$ buffer systems. Eluent $\mathrm{A}: 10 \mathrm{mM} \mathrm{KOAc}$ buffer, $\mathrm{pH}=4$; Eluent $\mathrm{B}:(9: 1) \mathrm{CH}_{3} \mathrm{CN} / 10 \mathrm{mM}$ KOAc buffer, $\mathrm{pH}=4$ using a gradient of 10 to $95 \% \mathrm{CH}_{3} \mathrm{CN}$ in $25 \mathrm{~min}$. Column: Phenomenex Jupiter $(21.5 \times 250 \mathrm{~mm}), 5$ micron, $300 \AA$; Flow rate: $10 \mathrm{~mL} / \mathrm{min}$; UV detection: $220 \mathrm{~nm}, 254 \mathrm{~nm}, 280 \mathrm{~nm}$. The product fractions were pooled, frozen and lyophilized to give the desired KAT-peptide along with KOAc. Analytical HPLC and MALDIFTMS (negative mode) were used to confirm the purity and identity of the isolated product 27. $\mathrm{m} / \mathrm{z}$ calculated for $27 \mathrm{C}_{87} \mathrm{H}_{123} \mathrm{BF}_{3} \mathrm{~N}_{20} \mathrm{O}_{35} \mathrm{~S}$ 2107.8239; measured $2106.8127[\mathrm{M}-\mathrm{H}]$. 
Note: Under MALDI-TOF measurement conditions using HCCA as the matrix, presumably the proto-deborylated and difluoroborate products are observed as the molecular ion peak, which is pronounced for sequences rich in acidic residues.
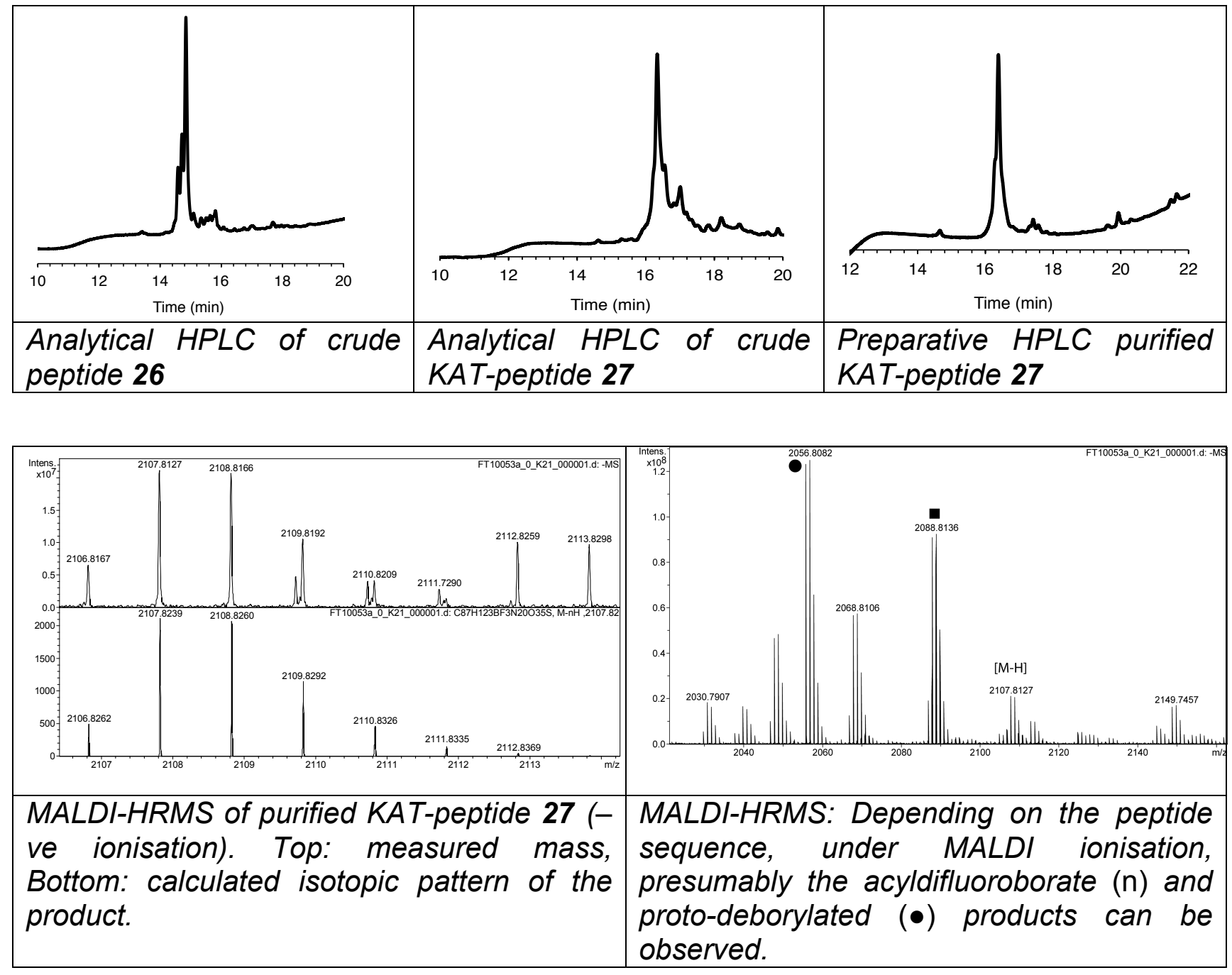

KAT ligation with purified KAT-peptide: KAT-peptide 27 (4.0 mg, 1.9 Hmol, 1.0 equiv) and phenethylcarbamoyl hydroxylamine $22(0.9 \mathrm{mg}, 3.7 \mu \mathrm{mol}, 2.0$ equiv) were dissolved in 7:3 $\mathrm{CH}_{3} \mathrm{CN} / \mathrm{H}_{2} \mathrm{O}$ with $0.1 \mathrm{M}$ oxalic acid and $0.01 \mathrm{M}$ potassium oxalate $(373.0 \mu \mathrm{L}, 5 \mathrm{mM})$ and allowed to react at $25^{\circ} \mathrm{C}$. The progress of the ligation was monitored by analytical HPLC using a Shiseido capcell pak UG80 C18 column (4.6 x $250 \mathrm{~mm})$ using a gradient of 10 to $95 \% \mathrm{CH}_{3} \mathrm{CN}$ with $0.1 \%$ TFA in $22 \mathrm{~min}$. An aliquot of the ligation mixture $(3 \mu \mathrm{L})$ was taken at $15 \mathrm{~min}$ and $90 \mathrm{~min}$, diluted to $15 \mu \mathrm{L}$ with ligation solvent and injected on HPLC. No change in the peak ratios was observed after $15 \mathrm{~min}$. The reaction mixture was diluted to $0.9 \mathrm{~mL}$ and purified by preparative HPLC using a Phenomenex Jupiter column (21.5 x $250 \mathrm{~mm}$ ), 5 micron, $300 \AA$ with a gradient of 10 to $95 \% \mathrm{CH}_{3} \mathrm{CN}$ with $0.1 \%$ TFA in $25 \mathrm{~min}$; Flow rate: $10 \mathrm{~mL} / \mathrm{min}$; UV detection: $220 \mathrm{~nm}, 254 \mathrm{~nm}, 280 \mathrm{~nm}$. The fractions containing the product were pooled, frozen and lyophilized to give the desired KAT-ligated 
SUMO 2 C-terminal peptide 28 (1.3 mg, 32\% yield for KAT ligation and purification steps). Analytical HPLC and MALDI-FTMS (positive mode) were used to confirm the purity and identity of the ligated product 28 . m/z calculated for $28 \mathrm{C}_{95} \mathrm{H}_{133} \mathrm{~N}_{21} \mathrm{NaO}_{35} \mathrm{~S} 2182.8886$; measured 2182.8922 [M+Na].

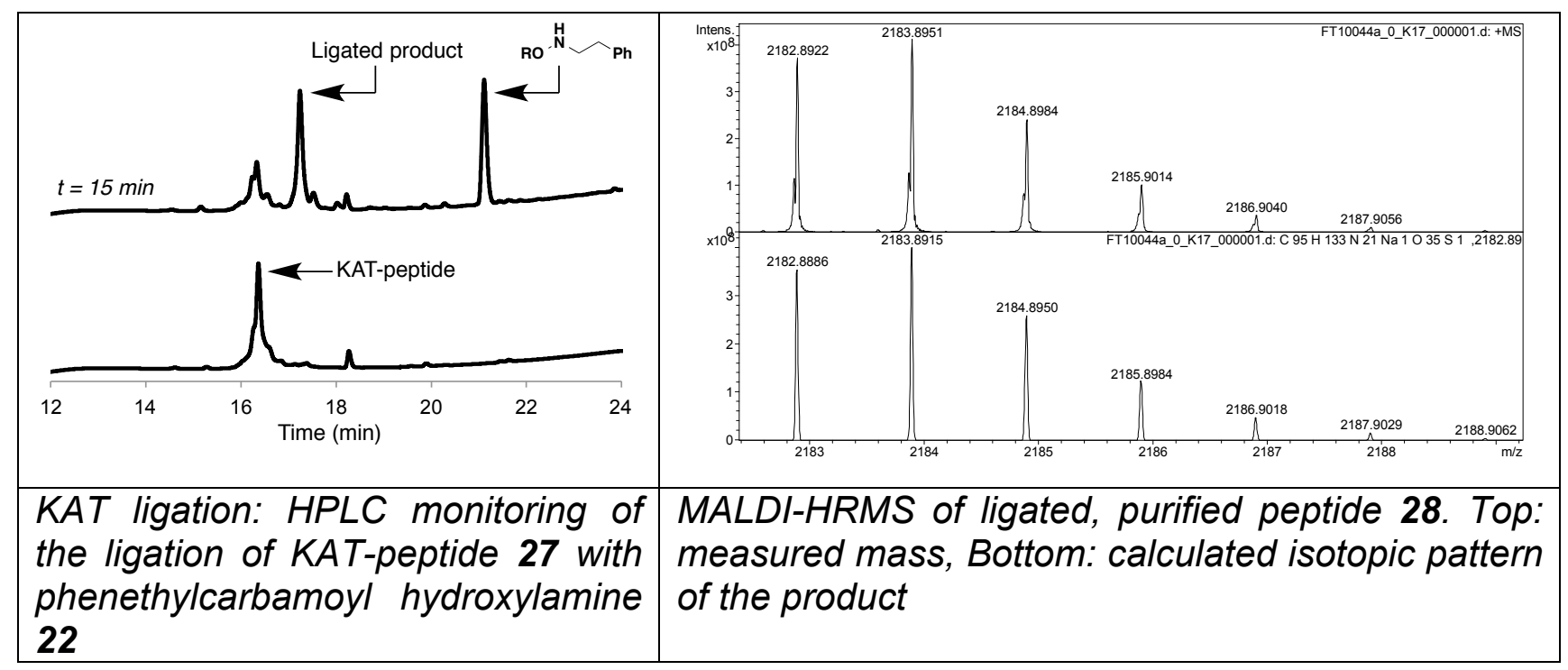




\section{Spectral Data}

4: ${ }^{1}$ H NMR (600 MHz, DMSO-d $)$

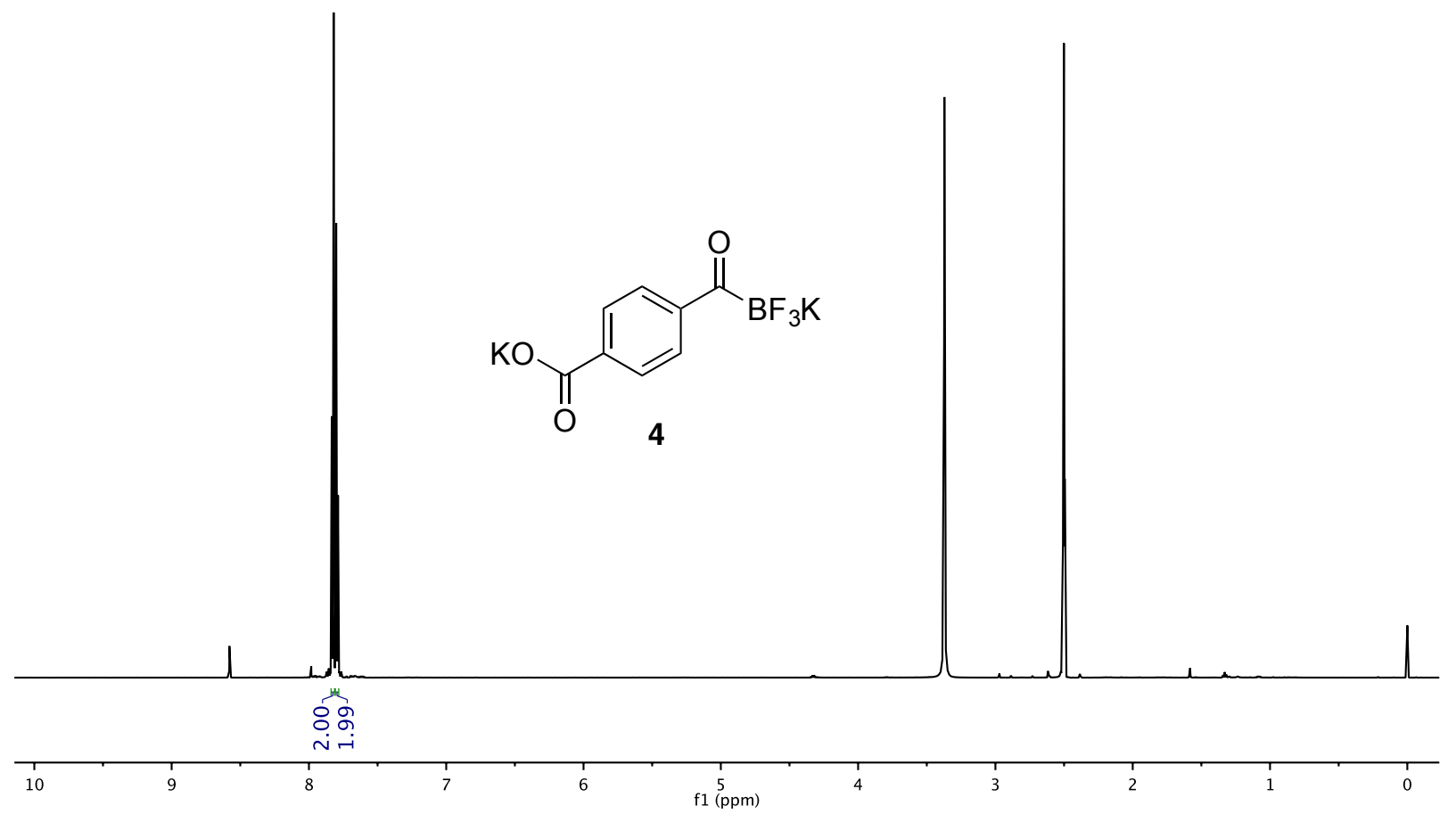

4: ${ }^{13}$ C NMR (151 MHz, DMSO-d $)$
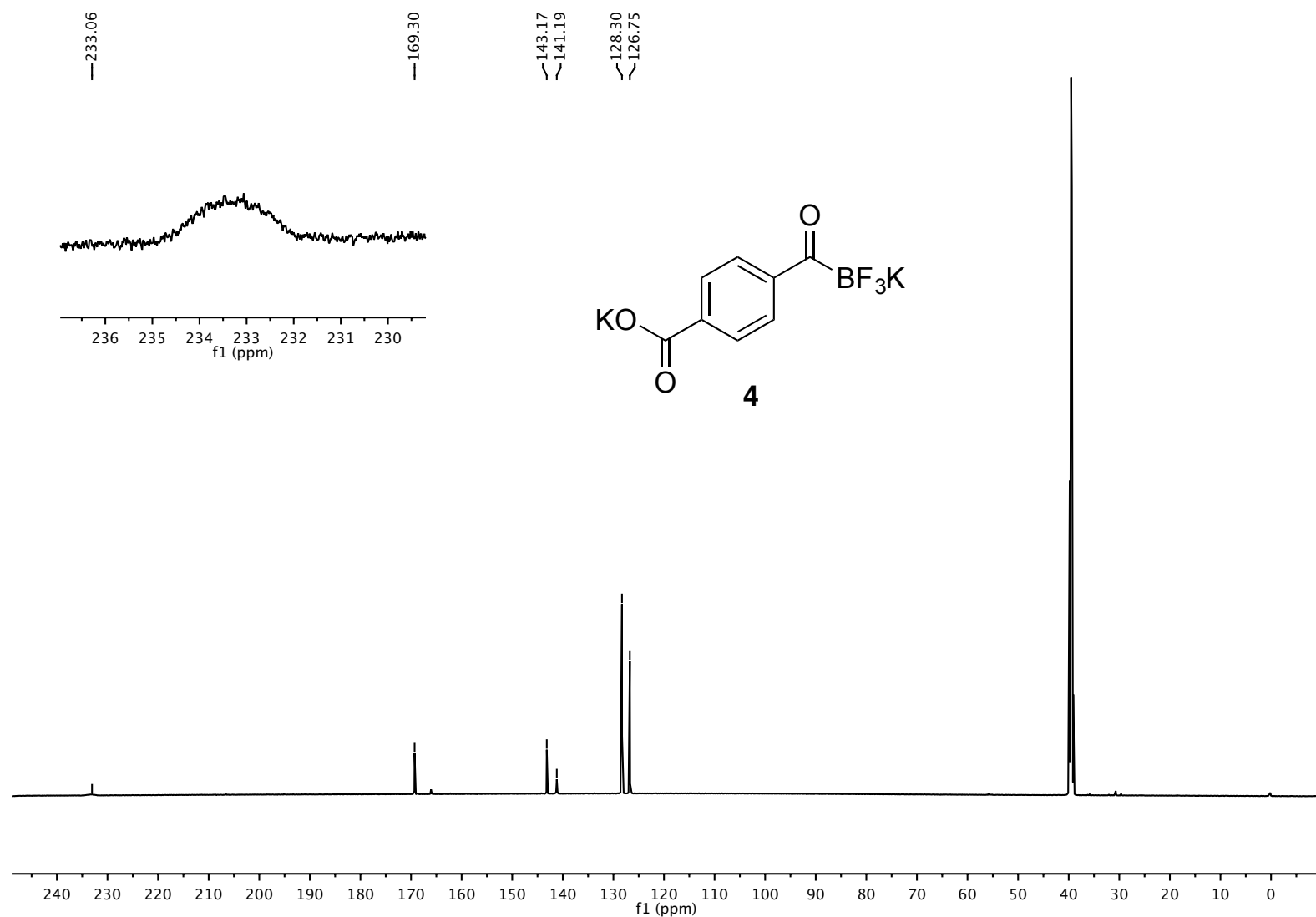
4: ${ }^{19}$ F NMR (470 MHz, DMSO-d6)<smiles>O=C(O)c1ccc(C(=O)Br)cc1</smiles>

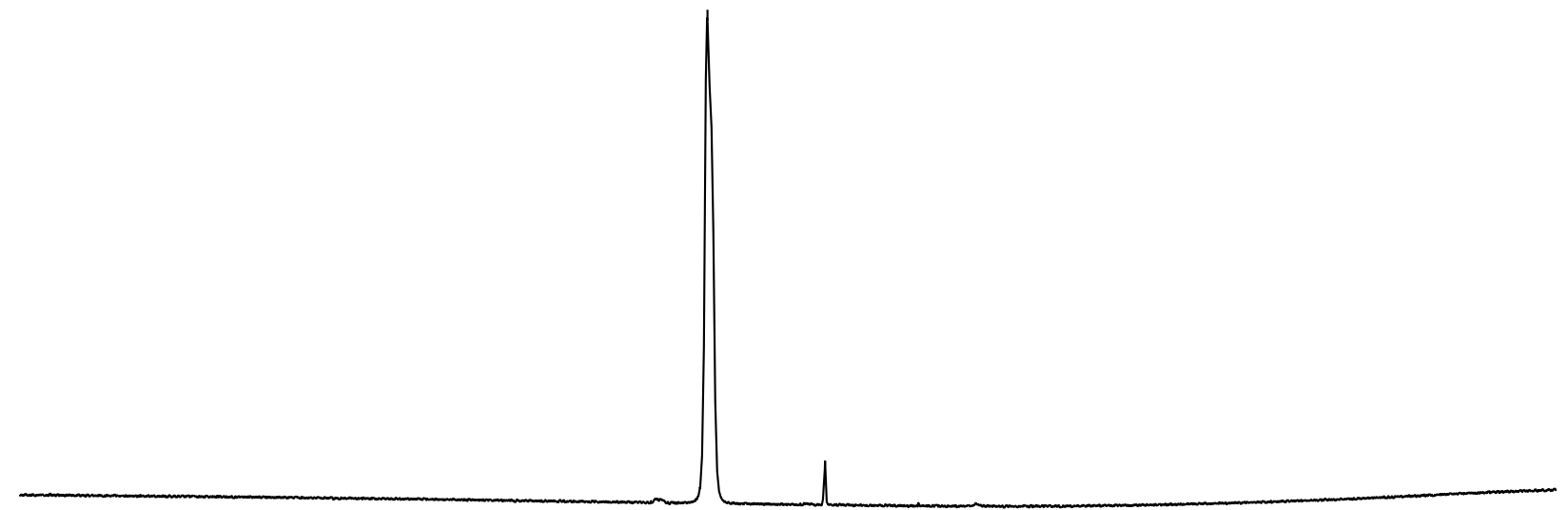

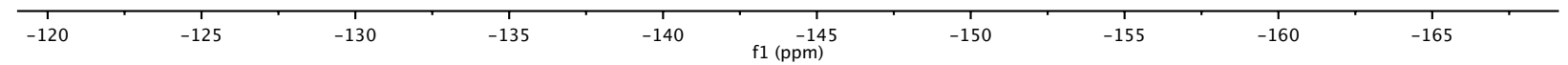

4: 11B NMR (160 MHz, DMSO-d $)$<smiles>O=C(O)c1ccc(C(=O)Br)cc1</smiles>

$\stackrel{\text { ț }}{\text { i }}$

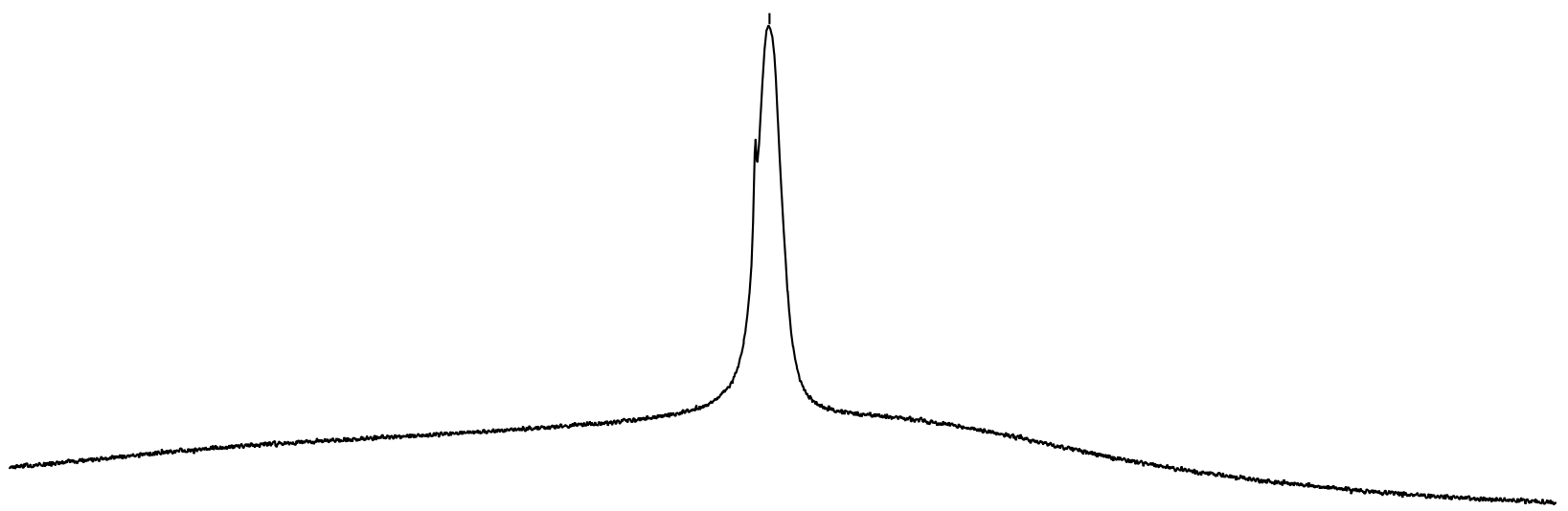

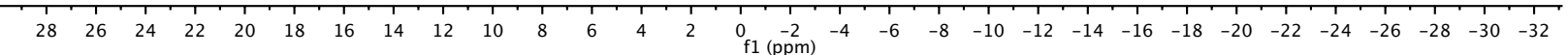


5: ${ }^{1} \mathrm{H}$ NMR (600 MHz, acetone- $\left.d_{6}\right)$
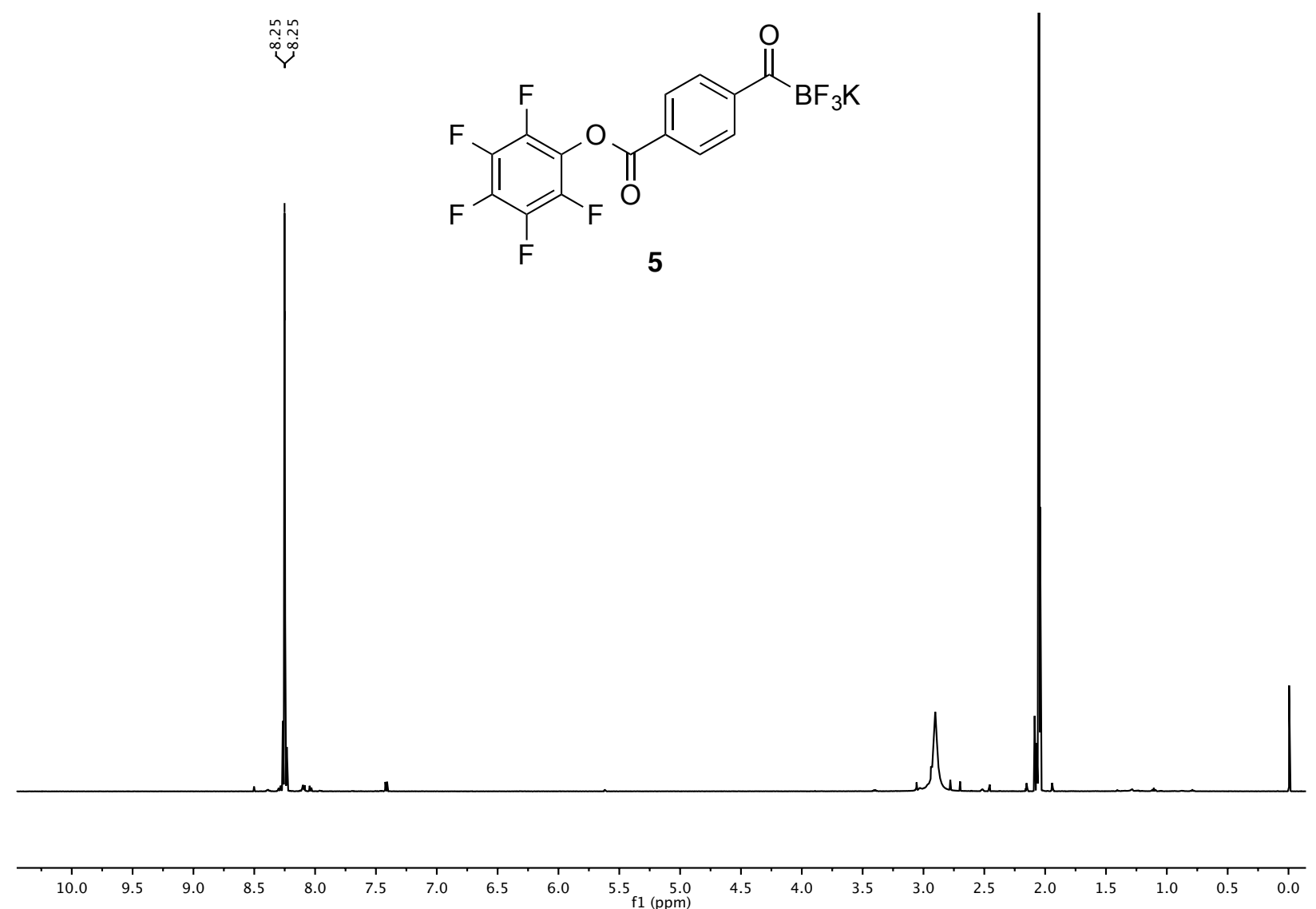

5: ${ }^{13}$ C NMR (151 MHz, acetone- $d_{6}$ )

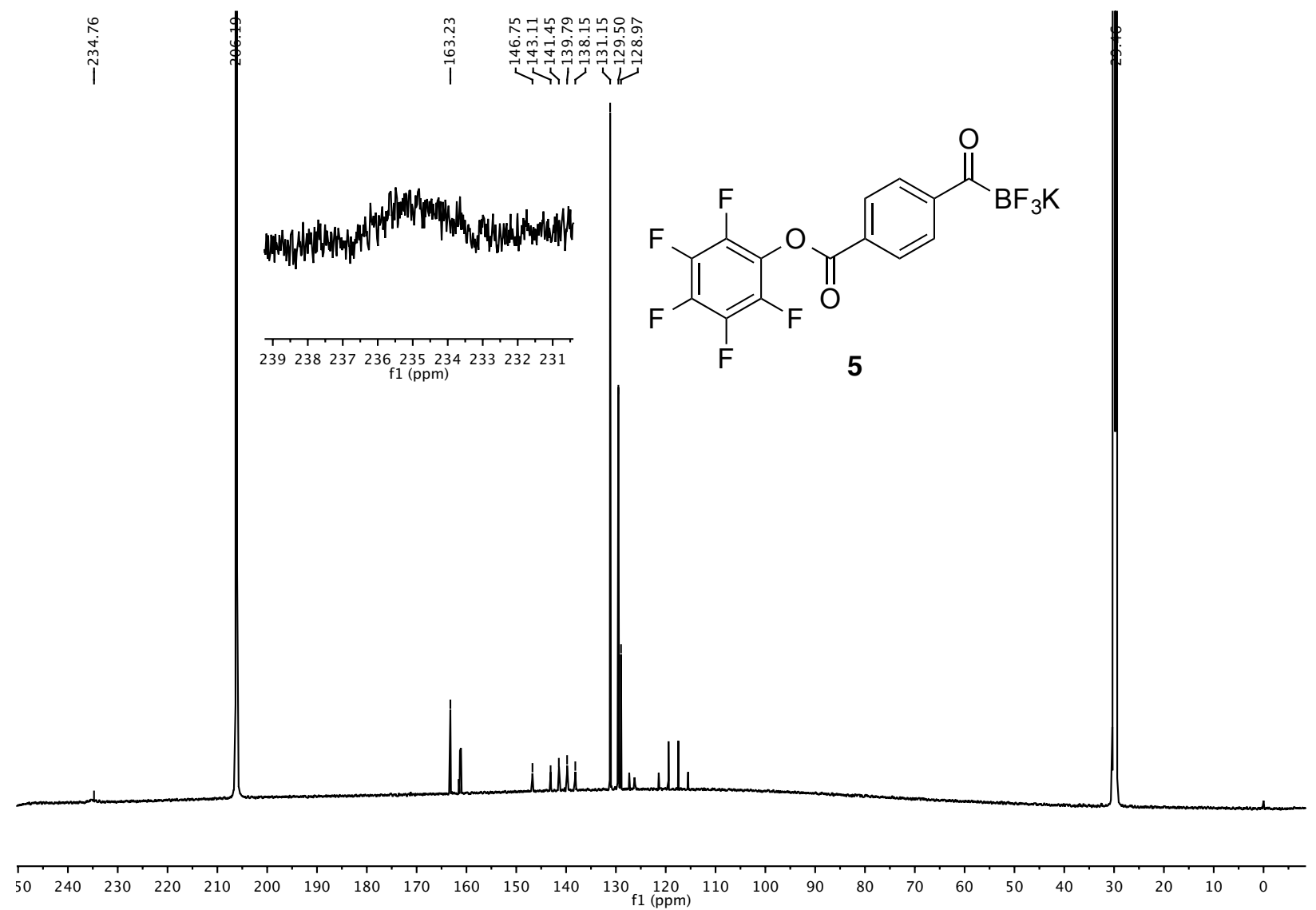


5: ${ }^{13} \mathrm{C}$ NMR decoupled (151 MHz, acetone- $d_{6}$ )

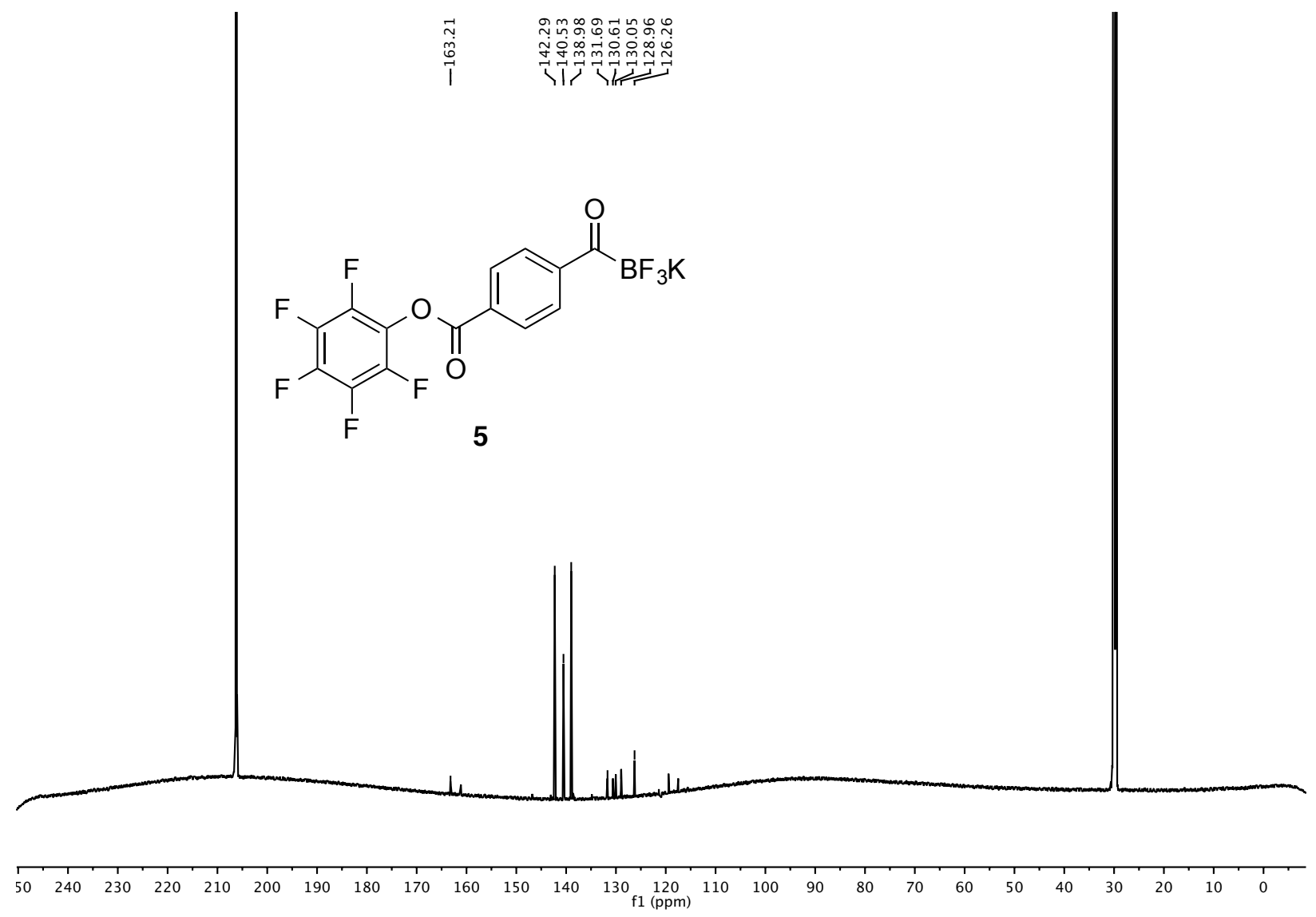

5: ${ }^{19}$ F NMR (470 MHz, acetone- $\left.d_{6}\right)$

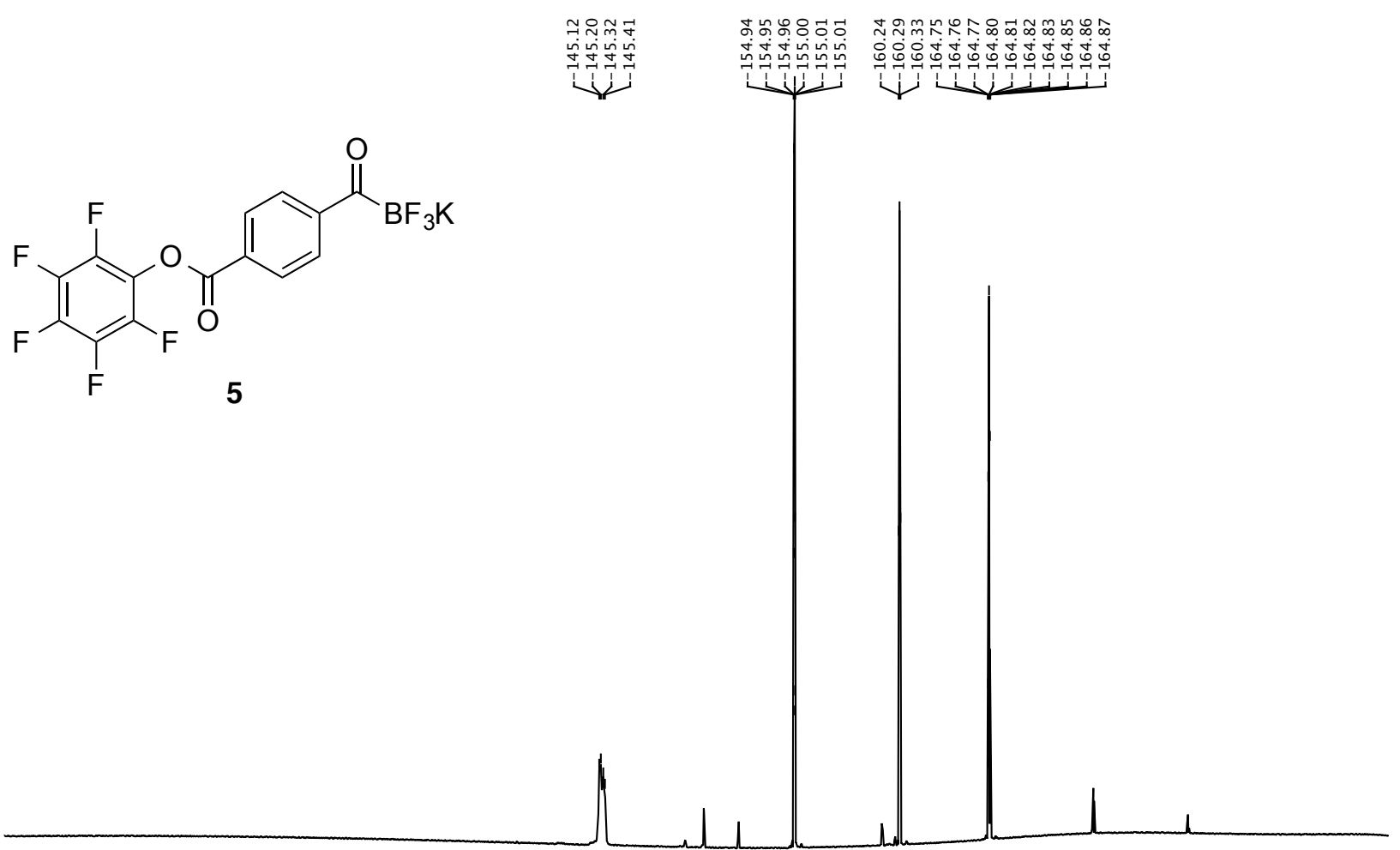

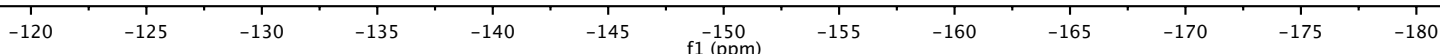


5: ${ }^{11}$ B NMR (160 MHz, acetone- $d_{6}$ )<smiles>O=C(Br)c1ccc(C(=O)Oc2c(F)c(F)c(F)c(F)c2F)cc1</smiles>
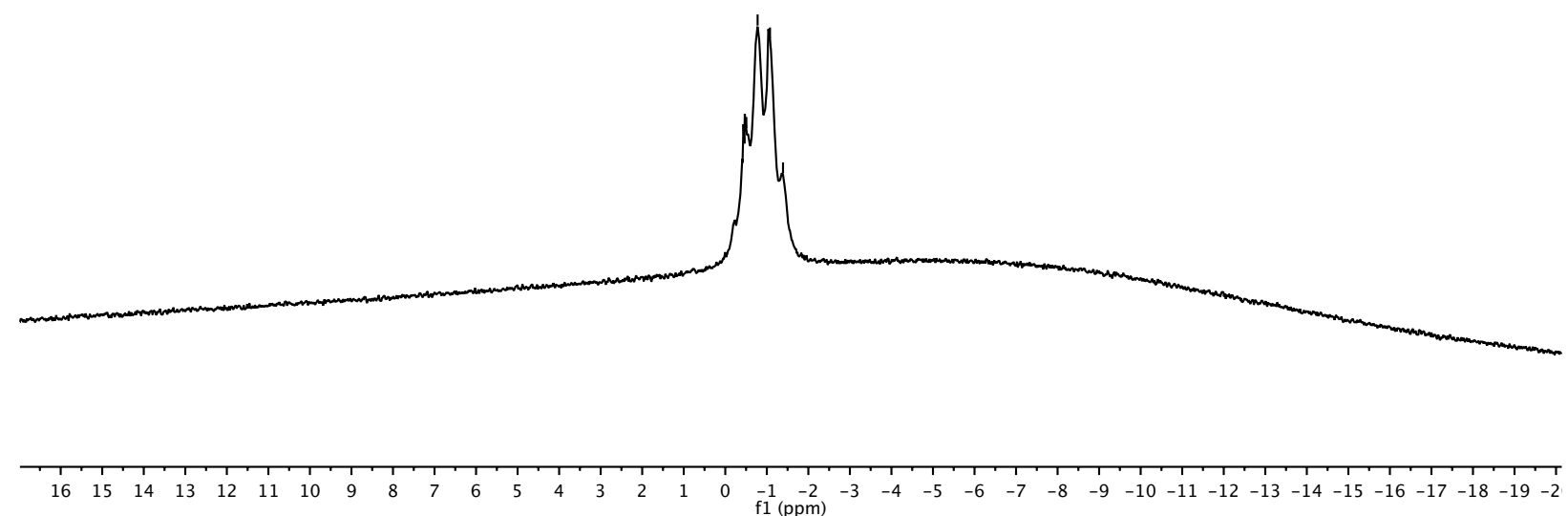

8: ${ }^{1}$ H NMR (600 MHz, DMSO-d $)$

l

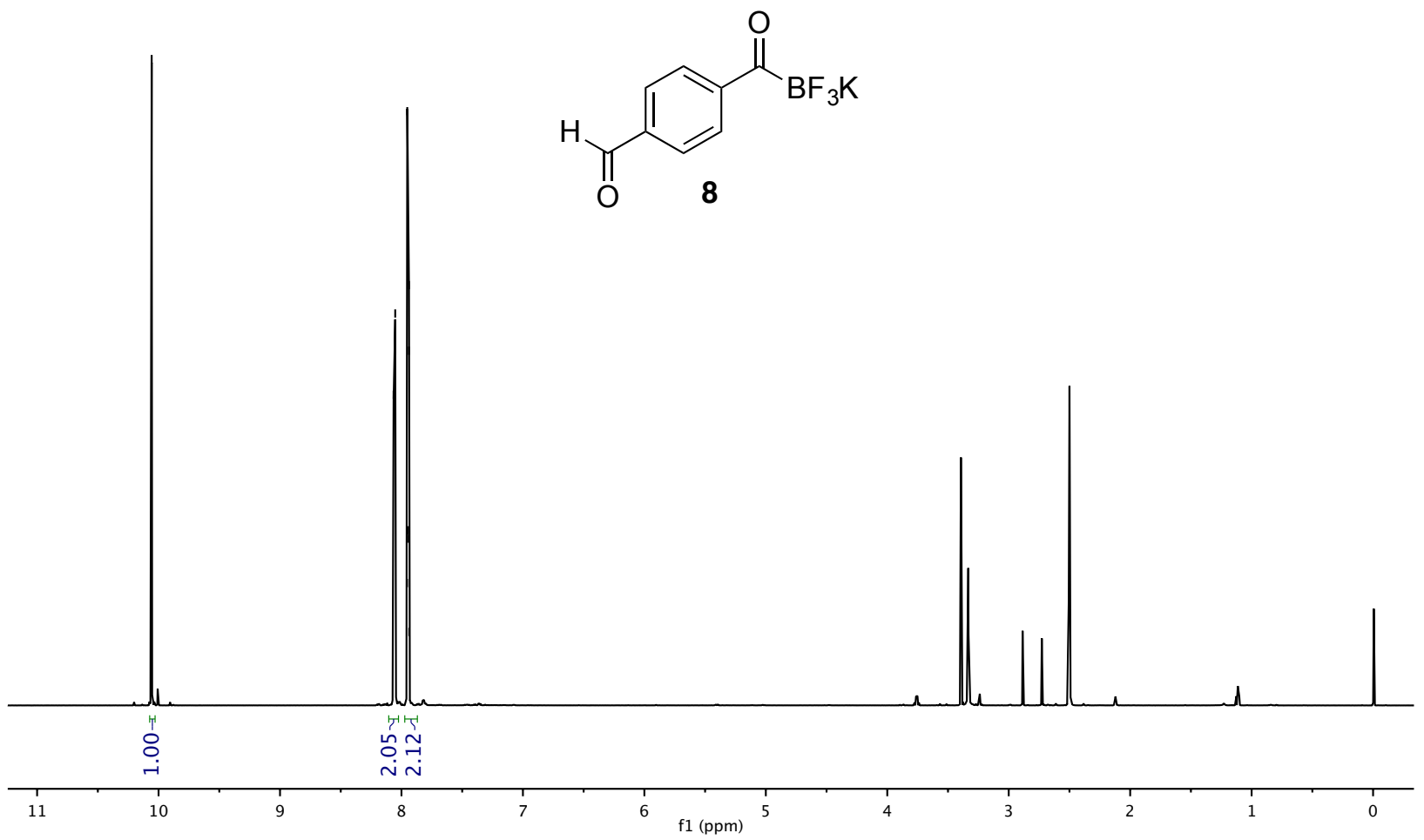

Page S22 of S44 
8: ${ }^{13}$ C NMR (151 MHz, DMSO-d 6 )

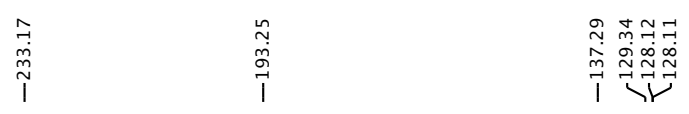<smiles>[X]C(Br)(Br)Br</smiles>
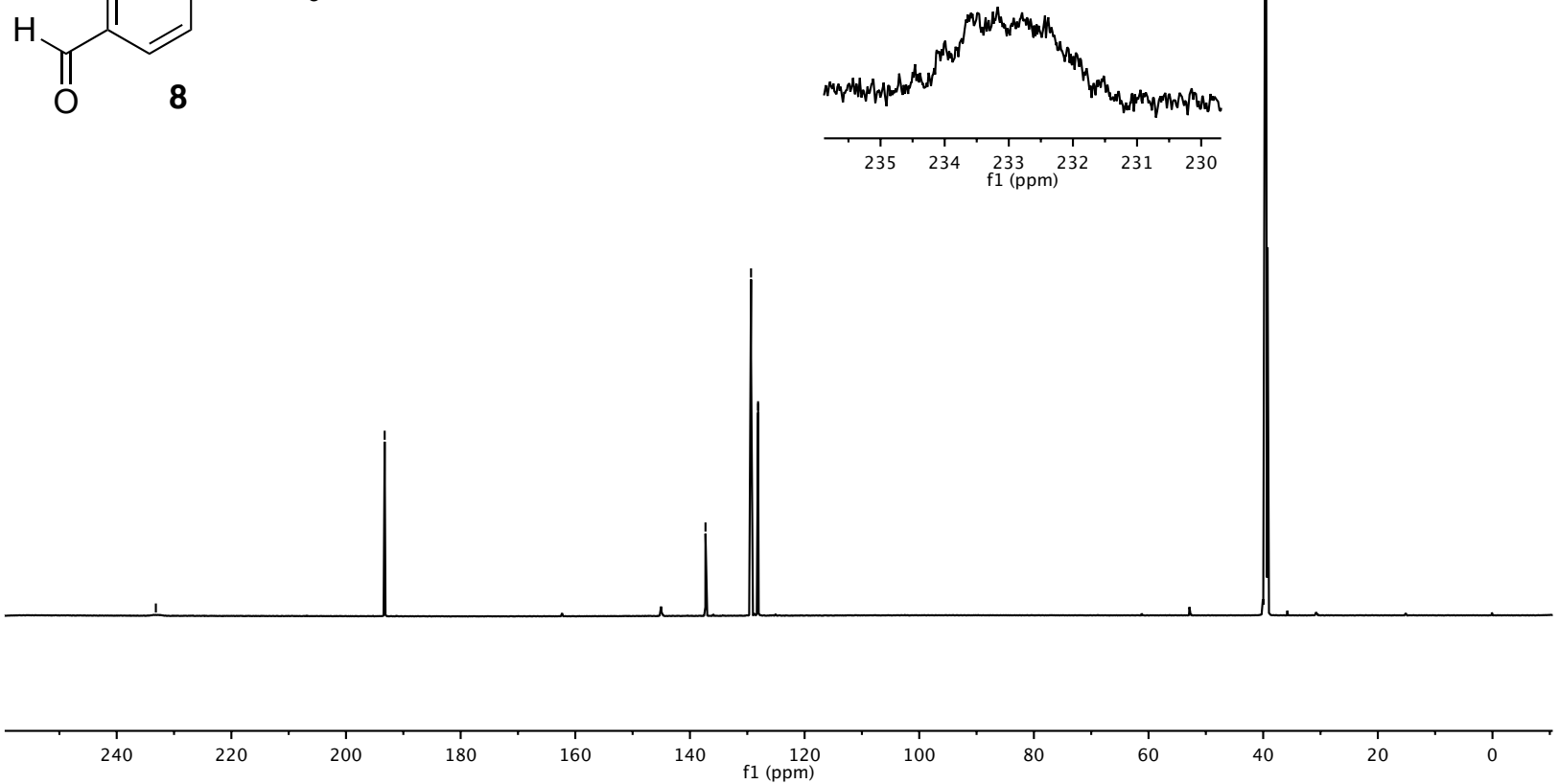

8: 19F NMR (151 MHz, DMSO-d 6 )<smiles>[X]C(Br)(Br)Br</smiles>

O
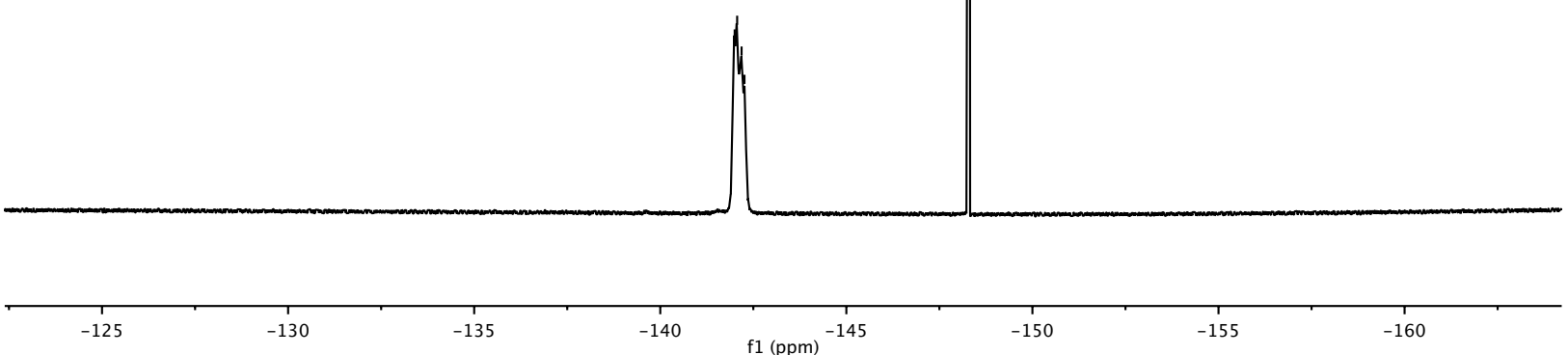
8: 11B NMR (160 MHz, DMSO-d $)$<smiles>[X]C(Br)(Br)Br</smiles>
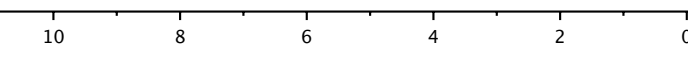

f1 $\stackrel{-2}{-2}$

11: ${ }^{1} \mathrm{H}$ NMR (600 MHz, acetone- $d_{6}$ )<smiles>O=C(Br)CCCCCCl</smiles>

11

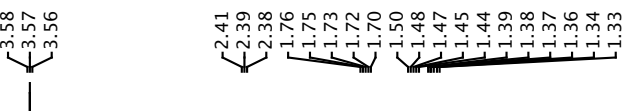

$\mathrm{BF}_{3} \mathrm{~K}$

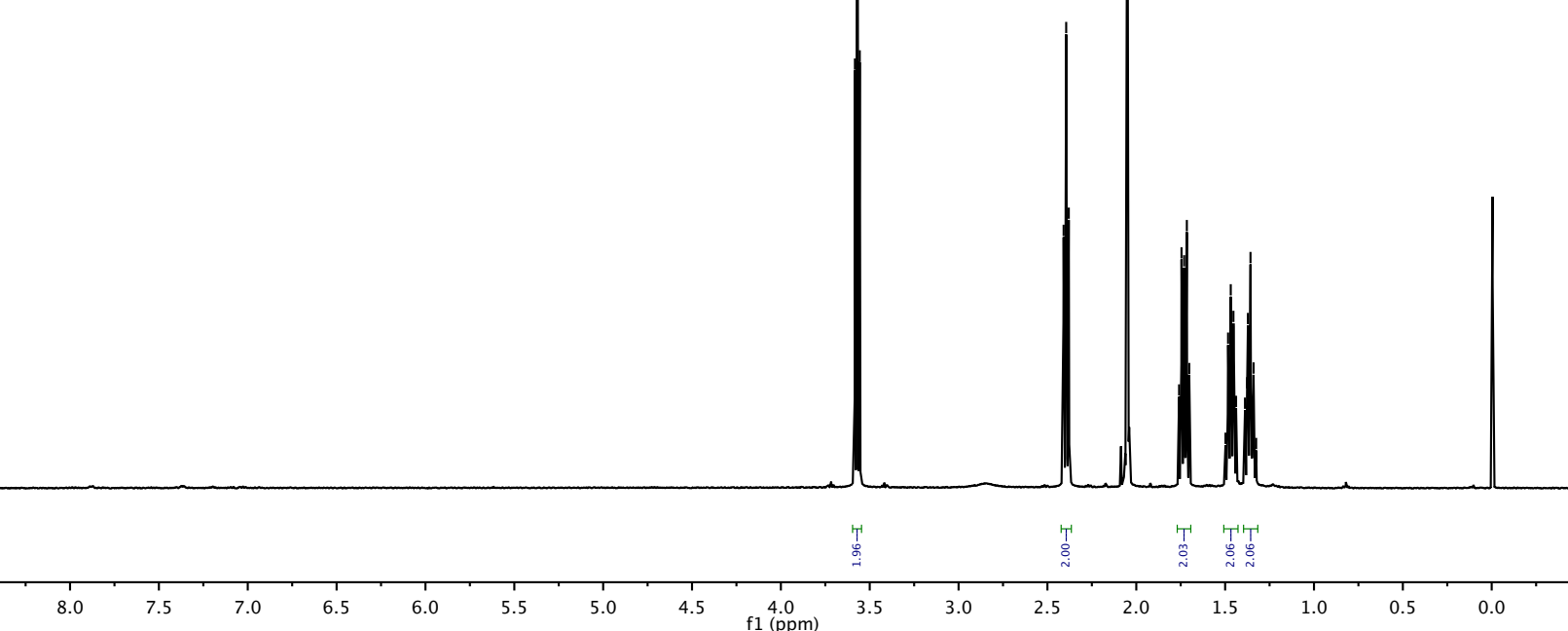


11: ${ }^{12}$ C NMR (151 MHz, acetone- $d_{6}$ )

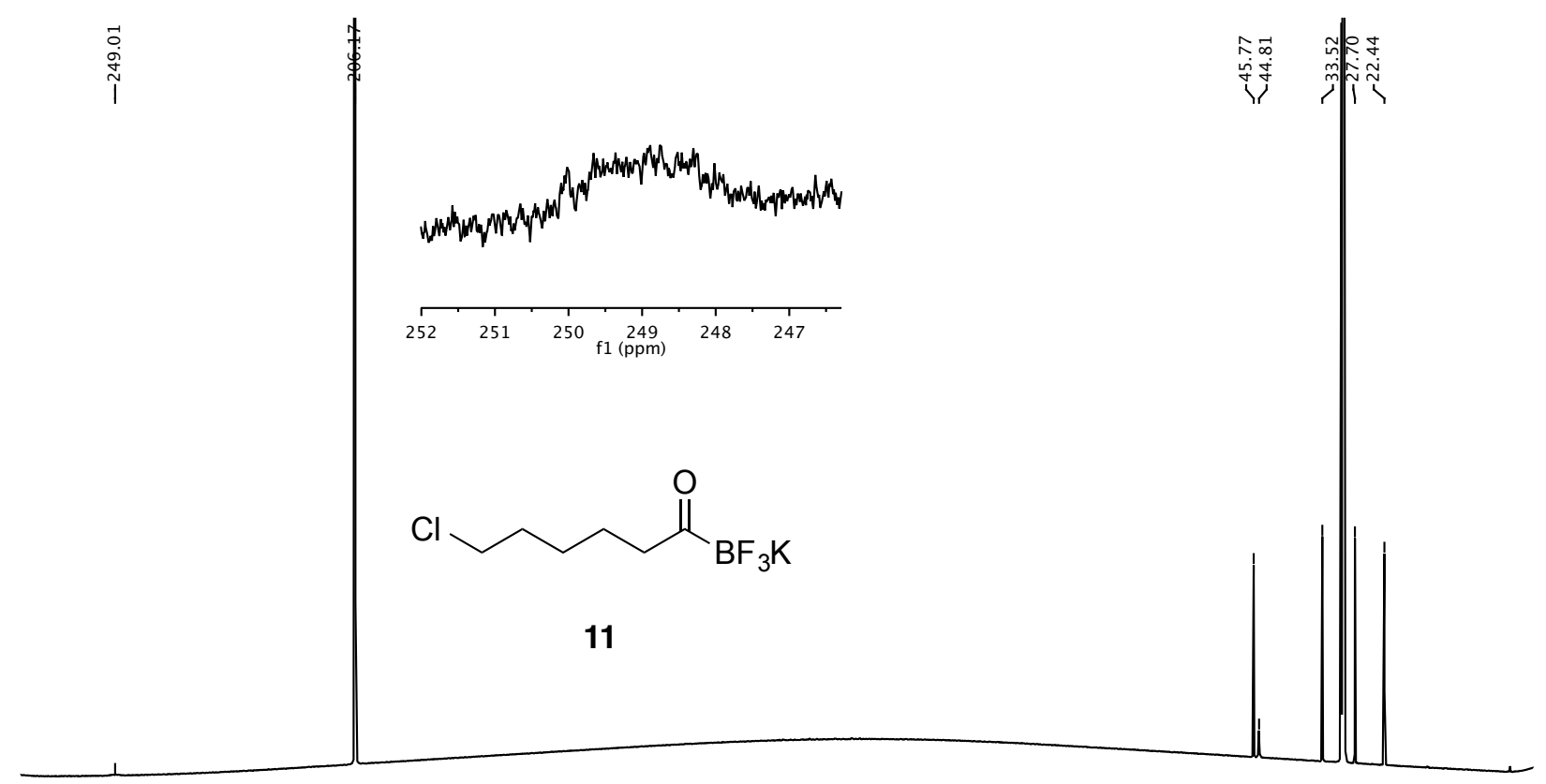

$\begin{array}{lllllllllllllllllllllllllllllllllllllllll}260 & 250 & 240 & 230 & 220 & 210 & 200 & 190 & 180 & 170 & 160 & 150 & 140 & 130 & 120 & 110 & 100 & 90 & 80 & 70 & 60 & 50 & 40 & 30 & 20 & 10 & 0\end{array}$

11: ${ }^{19}$ F NMR (470 MHz, acetone- $\left.d_{6}\right)$

تر<smiles>O=C(Br)CCCCCCl</smiles>

11

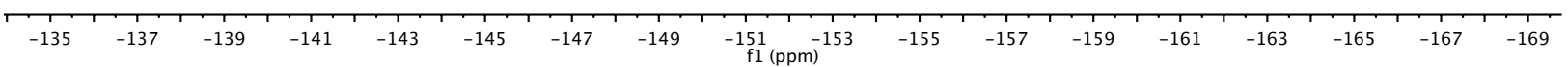


11: ${ }^{11}$ B NMR (160 MHz, acetone- $d_{6}$ )

نأij

$\mathrm{Cl} \sim_{\mathrm{BF}_{3} \mathrm{~K}}^{\mathrm{O}}$

11
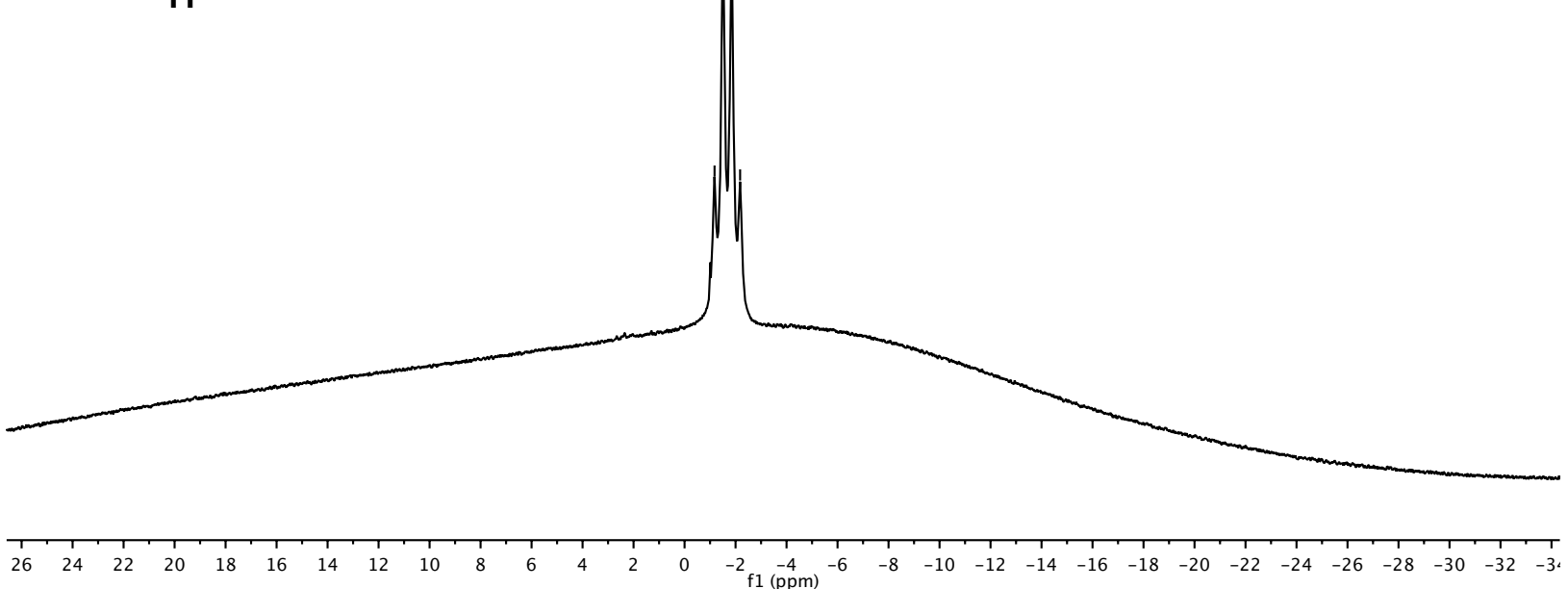

12a: ${ }^{1} \mathrm{H}$ NMR (600 MHz, acetone- $\left.d_{6}\right)$

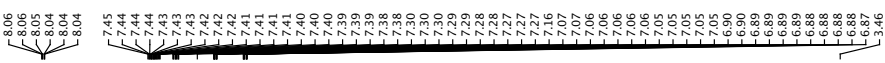<smiles>COC(Br)c1cccc(OC(C)(C)C)c1</smiles>

$12 a$

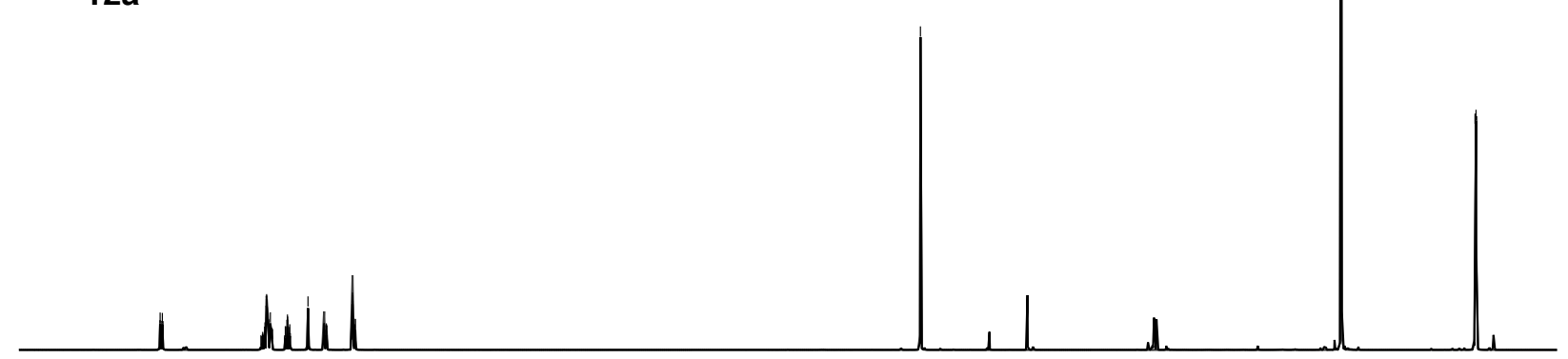

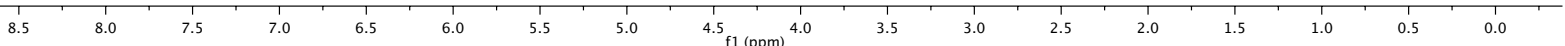


12a: ${ }^{13} \mathrm{C}$ NMR (151 MHz, acetone- $d_{6}$ )
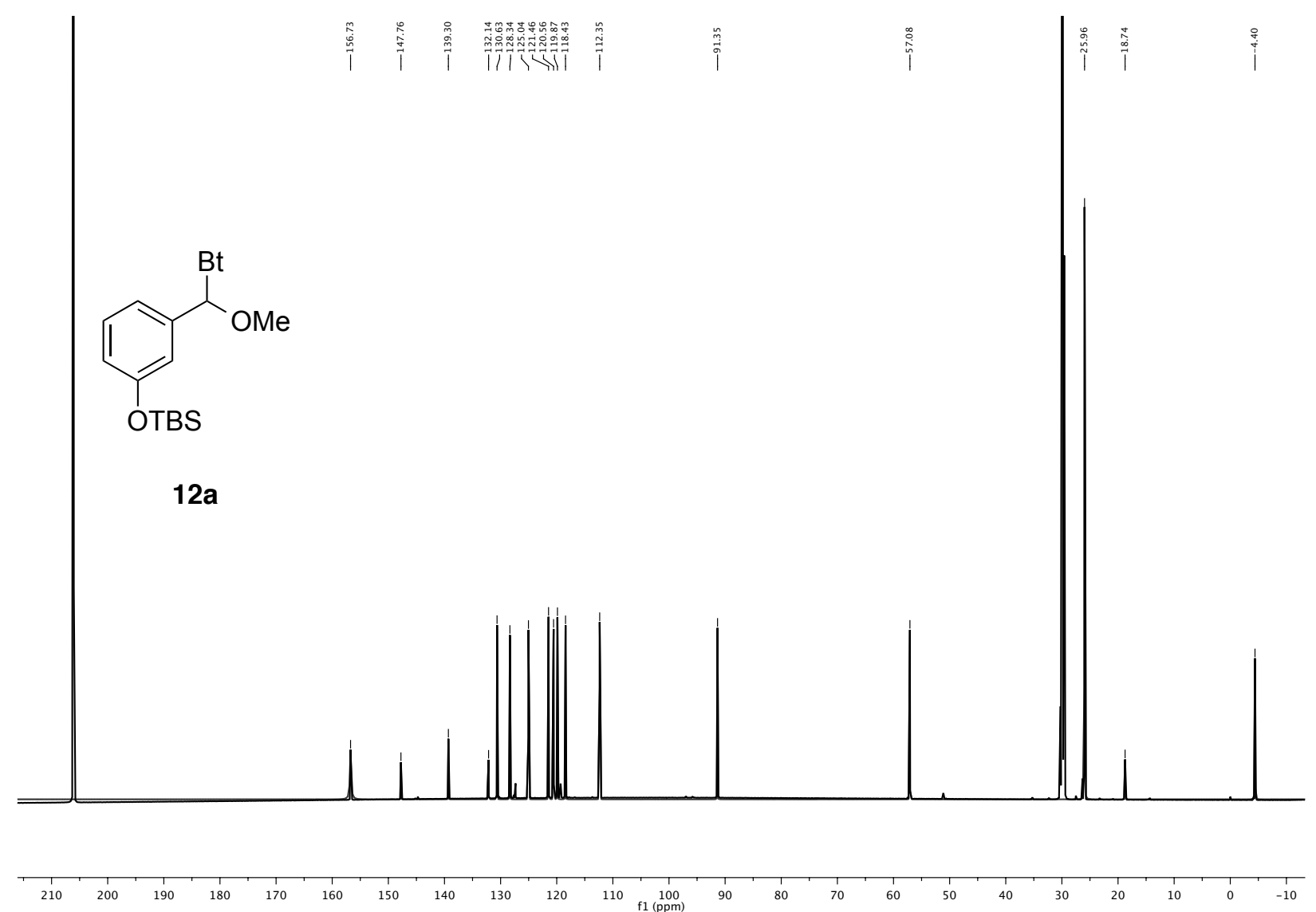

12: ${ }^{1} \mathrm{H}$ NMR (600 MHz, acetone- $d_{6}$ )

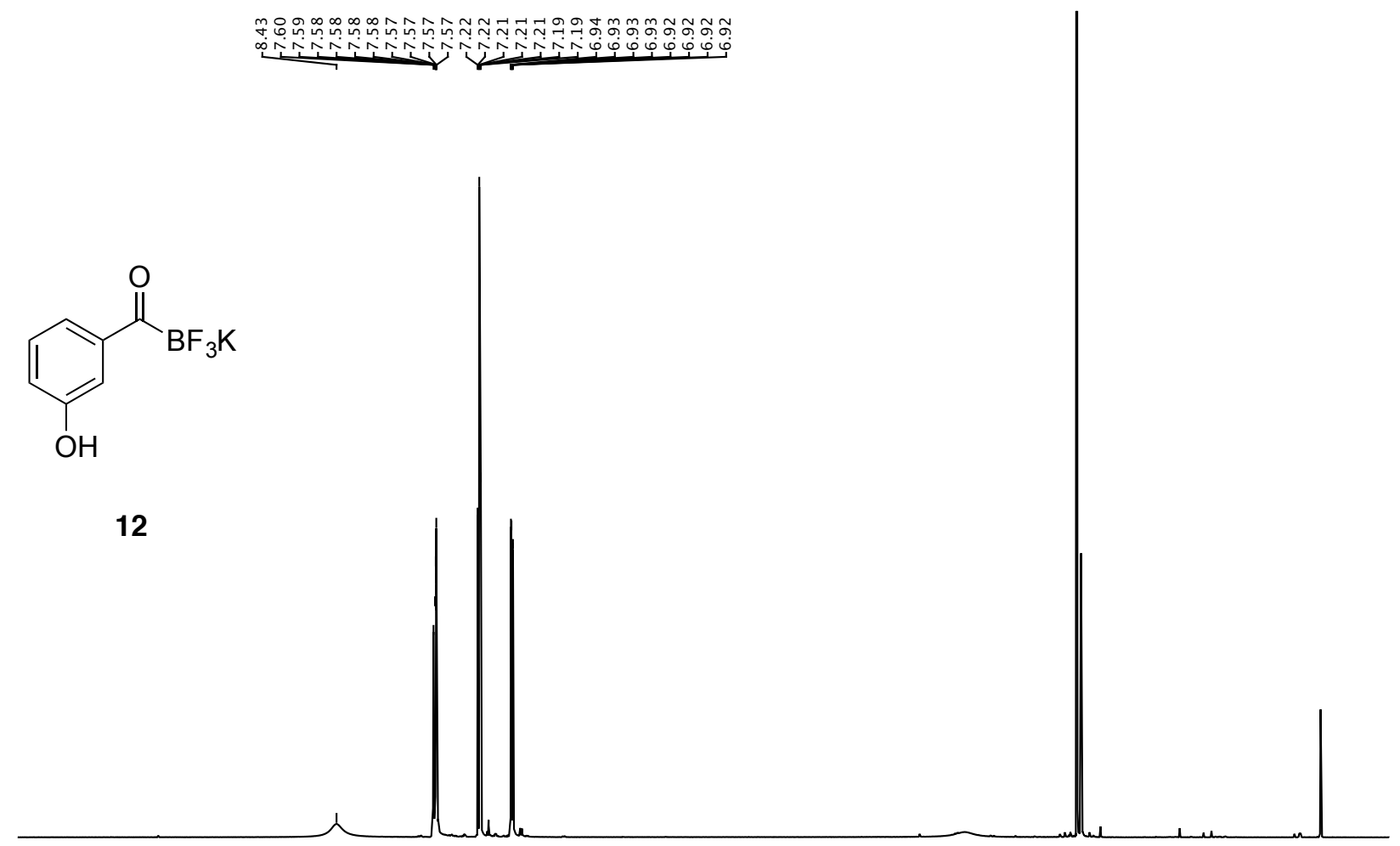

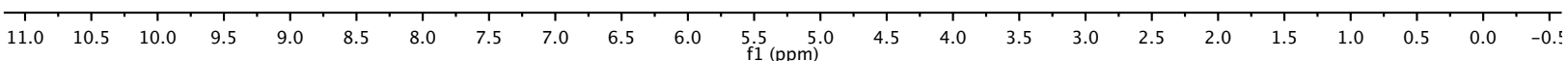


12: ${ }^{13} \mathrm{C}$ NMR (151 MHz, acetone- $d_{6}$ )

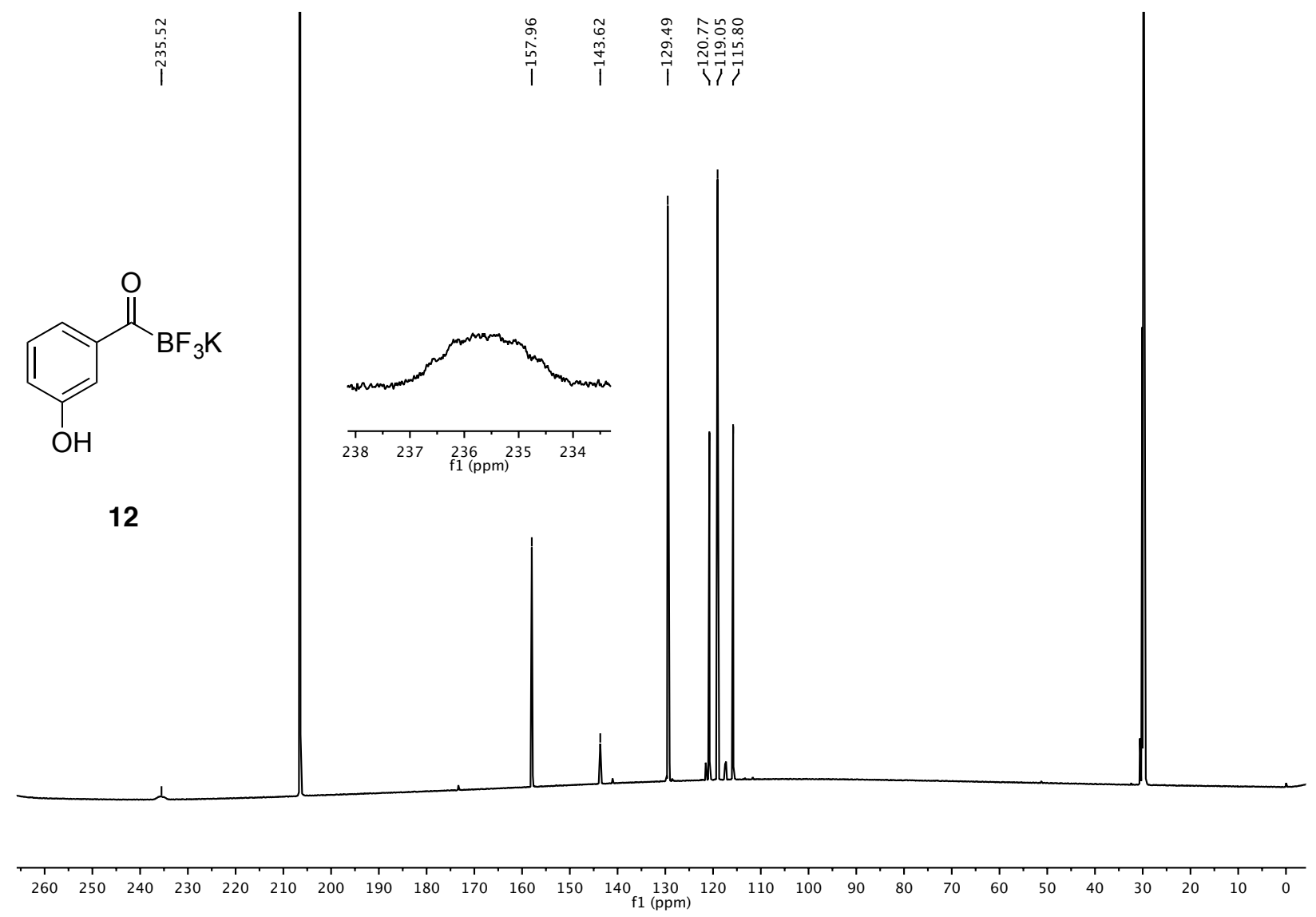

12: ${ }^{19} \mathrm{~F}$ NMR (470 MHz, acetone- $d_{6}$ )<smiles>O=C(Br)c1cccc(O)c1</smiles>

12 $-129-130-131-132-133-134-135-136-137-138-139-140-141-142-143-144-145-146-147-148-149-150-151-152-153-154-155-156-157-158-159-160$ 
12: ${ }^{11 B}$ NMR (160 MHz, acetone- $d_{6}$ )

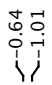

${ }_{\mathrm{OH}}^{\mathrm{BH}}$

12

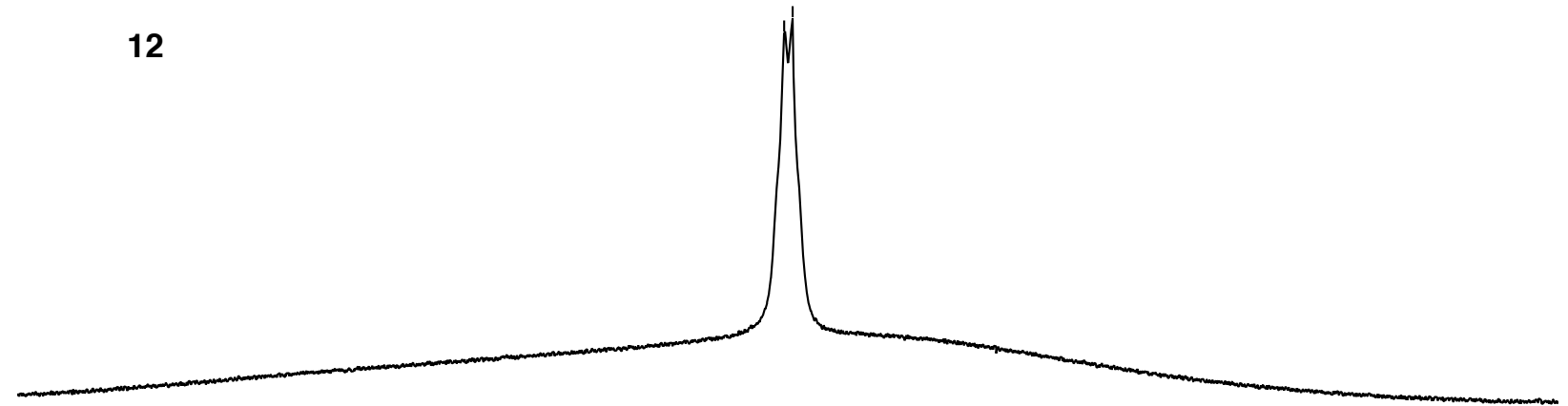

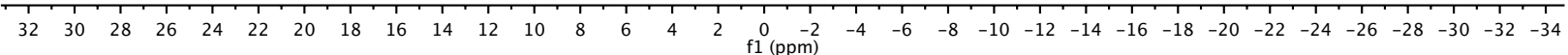

13a: ${ }^{1} \mathrm{H}$ NMR (600 MHz, $\left.\mathrm{CDCl}_{3}\right)$

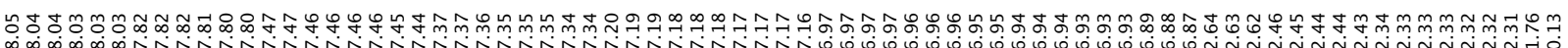

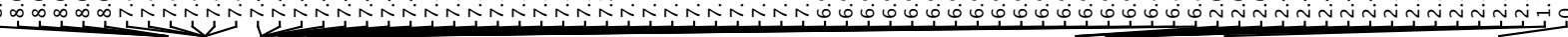<smiles>CSC#CCCCC(c1ccccc1)n1nnc2ccccc21</smiles>

$13 a$

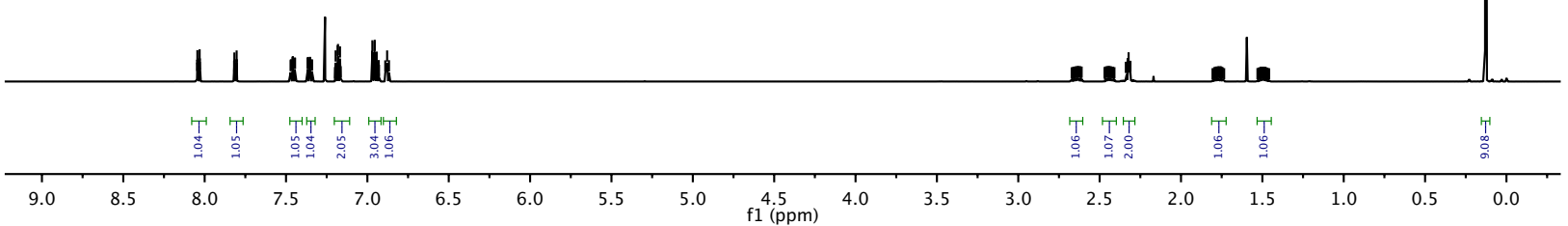


13a: ${ }^{13} \mathrm{C}$ NMR (151 MHz, $\mathrm{CDCl}_{3}$ )
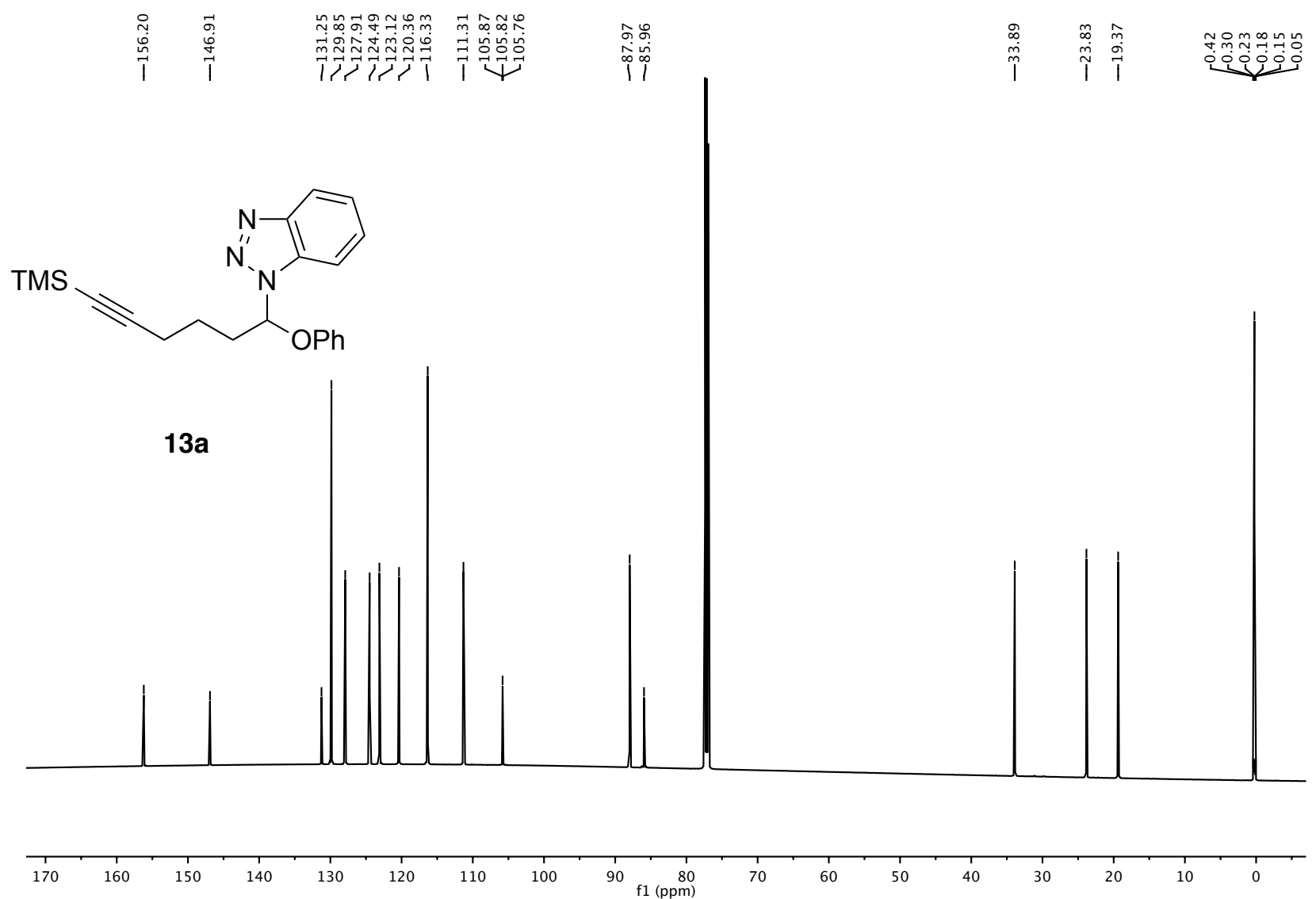

13: ${ }^{1} \mathrm{H}$ NMR (600 MHz, acetone- $d_{6}$ )<smiles>[B-]C(=O)CCCC#C</smiles>

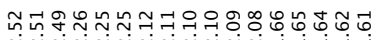

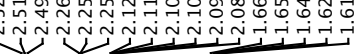

13

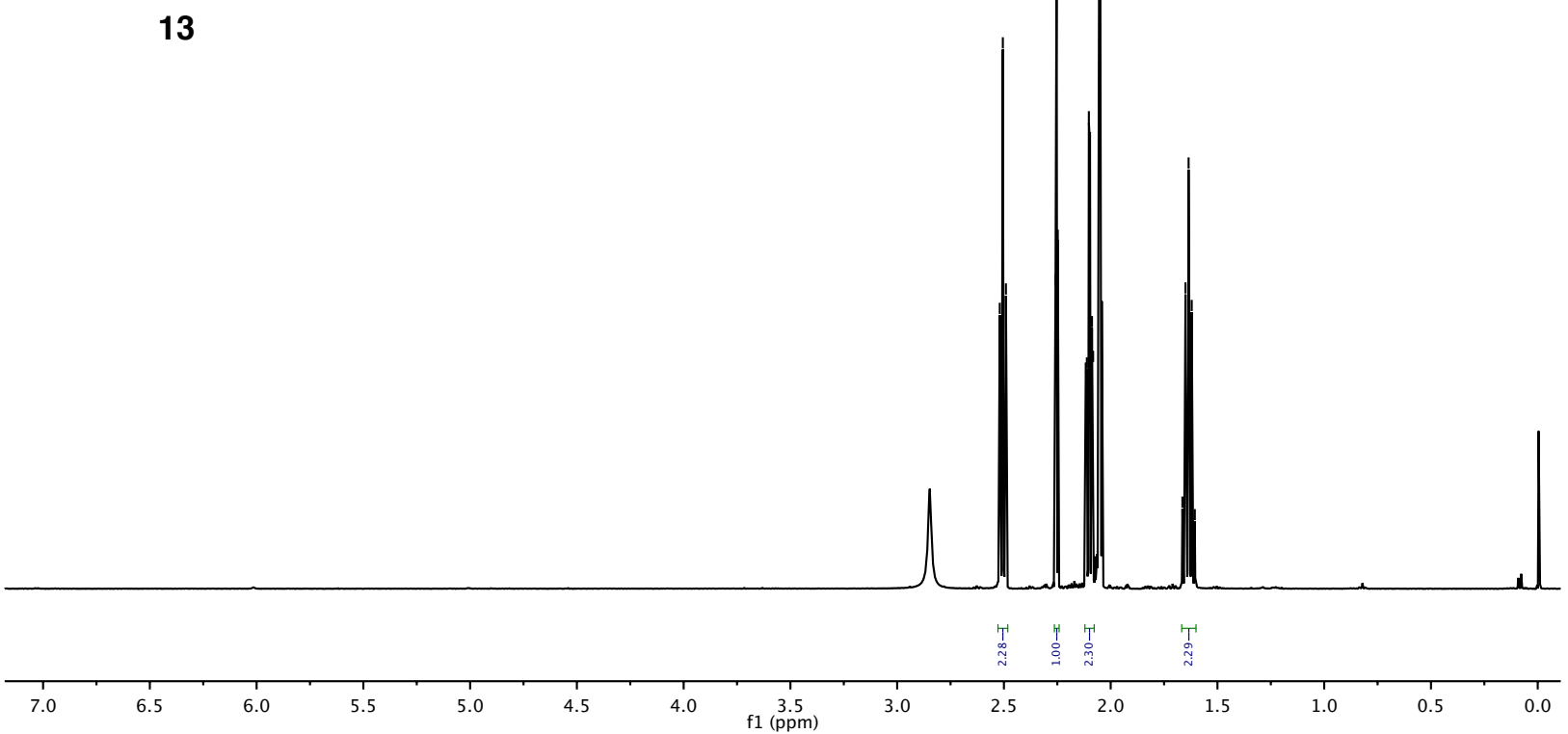


13: ${ }^{12} \mathrm{C}$ NMR (151 MHz, acetone- $d_{6}$ )

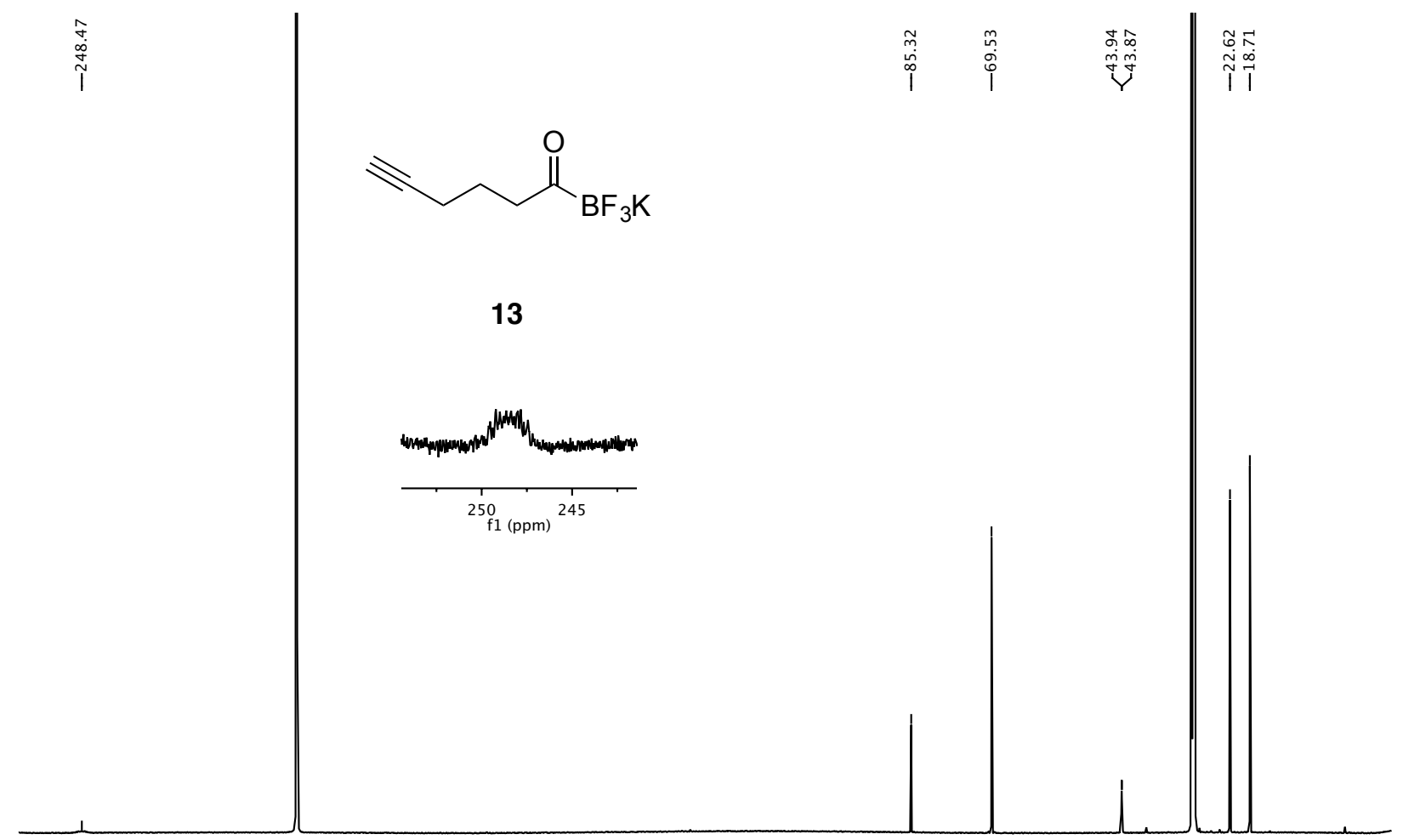

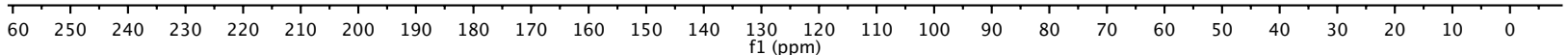

13: ${ }^{9} \mathrm{~F}$ NMR (470 MHz, acetone- $d_{6}$ )

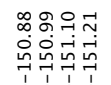

पili<smiles>C#CCCCC(=O)Br</smiles>

13

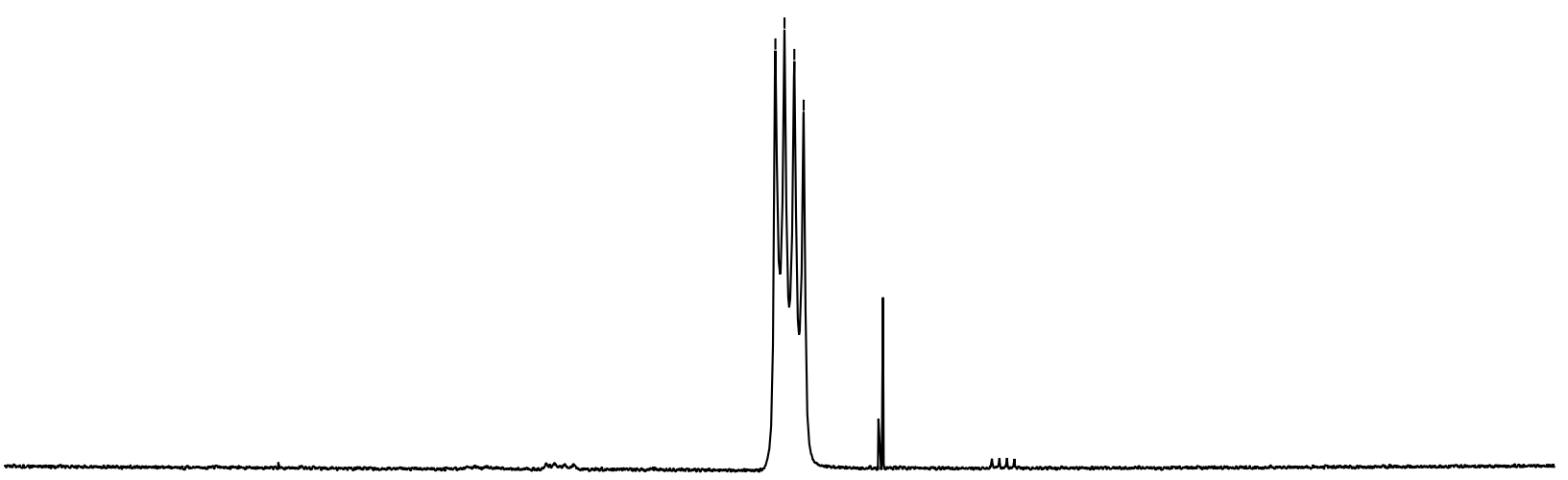

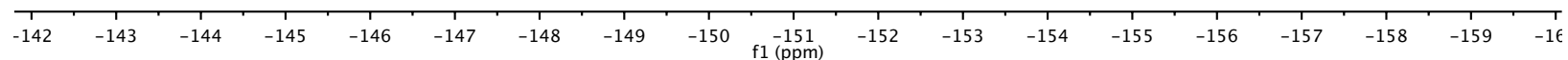


13: ${ }^{11 B}$ NMR (160 MHz, acetone- $d_{6}$ )

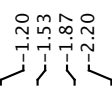

$\overbrace{\mathrm{BF}_{3} \mathrm{~K}}^{\mathrm{O}}$

13

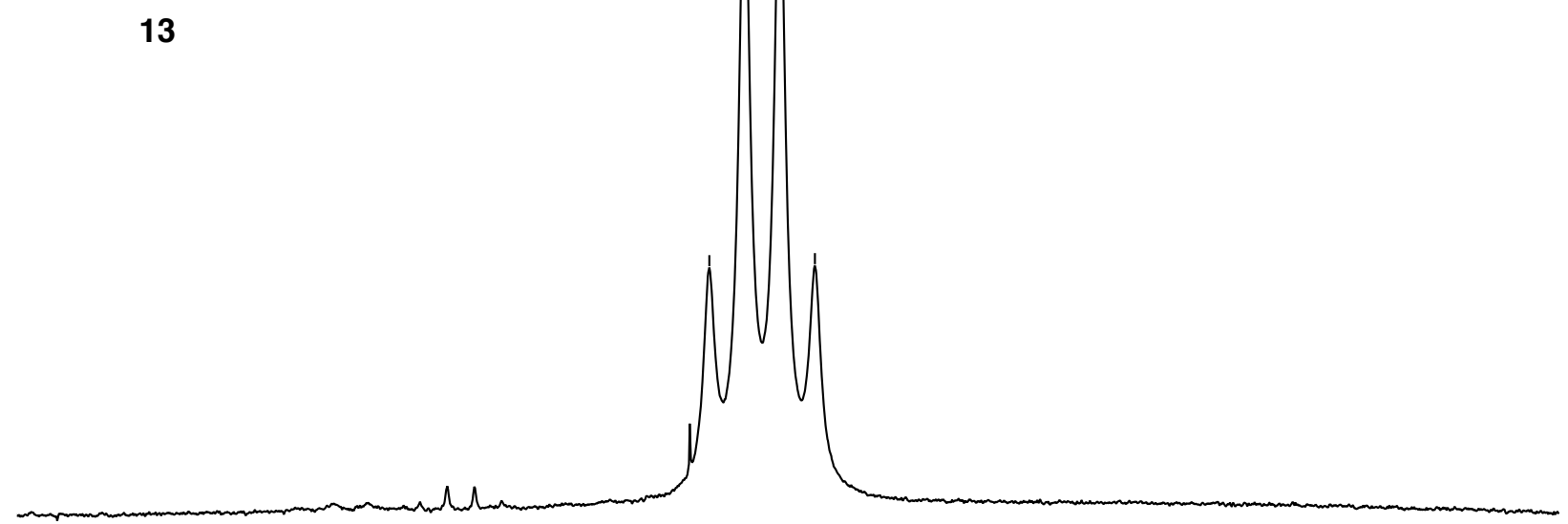

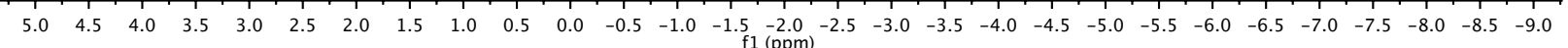

14: ${ }^{1} \mathrm{H}$ NMR (600 MHz, acetone- $d_{6}$ )

$\mathrm{N}_{\mathrm{BF}_{3} \mathrm{~K}}^{\mathrm{O}}$

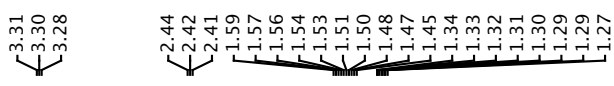

14

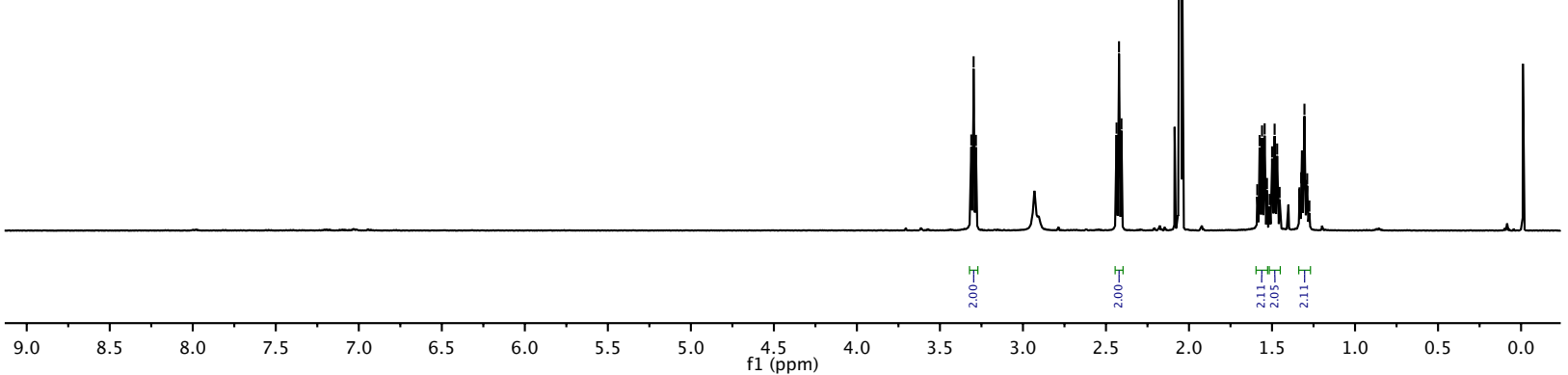


14: ${ }^{13} \mathrm{C}$ NMR (151 MHz, acetone- $d_{6}$ )

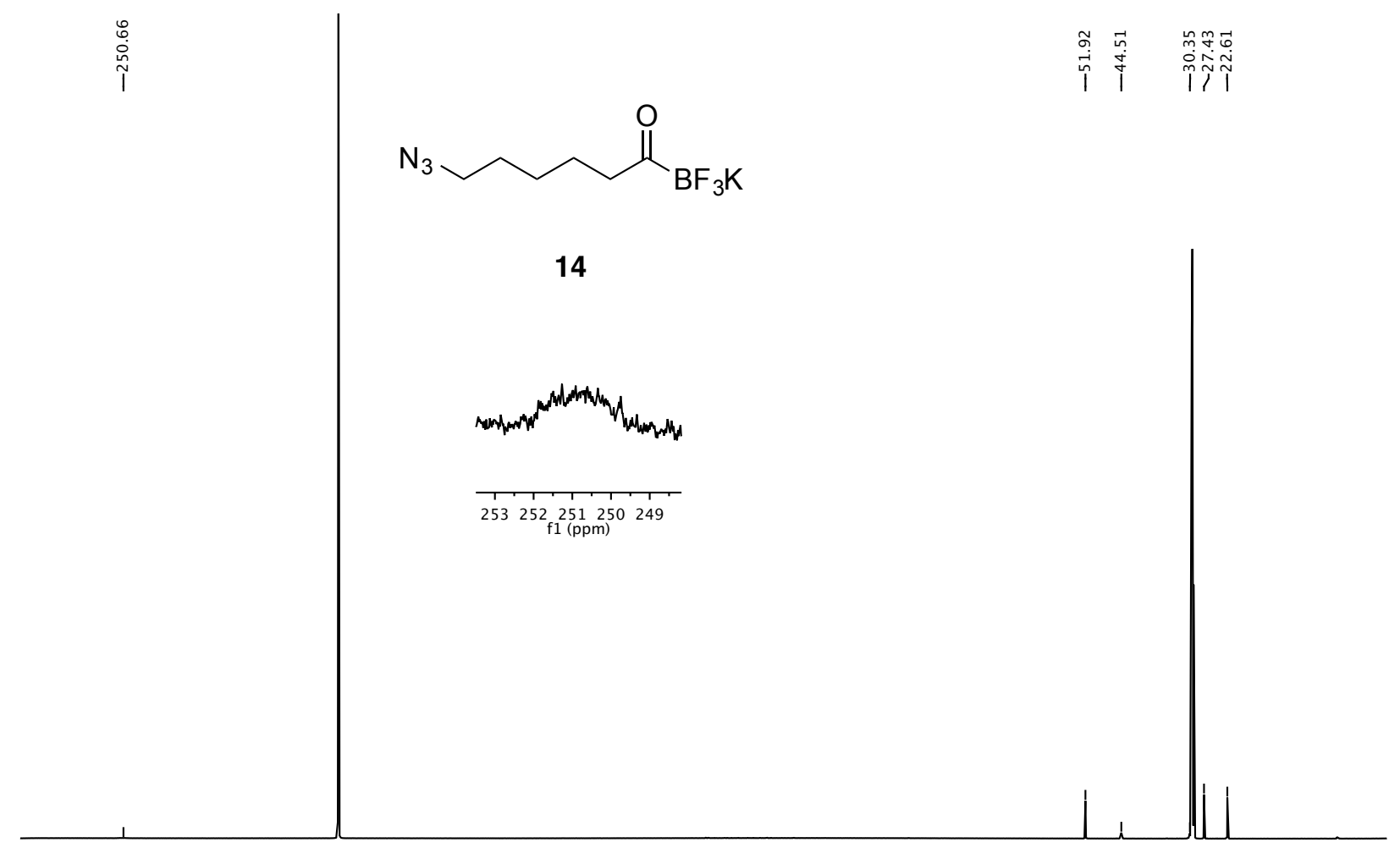

$\begin{array}{llllllllllllllllllllllllllllllllllllllllllll}270 & 260 & 250 & 240 & 230 & 220 & 210 & 200 & 190 & 180 & 170 & 160 & 150 & 140 & 130 & 120 & 110 & 100 & 90 & 80 & 70 & 60 & 50 & 40 & 30 & 20 & 10 & 0 & -1\end{array}$

14: 19F NMR (470 MHz, acetone- $d_{6}$ )

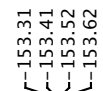

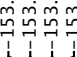

$\mathrm{N}_{\mathrm{BF}_{3} \mathrm{~K}}^{\mathrm{O}}$

14

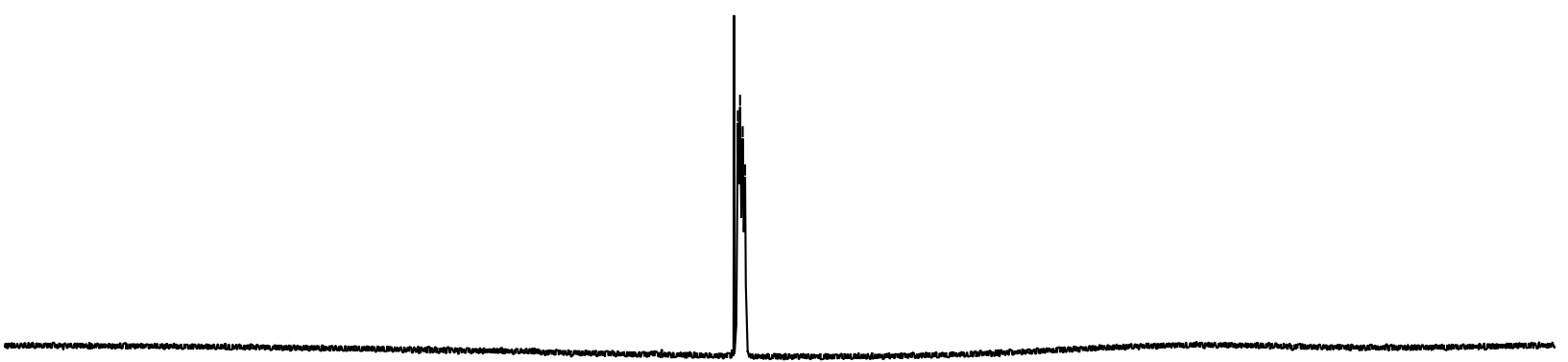

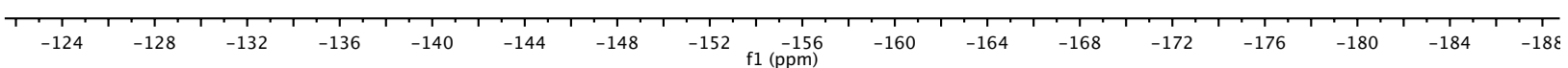


14: ${ }^{11 B}$ NMR (160 MHz, acetone- $d_{6}$ )
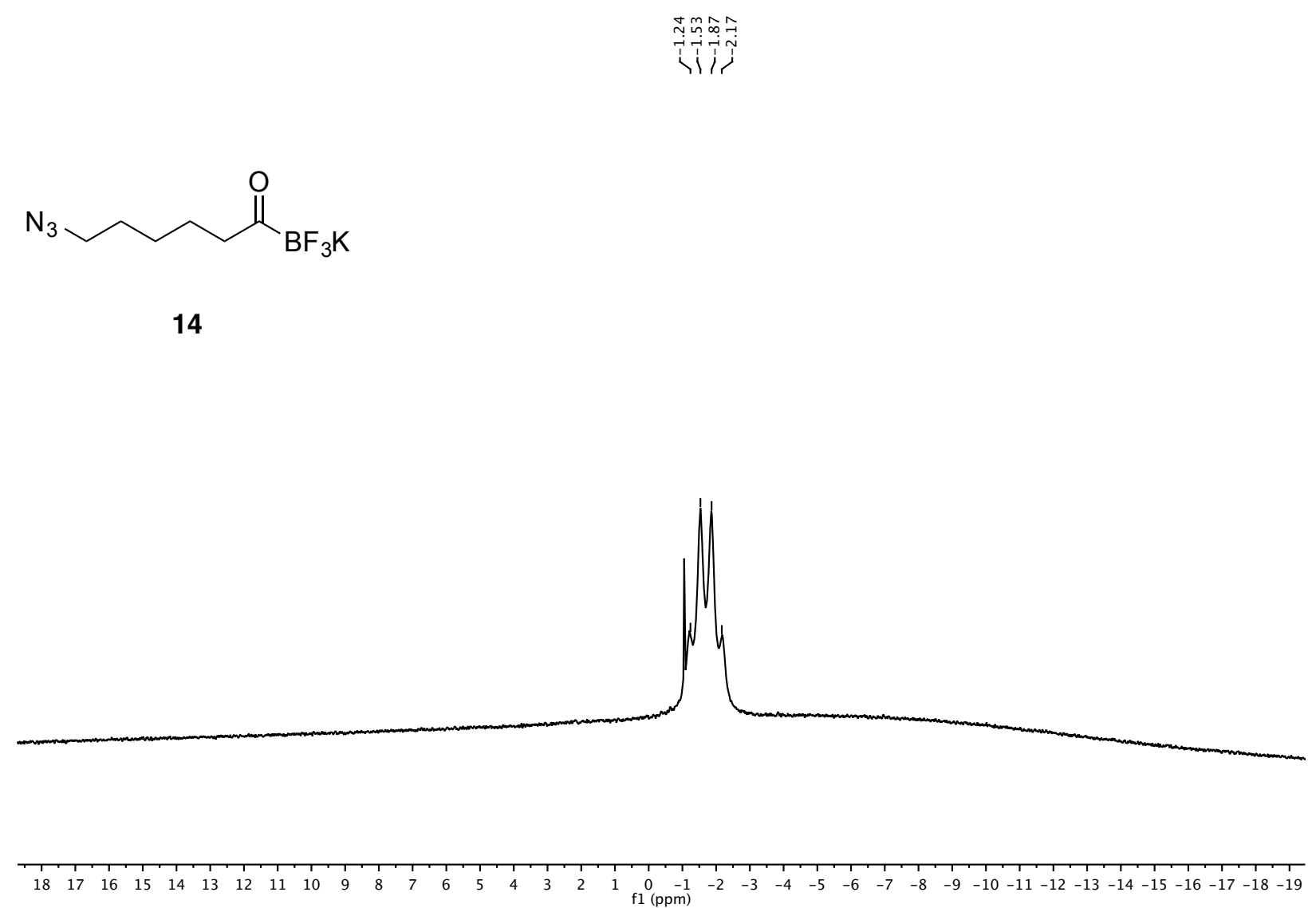

16: ${ }^{1} \mathrm{H}$ NMR (600 MHz, acetone- $\left.d_{6}\right)$

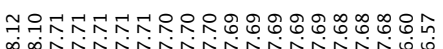

onisinisinisinisisio

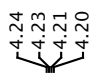

تَivi

(1)

16

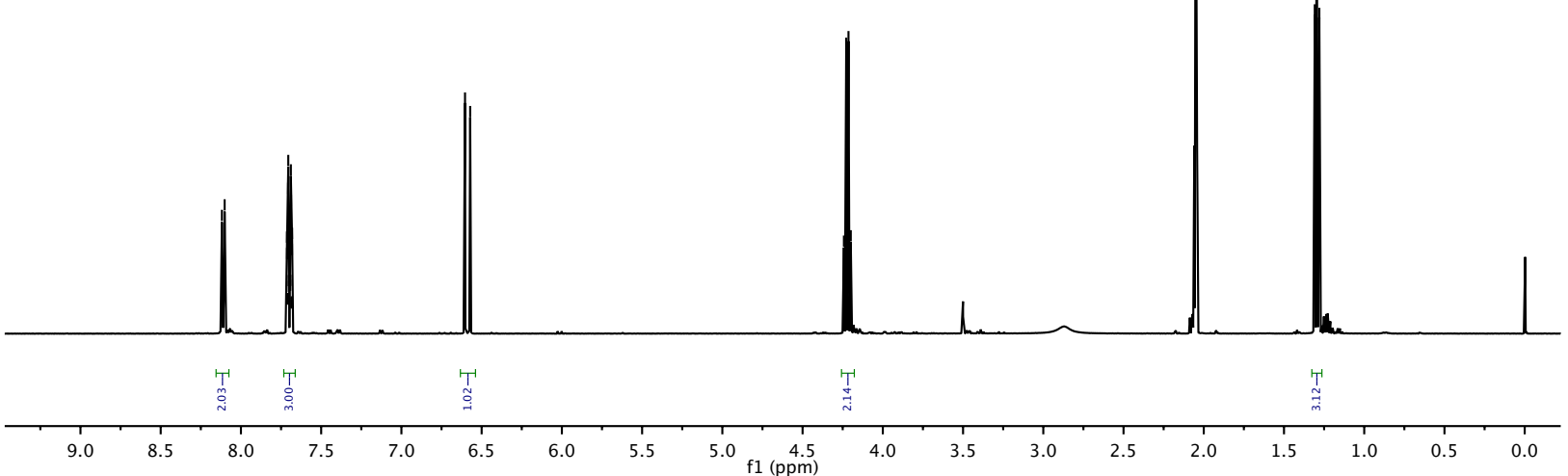


16: ${ }^{13} \mathrm{C}$ NMR (151 MHz, acetone- $d_{6}$ )
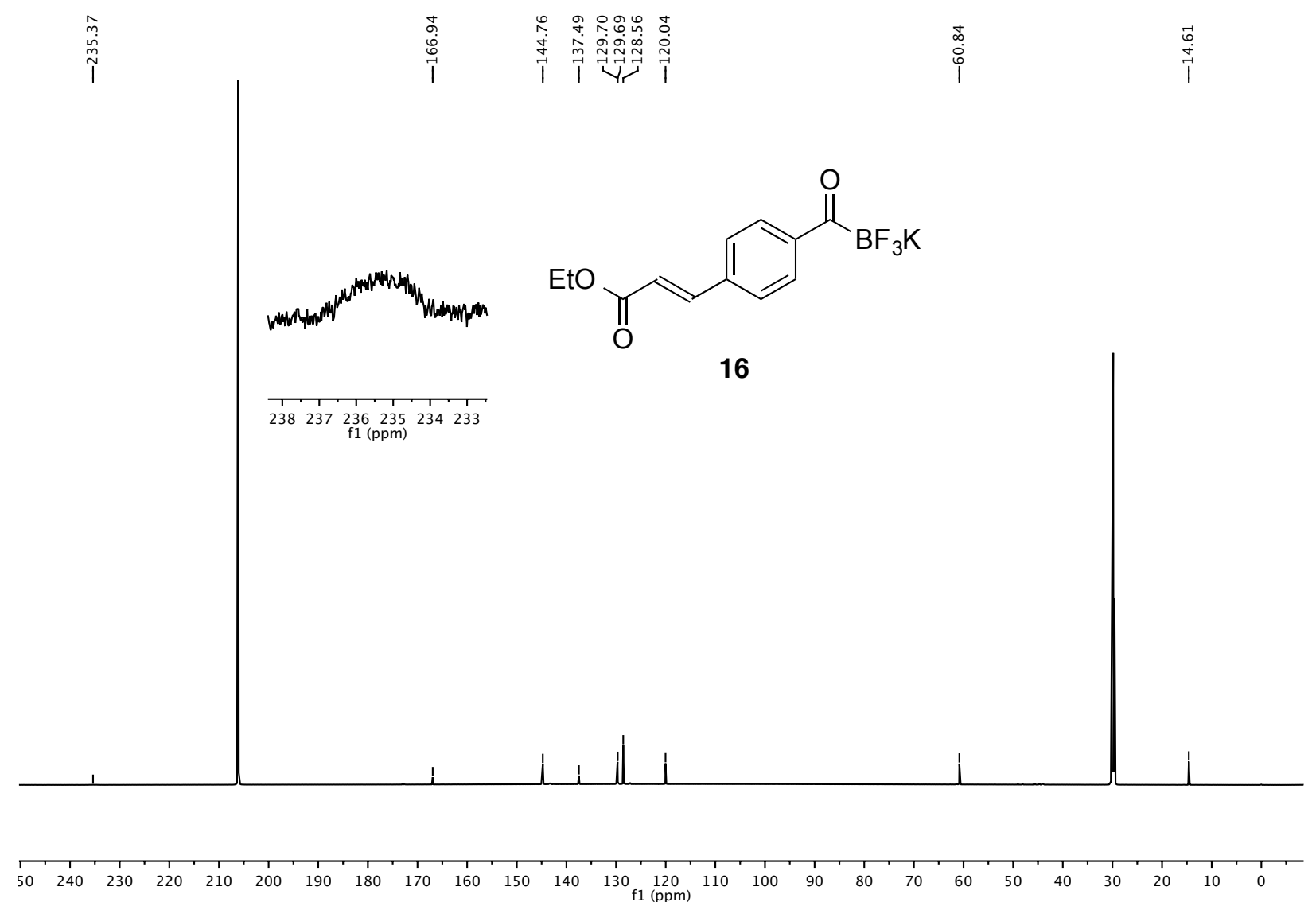

16: 19F NMR (470 MHz, acetone- $d_{6}$ )

我苏电

年守守学

पir

$\prod_{\mathrm{O}}$

16

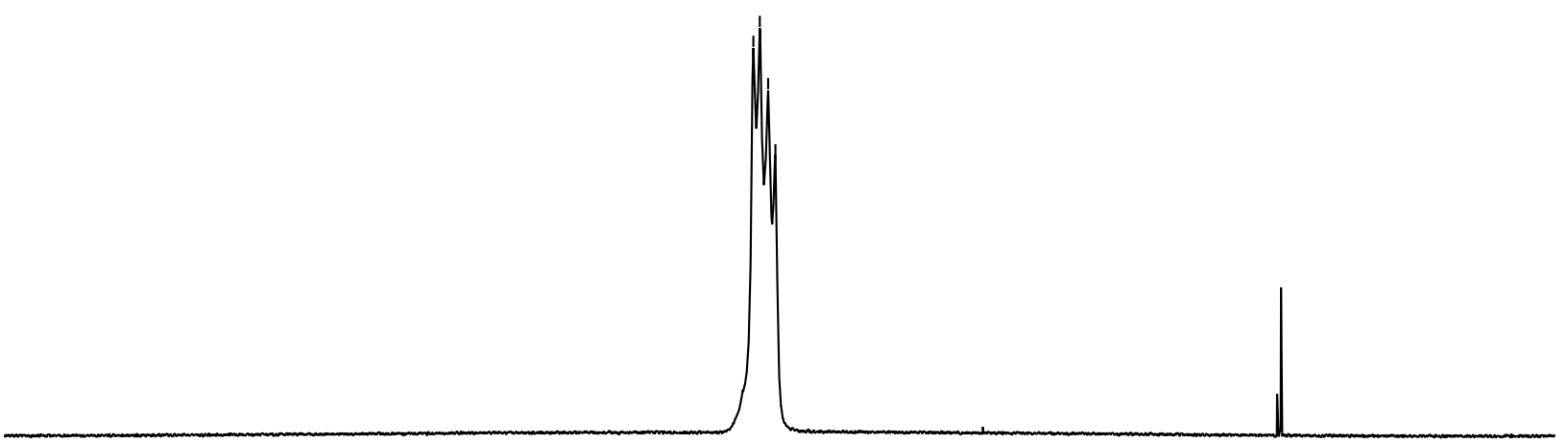

\begin{tabular}{llllllllllllllllllllllllll}
\hline 1 & 135 & -136 & -137 & -138 & -139 & -140 & -141 & -142 & -143 & -144 & -145 & -146 & -147 & -148 & -149 & -150 & -151 & -152 & -153 & -154 & -155 &
\end{tabular} 
16: ${ }^{11}$ B NMR (160 MHz, acetone- $d_{6}$ )

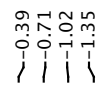

$\overbrace{O}$

16
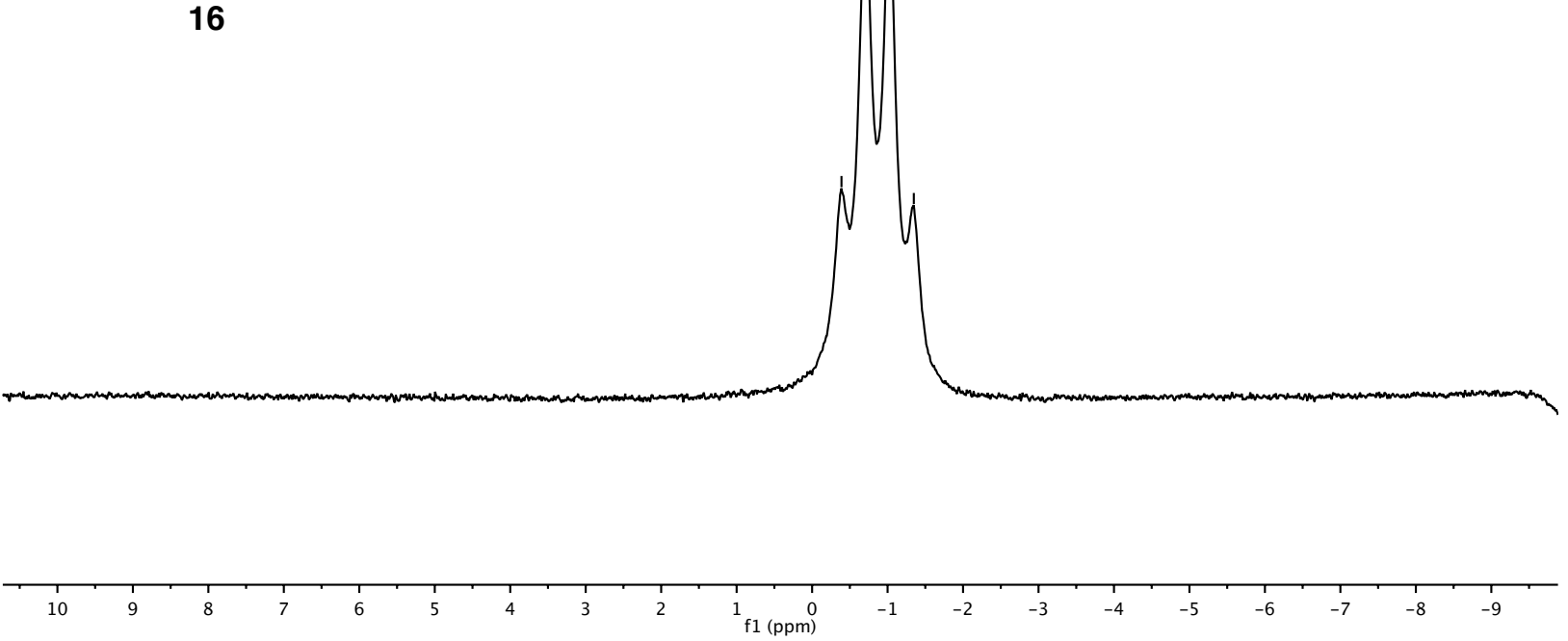

18: ${ }^{1} \mathrm{H}$ NMR (600 MHz, acetone- $\left.d_{6}\right)$

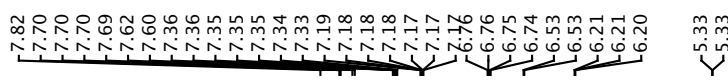

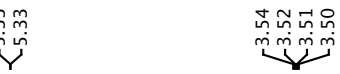

in

$\overbrace{O}^{O}$

18

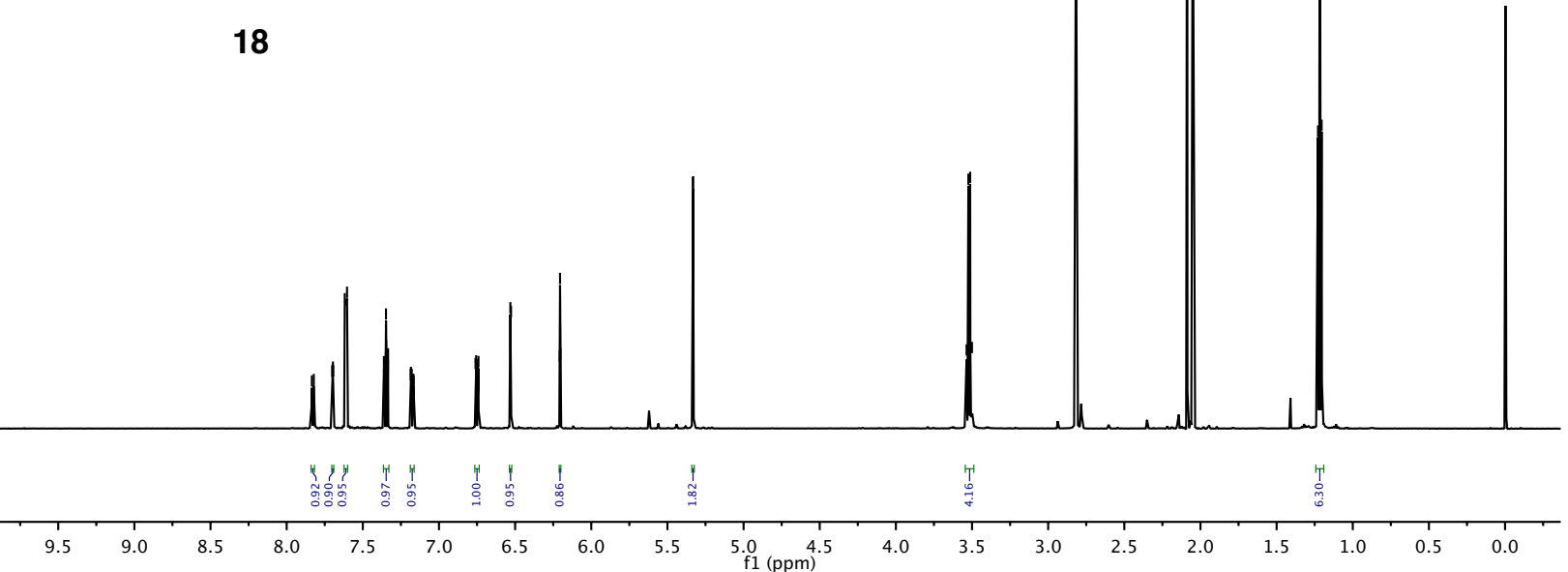


18: ${ }^{13} \mathrm{C}$ NMR (151 MHz, acetone- $d_{6}$ )

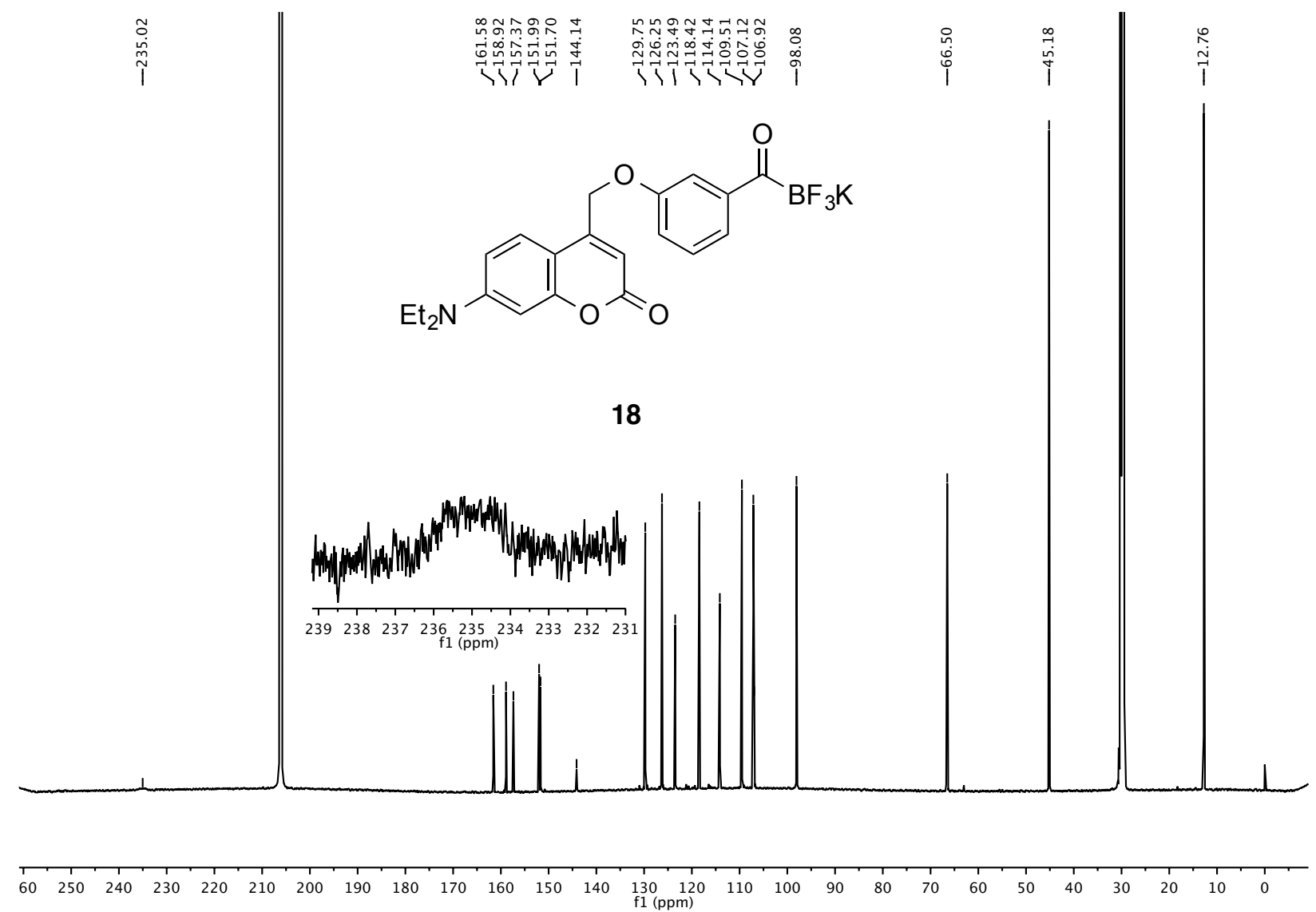

18: ${ }^{19}$ F NMR (470 MHz, acetone- $d_{6}$ )<smiles>CCNc1ccc2c(COc3cccc(C(=O)Br)c3)cc(=O)oc2c1</smiles>

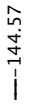

\begin{tabular}{|c|c|c|c|c|c|c|c|c|c|c|c|c|c|}
\hline-110 & -115 & -120 & -125 & -130 & -135 & -140 & f1 (ppm) & -150 & -155 & -160 & -165 & -170 & -175 \\
\hline
\end{tabular}


18: 11F NMR (160 MHz, acetone- $d_{6}$ )<smiles>CCNc1ccc2c(COc3cccc(C(=O)Br)c3)cc(=O)oc2c1</smiles>

18

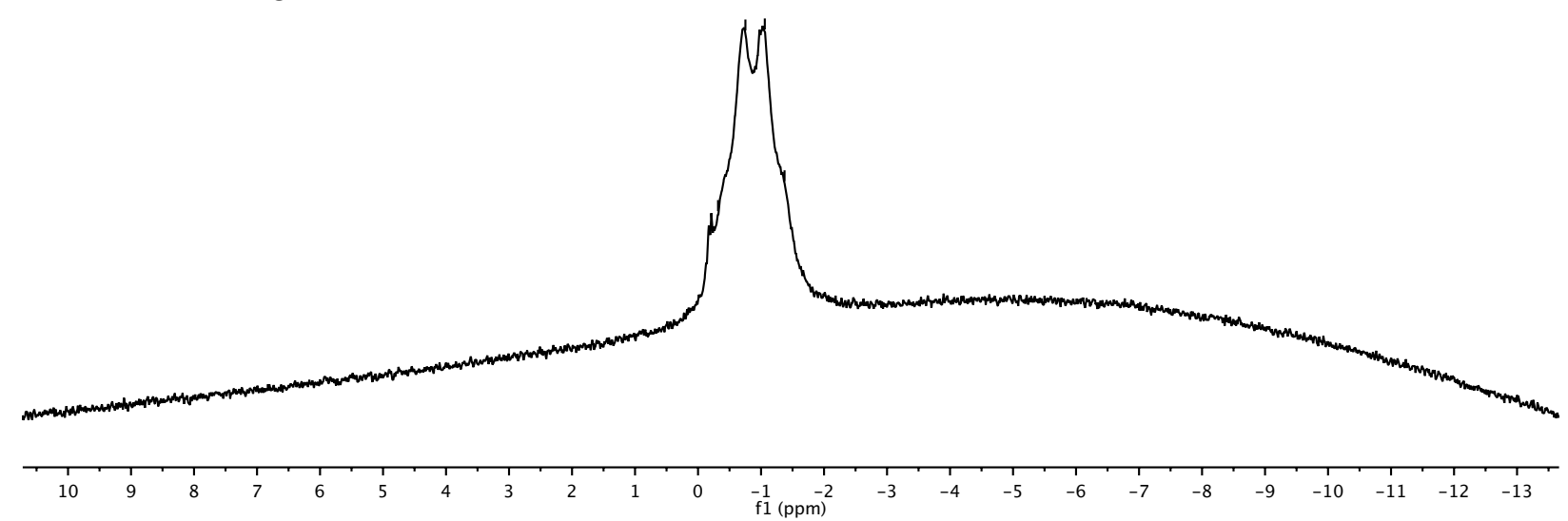

19a: ${ }^{1} \mathrm{H}$ NMR (400 MHz, $\mathrm{CDCL}_{3}$ )

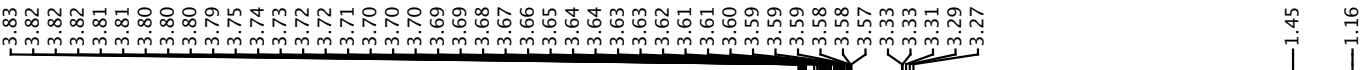

$\mathrm{Et}_{2} \mathrm{~N} \stackrel{\mathrm{O}}{\mathrm{O}} \mathrm{O}_{\mathrm{O}}^{\mathrm{Boc}} \sim \sim_{\mathrm{OH}}^{\mathrm{O}} \sim_{\mathrm{OH}}$

$19 a$

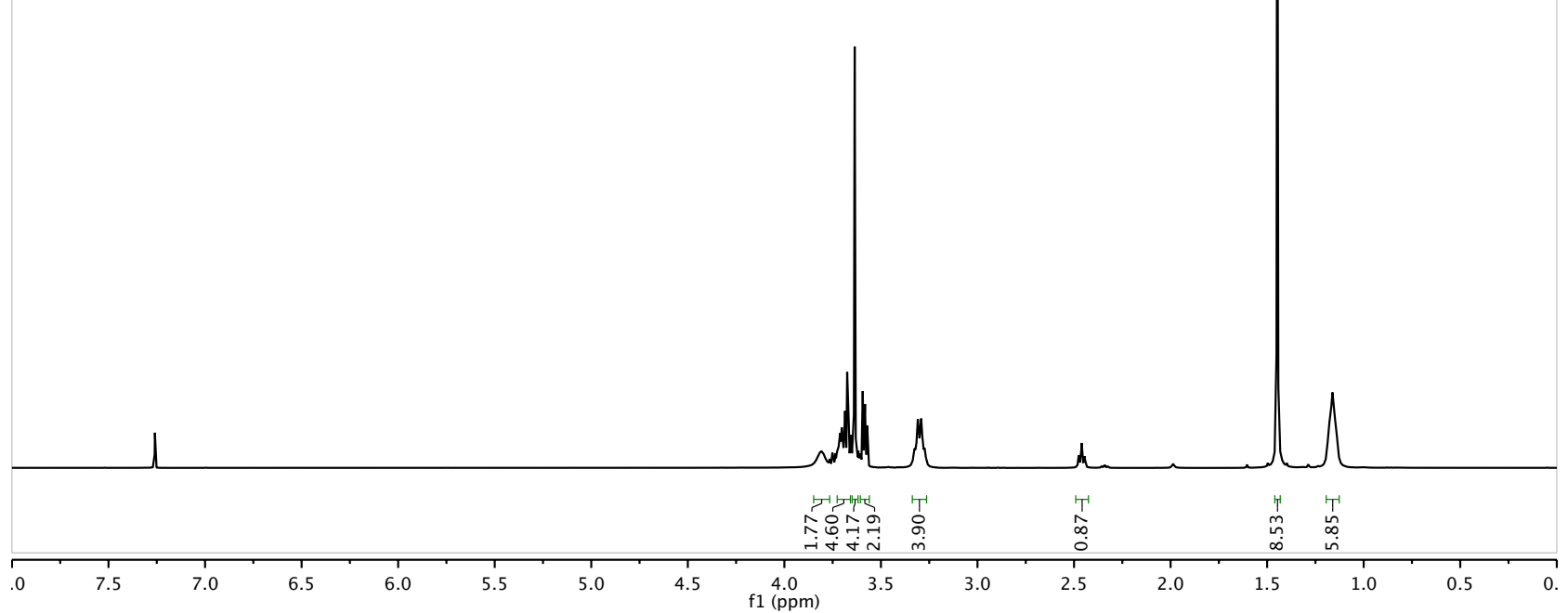


19a: ${ }^{13} \mathrm{C}$ NMR (101 MHz, $\mathrm{CDCl}_{3}$ )
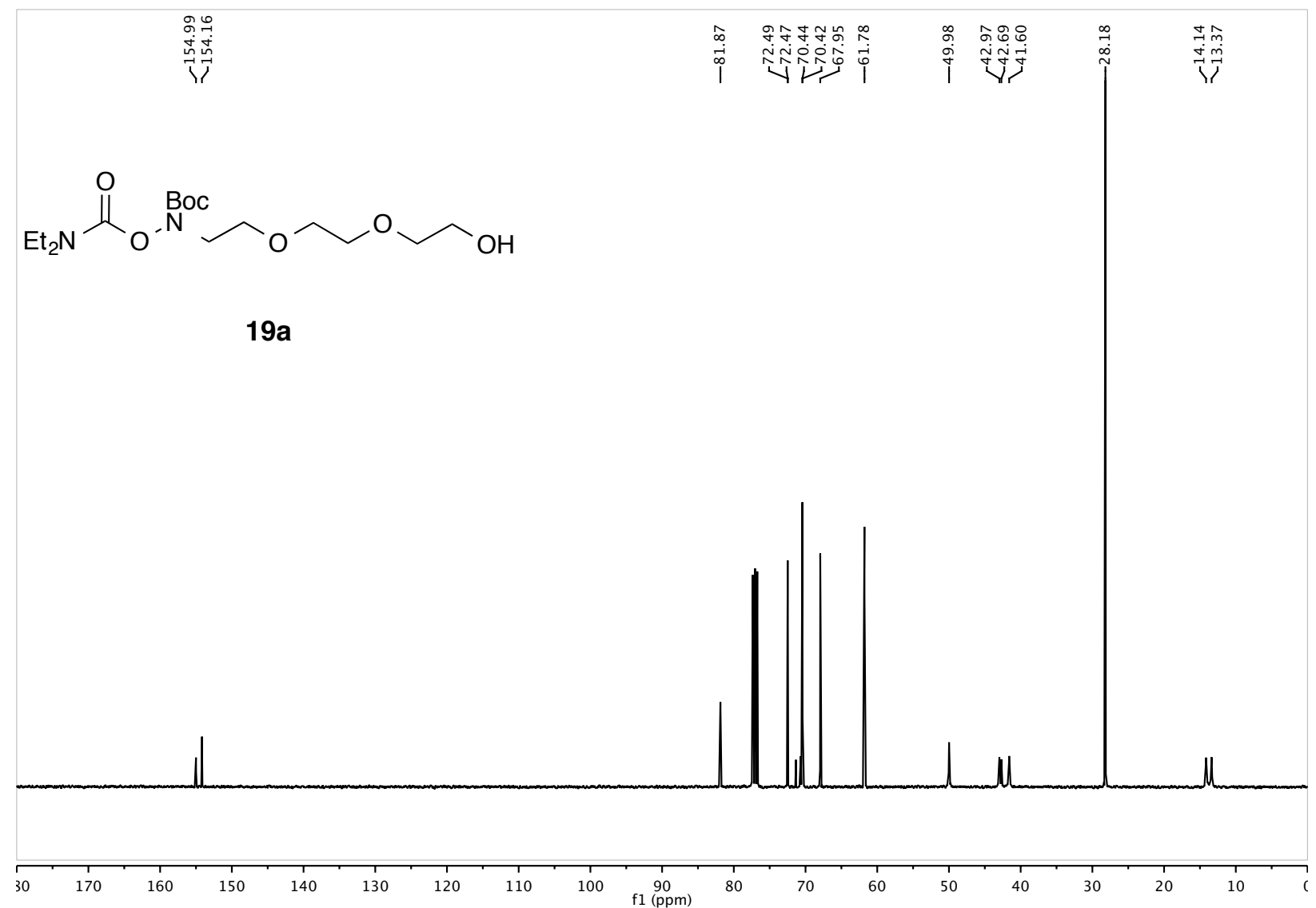

19: ${ }^{1} \mathrm{H}$ NMR (400 MHz, $\mathrm{CDCl}_{3}$ )

$\mathrm{Et}_{2} \mathrm{~N} \stackrel{\mathrm{O}}{\mathrm{O}} \mathrm{N}^{\mathrm{Boc}} \sim \sim_{\mathrm{O}} \sim \sim_{\mathrm{OMs}}$

19

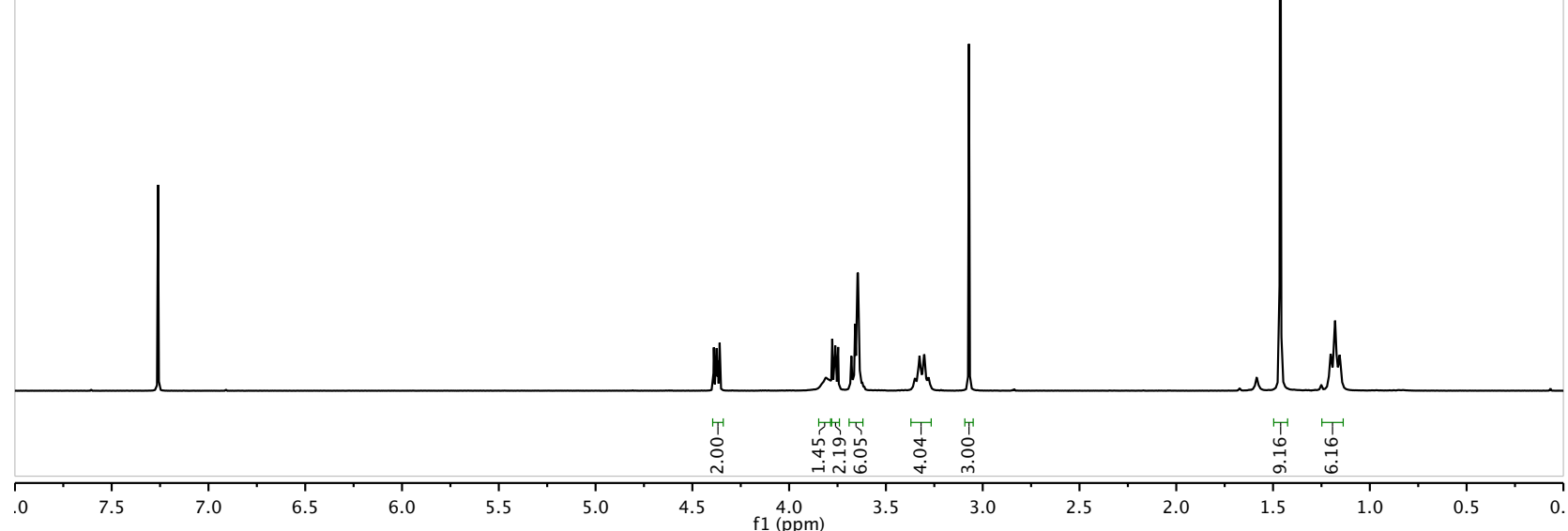


19: ${ }^{13} \mathrm{C}$ NMR (101 $\mathrm{MHz}, \mathrm{CDCl}_{3}$ )

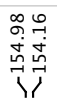<smiles>CCNC(=O)ON(CCOCCOCCOC)C(=O)OC</smiles>

19

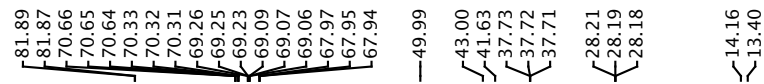

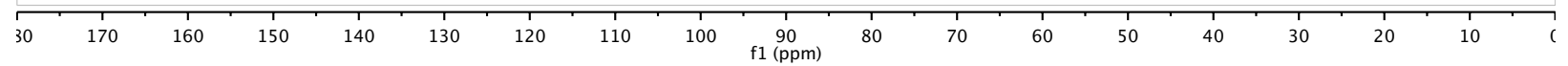

20: ${ }^{1} \mathrm{H}$ NMR (600 MHz, acetone- $\left.d_{6}\right)$

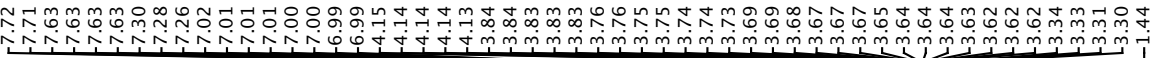<smiles>CCN(CC)C(=O)ON(CCOc1cccc(C(=O)Br)c1)C(=O)OCc1ccccc1</smiles>

20

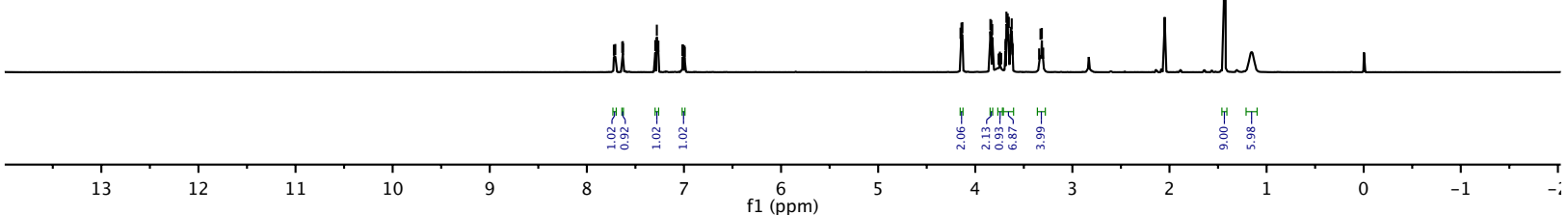




\section{0: ${ }^{13} \mathrm{C}$ NMR (151 MHz, acetone- $d_{6}$ )}
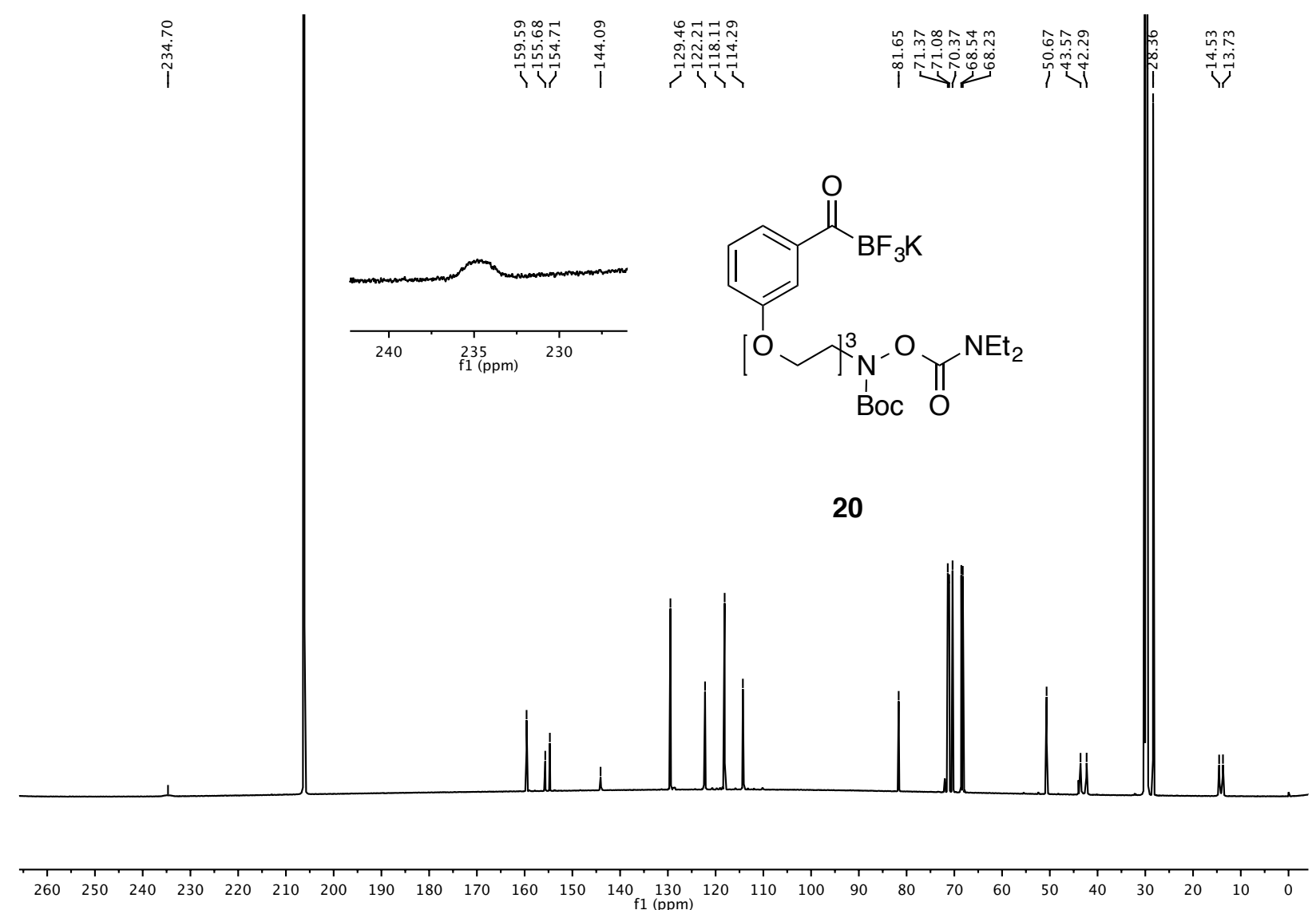

20: ${ }^{19} \mathrm{~F}$ NMR (470 MHz, acetone- $d_{6}$ )<smiles>CCN(CC)C(=O)ON(CCOc1ccccc1)C(=O)OCc1ccccc1</smiles>

20

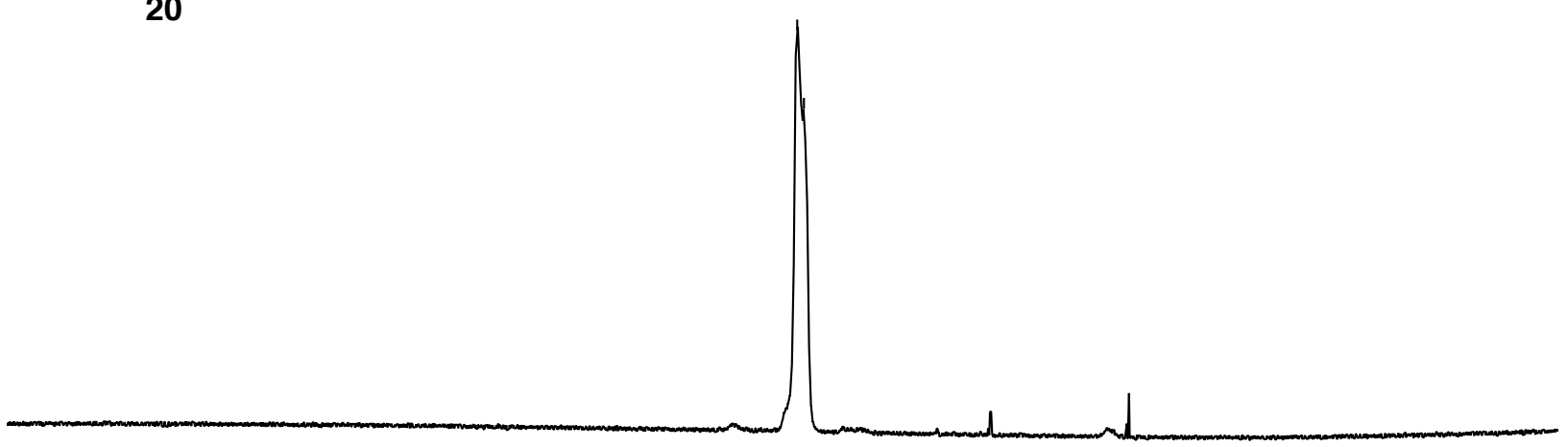

$\begin{array}{rlllllllllllllllllll}722 & -124 & -126 & -128 & -130 & -132 & -134 & -136 & -138 & -140 & -142 & -144 & -146 & -148 & -150 & -152 & -154 & -156 & -158 & -160\end{array}$ 
20: ${ }^{11 B}$ NMR (160 MHz, acetone- $d_{6}$ )<smiles>CCN(CC)C(=O)ON(CCOc1cccc(C(=O)Br)c1)C(=O)OC</smiles>

20

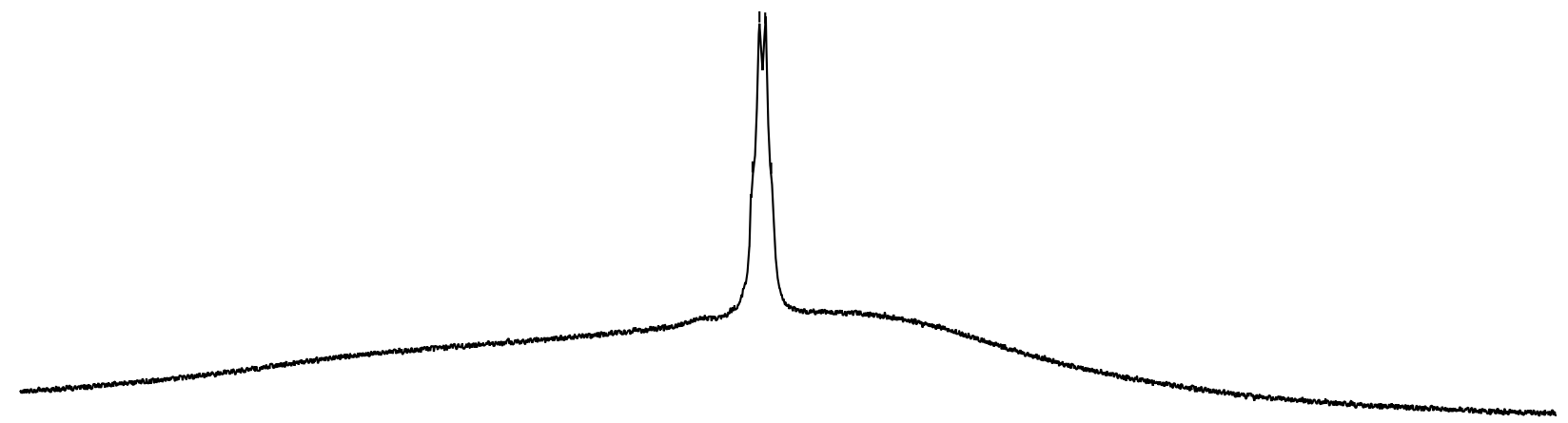

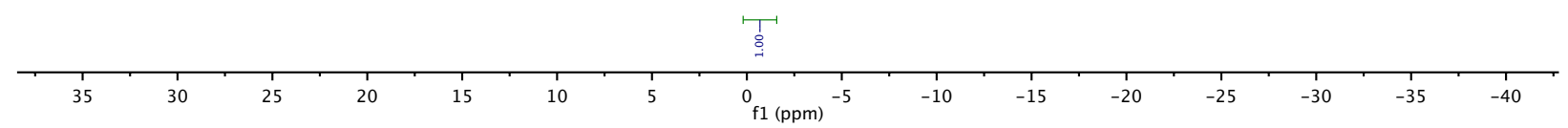

23: ${ }^{1} \mathrm{H}$ NMR (600 MHz, $\left.\mathrm{CD}_{3} \mathrm{OD}\right)$

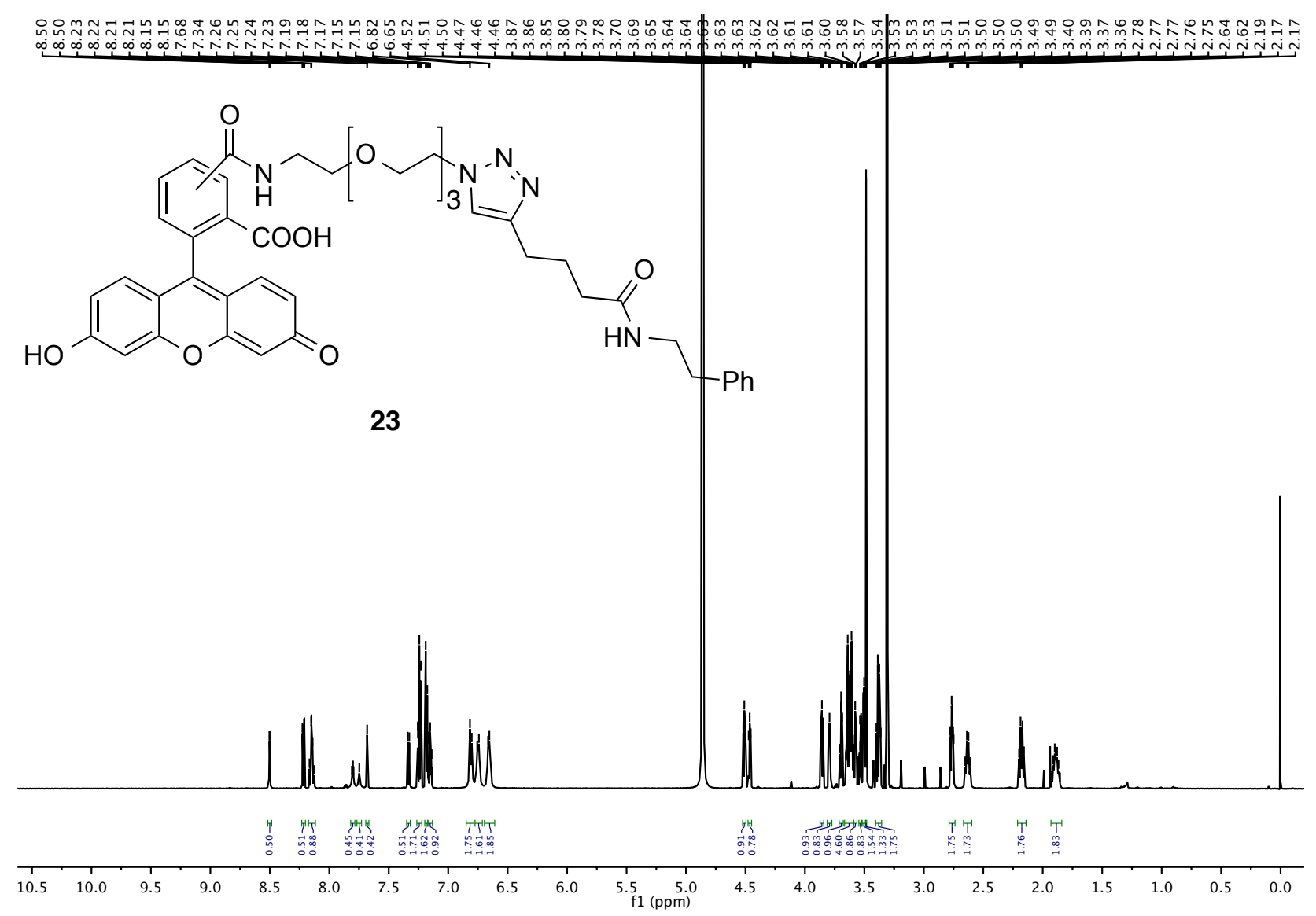




\section{3: ${ }^{13} \mathrm{C}$ NMR (151 MHz, $\left.\mathrm{CD}_{3} \mathrm{OD}\right)$}

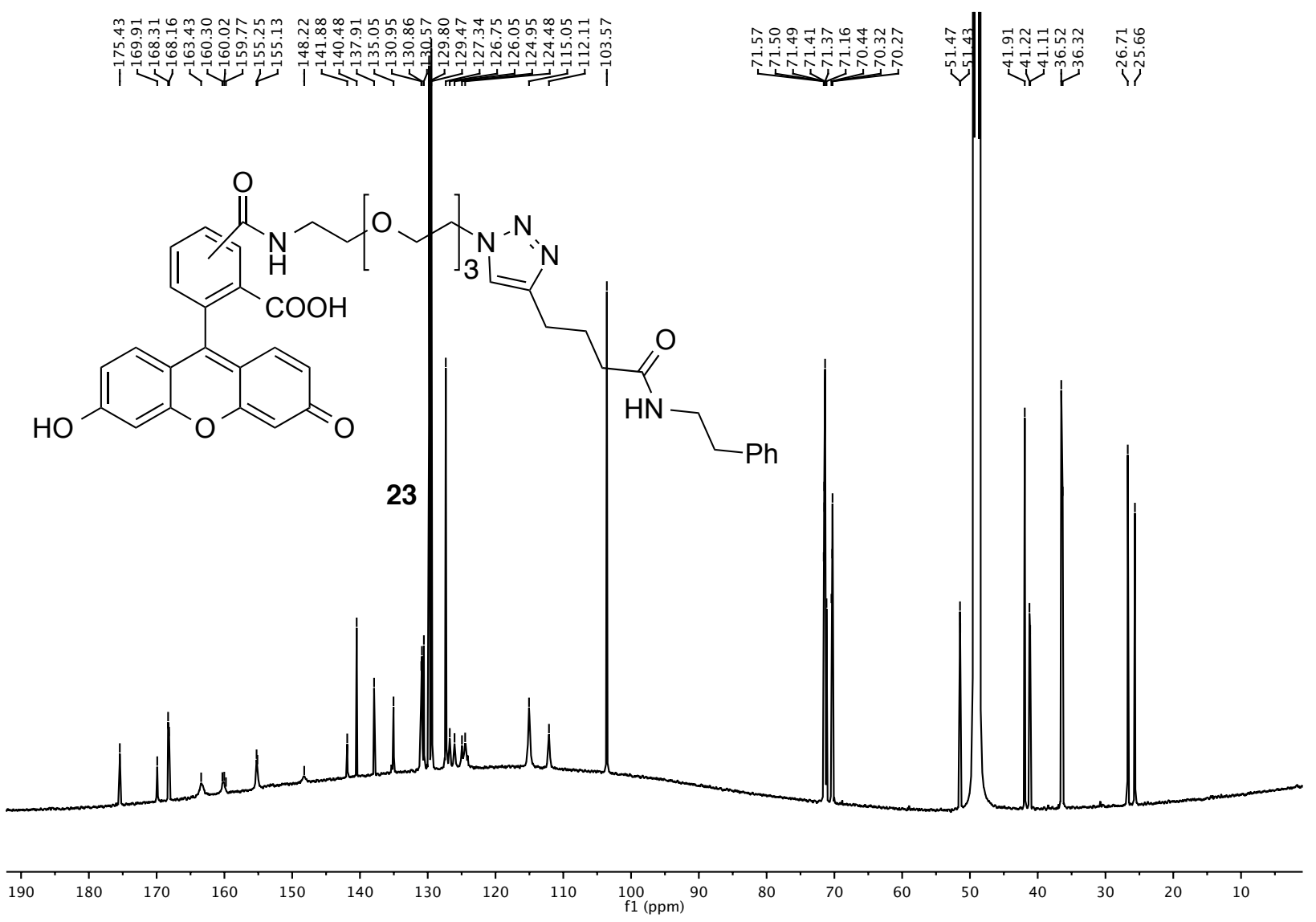

\section{5: ${ }^{1} \mathrm{H}$ NMR (600 MHz, $\left.\mathrm{CH}_{3} \mathrm{OD}\right)$}

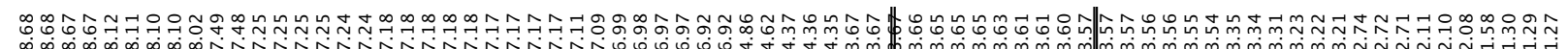

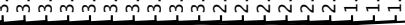

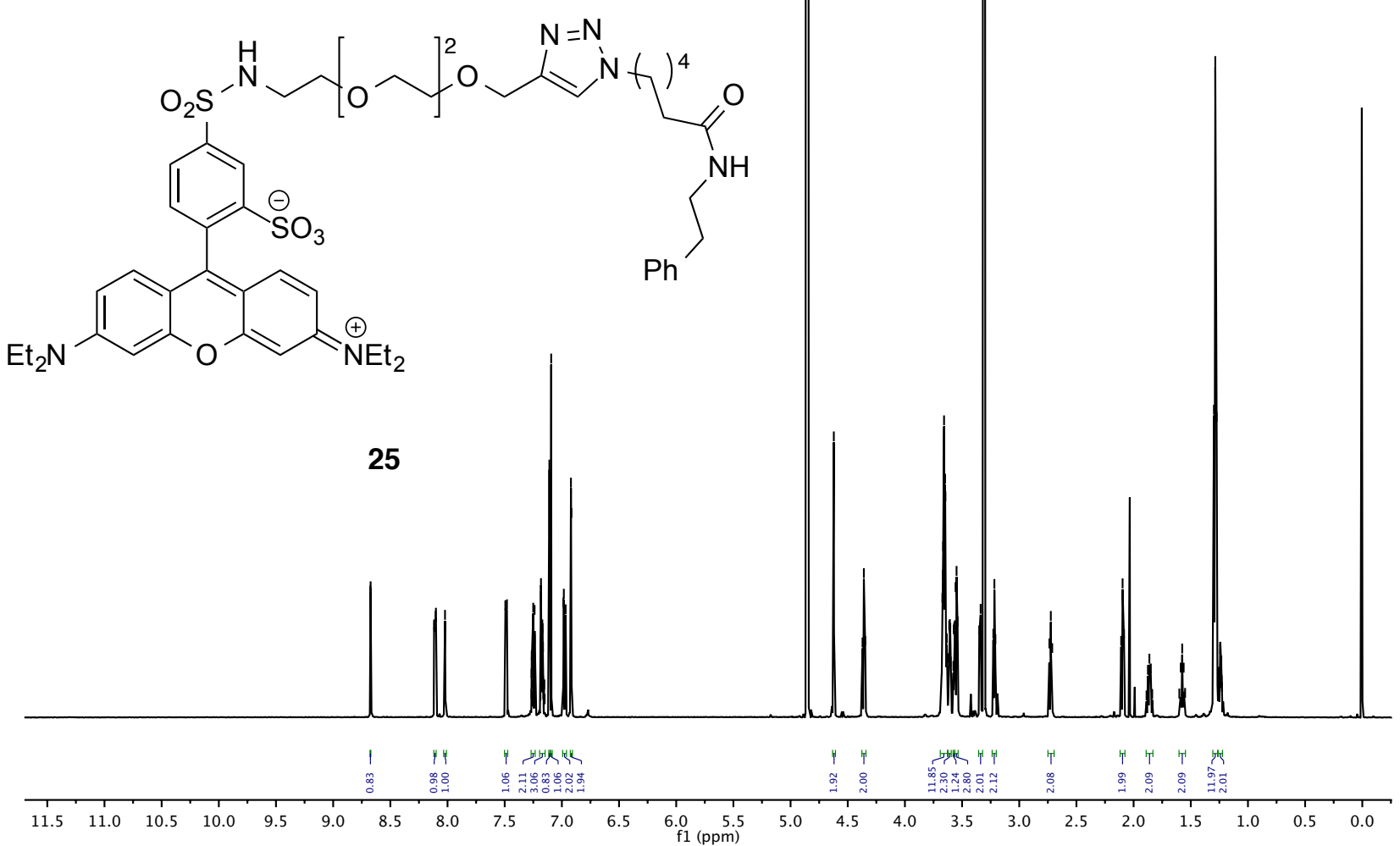


25: ${ }^{13} \mathrm{C}$ NMR (470 MHz, $\left.\mathrm{CD}_{3} \mathrm{OD}\right)$

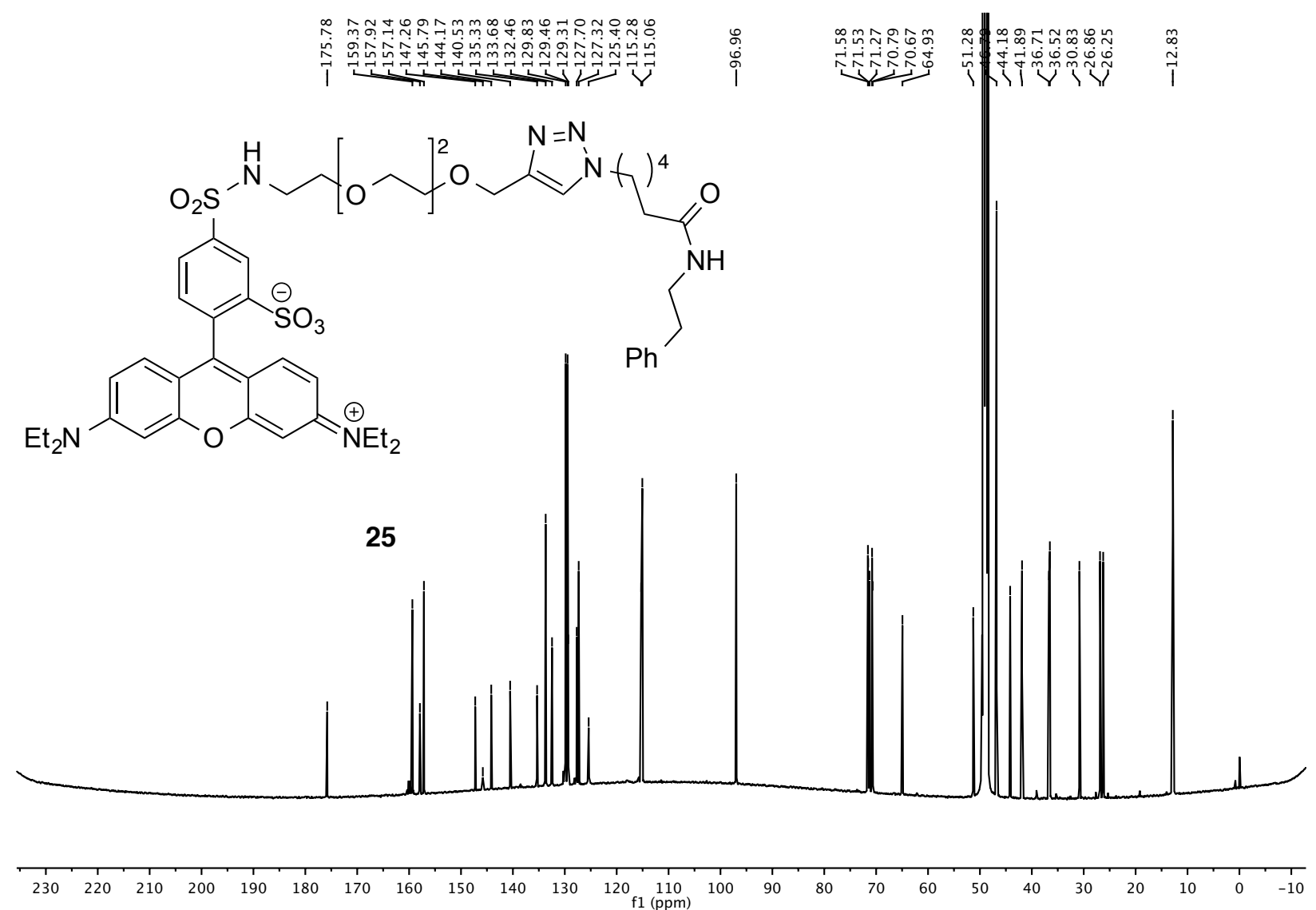

\section{References}

(1) Erös, G.; Kushida, Y.; Bode, J.W. Angew. Chem. Int. Ed. 2014, 53, 7604-7607.

(2) Dumas, A.M.; Bode, J.W. Org. Lett. 2012, 14, $2138-2141$.

(3) Seven, I.; Weinrich, T.; Gränz, M.; Grünewald, C.; Brüß, S.; Krstic, I.; Prisner, T.F.; Heckel, A.; Göbel, M.W. Eur. J. Org. Chem. 2014, 19, 4037-4043.

(4) Serdjukow, S.; Kink, F.; Steigenberger, B.; Tomas-Gamasa, M.; Carell, T. Chem. Commun. 2014, 50, 1861-1863.

(5) Goswami, L.N.; Khan, A.A.; Jalisatg, S.S.; Hawthorne, M.F. Chem. Commun. 2014, 50, 5793-5795. 